NBER WORKING PAPER SERIES

\title{
ARE MARRIAGE-RELATED TAXES AND SOCIAL SECURITY BENEFITS HOLDING BACK FEMALE LABOR SUPPLY?
}

\author{
Margherita Borella \\ Mariacristina De Nardi \\ Fang Yang \\ Working Paper 26097 \\ http://www.nber.org/papers/w26097 \\ NATIONAL BUREAU OF ECONOMIC RESEARCH \\ 1050 Massachusetts Avenue \\ Cambridge, MA 02138
}

July 2019, Revised March 2021

De Nardi gratefully acknowledges support from the ERC, grant 614328 "Savings and Risks." Yang gratefully acknowledges MRRC grant number 08098401 and hospitality from the Opportunity and Inclusive Growth Institute at the Federal Reserve Bank of Minneapolis. We thank Veronica Guerrieri and four anonymous referees, Joe Altonji, Richard Blundell, Monica Costa Dias, Zvi Eckstein, Joan Gieseke, Rasmus Lenz, Derek Neal, and Jon Skinner for useful comments and suggestions. The views expressed herein are those of the authors and do not necessarily reflect the views of the National Bureau of Economic Research, MRRC, the SSA, the CEPR, any agency of the federal government, the Federal Reserve Bank of Minneapolis, or the Federal Reserve System.

NBER working papers are circulated for discussion and comment purposes. They have not been peer-reviewed or been subject to the review by the NBER Board of Directors that accompanies official NBER publications.

(C) 2019 by Margherita Borella, Mariacristina De Nardi, and Fang Yang. All rights reserved. Short sections of text, not to exceed two paragraphs, may be quoted without explicit permission provided that full credit, including $\odot$ notice, is given to the source. 
Are Marriage-Related Taxes and Social Security Benefits Holding Back Female Labor Supply? Margherita Borella, Mariacristina De Nardi, and Fang Yang

NBER Working Paper No. 26097

July 2019, Revised March 2021

JEL No. E21,H2,J22,J31

\begin{abstract}
In the United States, both taxes and old age Social Security benefits depend on one's marital status and tend to discourage the labor supply of the secondary earner. To what extent are these provisions holding back female labor supply? We estimate a rich dynamic life-cycle model of labor supply and savings for couples and singles using the Method of Simulated Moments for the 1945 and 1955 birth cohorts. Our model matches well the life cycle profiles of labor market participation, hours, and savings for married and single people, and generates plausible elasticities of labor supply. It implies that eliminating these marriage-related provisions would drastically increase the participation of married women over their entire life cycle, reduce the participation of married men after age 60, and increase savings. If the resulting government surplus were used to lower income taxation, there would be large welfare gains for the vast majority of the population. These results hold for both cohorts, including the later one, which has similar participation to that of more recent generations.

Margherita Borella

Università di Torino

Dipartimento di Scienze Economico-Sociali

e Matematico-Statistiche

Torino, Italy

margherita.borella@unito.it

Mariacristina De Nardi

University of Minnesota

1925 S 4th St

Minneapolis, MN 55455

and Federal Reserve Bank of Minneapolis and CEPR

and also NBER

denardim@nber.org

Fang Yang

Louisiana State University

Department of Economics, 2317

Business Education Complex,

Nicholson Extension

Baton Rouge, LA 70803

fyang@lsu.edu
\end{abstract}




\section{Introduction}

After increasing robustly from the 1960s to the early 1990s, the labor force participation of women in the United States has been stagnating. In this paper, we ask to what extent the dependence of taxes and old-age Social Security benefits on marital status has discouraged female labor supply and affected the welfare of cohorts with different degrees of female labor market participation, including more recent ones.

The mechanisms through which these marital provisions work are the following. First, since couples file taxes jointly, the secondary earner faces a higher marginal tax rate, which tends to discourage their labor supply. Second, married and widowed people can claim Social Security spousal and survivor benefits under their spouses' past contributions rather than their own. Hence, their reduced labor supply does not necessarily imply lower Social Security benefits. Since women have historically been the secondary earners, both provisions tend to discourage female labor supply. But to what extent are these disincentives holding it back?

To answer this question, we develop a rich dynamic life-cycle model with single and married people and estimate it for two cohorts using the Method of Simulated Moments (MSM) and data from the Panel Study of Income Dynamics (PSID) and the Health and Retirement Study (HRS). Our first cohort is the one born in 1941-1945 (the "1945" cohort), has by now completed a large part of its life cycle, and is covered by these two data sets (which provide excellent information over their working and retirement periods, respectively). Our second cohort is the 1951-1955 one (the "1955" cohort), has by now completed a large part of its working period, and has much higher participation of married women (and closer to that of more recent cohorts). Hence, for this cohort policy and welfare implications might be quite different.

In our model, single people meet partners and married people might get divorced. Every working-age person experiences wage shocks and every retiree faces medical expenses and lifespan risk. People in couples face the risks of both partners. Households can self-insure by saving and by choosing how much to work (for both partners if in a couple) and when to retire. Consistent with the data, we allow for human capital to affect wages. We explicitly model Social Security with spousal and survival benefits, the differential tax treatment of married and single people, the progressivity of the tax system (including the earned income tax credit (EITC)), and old-age means-tested transfer programs such as Medicaid and Supplemental Security Income 
(SSI). We also model the changes in the tax and Social Security systems over time.

Our estimated model matches the life-cycle profiles of labor market participation, hours worked by the workers, and savings for married and single people for both cohorts very well. It also generates elasticities of labor supply by age, gender, and marital status that are consistent with those previously estimated by others.

For the 1945 cohort, we find that the elimination of Social Security spousal and survivor benefits and joint income taxation has large effects on participation and savings. In particular, it raises the participation of married women at age 25 by over 20 percentage points and that of single women by 5 percentage points. At age 45, participation for these groups is still 15 and 3 percentage points higher, respectively. In addition, the participation of married men decreases starting at age 60, resulting in a participation rate that is 7 percentage points lower by age 65 . It also increases the savings of married couples by $20 \%$ at age 66 . In terms of welfare, abolishing these marital provisions would benefit most couples, all single men, and over one-third of single women and, thus, over $90 \%$ of the people in this cohort.

The effects of these marital provisions on the participation, wages, earnings, and savings of the 1955 cohort are also large, thus indicating that they continue to affect more recent cohorts. In terms of welfare, abolishing these marital provisions at age 25 for this cohort would benefit most couples, all single men, and over three-fourths of single women. In addition, the welfare benefits to those gaining would be much higher and the costs of those losing would be very small, compared with the older cohort, because at age 25 the human capital of women in the 1955 cohort is higher than that in the previous cohort.

Our paper provides several contributions. First, it is the first paper to study all marriage-related taxes and benefits in a unified framework. Second, it does so by allowing for the large observed changes in the labor supply of married women over time by studying two different cohorts. Third, it is the first dynamic estimated structural model of couples and singles that allows for participation and hours decisions of both men and women in a framework with savings. Fourth, our framework is very rich along many other dimensions that are important to study our problem. For instance, allowing for labor market experience to affect wages (of both men and women) is important to capture the endogeneity of wages and their response to policy and marital status changes. Allowing the tax structure to vary over time for each cohort (we estimate our tax functions from the PSID as a function of cohort, year, and 
marital status) takes this important variation into account when we estimate our model. Carefully modeling survival, health, and medical expenses in old age, and their heterogeneity by marital status and gender, is crucial to evaluate the effects of policy reforms on labor supply and savings. Modeling one-year periods gives people the ability to change their labor supply and savings in a more flexible and realistic way. Fifth, the model fits the data well, including in terms of elasticities that we do not match by construction, and thus provides a valid benchmark to evaluate policy reforms.

In terms of related literature, we build on the one on female labor supply over the life cycle. Attanasio, Low and Sánchez-Marcos (2008), Eckstein and Lifshitz (2011), and Eckstein, Keane and Lifshitz (2019) examine the determinants of married women's participation over time. Hubener, Maurer and Mitchell (2016) study the effects of family dynamics and labor supply on portfolio choice and retirement. In addition, we contribute to the small body of literature studying policy reforms in environments that include couples. Guner, Kaygusuz and Ventura (2012) study the switch to a proportional income tax and a reform in which married individuals can file taxes separately and find that these reforms substantially increase female labor participation. Kaygusuz (2015), Nishiyama (2017), and Groneck and Wallenius (forthcoming) find that removing spousal and Social Security survivor benefits would increase female labor participation, female hours worked, and aggregate output. Bick and Fuchs-Schündeln (2018) focus on a simpler static model of married couples and find that income taxes are an important factor driving differences in the labor supply of married women across countries. Finally, our work is also related to the work on optimal income taxation of couples. Kleven, Kreiner and Saez (2009) and Gayle and Shephard (2019) use static models of the couple. Kleven, Kreiner and Saez (2009) show that dual-earner couples can arise either because the secondary earner has low costs of participating in the labor market or because it has low ability in home production. As the first case is the most empirically relevant, optimal tax rates display positive tax rates on secondary earnings along with negative jointness, whereby the tax rate of one person decreases with the earnings of the spouse. Gayle and Shephard (2019) empirically explore taxation design in a collective model of the household with a marriage market and find that the optimal tax system for couples is characterized by negative jointness but that the welfare gains from jointness are modest. 


\section{Marriage, taxes, and Social Security benefits}

Many countries tax the income of married people as if they were single (individual taxation). As a result, when the secondary earners in couples work, their marginal tax rate is based on their own income rather than on the sum of their partner's income and their own. The United States, instead, taxes the income of married couples jointly (joint taxation) and uses a different tax schedule for married and single people. The combination of joint taxation and a progressive tax system typically implies that a married secondary earner faces a higher marginal tax rate than a single earner.

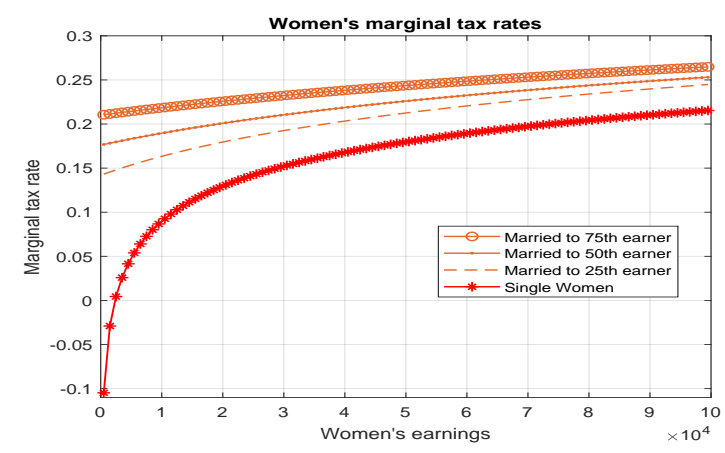

Figure 1: Women's marginal tax rates as a function of earnings (2016 dollars). Single (starred) and married to men at different earnings percentiles: 25th (dashed), 50 th (dotted), and 75th (circled).

To illustrate the secondary earner's disincentives to work, Figure 1 displays the effective tax rates that we estimate from the PSID in 1988, when the EITC program is already active and people in our 1945 cohort are 45 years old. ${ }^{1}$ It illustrates that, for instance, a single woman earning $\$ 500$ a year faces a marginal tax rate of $-10 \%$ while a married woman earning the same amount faces a marginal tax rate of $14 \%$, $18 \%$, and $21 \%$, respectively, if she is married to a man in the $25 \mathrm{th}, 50 \mathrm{th}$, and $75 \mathrm{th}$ income percentiles (which correspond to, respectively, $\$ 43,090, \$ 68,995$, and $\$ 113,288$ in 2016 dollars). Our estimated negative tax rate at low income levels is due to the EITC. This graph shows that married women tend to face a higher marginal tax rate than single women, thus suggesting that making married people file as single rather than jointly could have large incentives for the labor market participation of married women.

\footnotetext{
${ }^{1}$ The details of our tax computations are at the end of Appendix B.
} 
Social Security for a single person is a function of one's average lifetime earnings. Social Security for a married person is the higher between one's own benefit entitlement and half of the spouse's entitlement while the other spouse is alive (spousal benefit) and the higher between one's own benefit entitlement and the deceased spouse's after the spouse's death (survival benefit).

We use data from the PSID for 66-year-old couples in our 1945 cohort and Social Security rules to generate Figure 2, which displays the size of Social Security spousal benefits. The left graph of Figure 2 plots household Social Security benefits while the
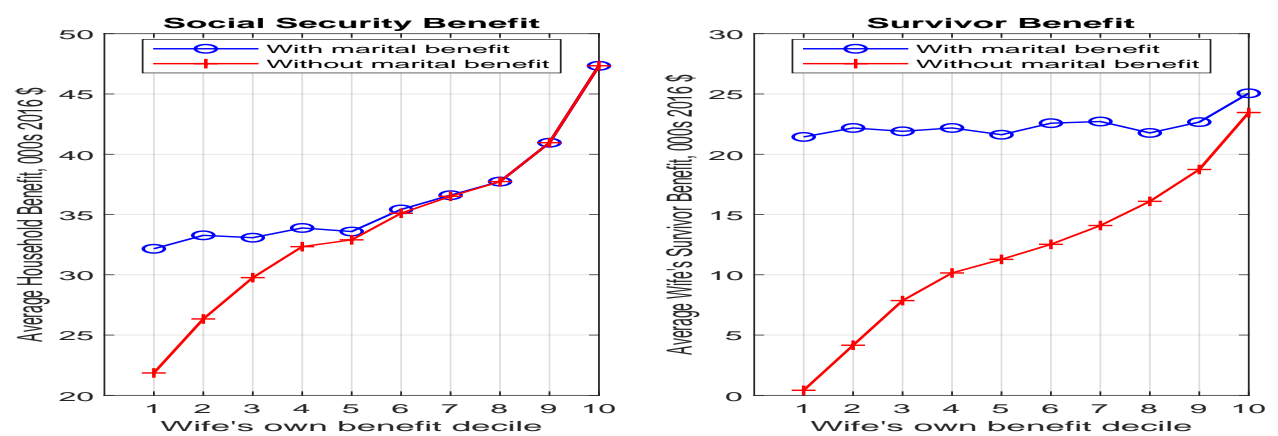

Figure 2: Average household Social Security benefits (left) and average survivor benefit (right), both by wife's own Social Security benefit decile at age 66, with marital benefits (circled) or without (crossed). All in 2016 dollars.

husband is alive. It takes married women at retirement age and, based on the deciles of their own Social Security entitlement, plots their average household yearly Social Security benefits with (circled line) and without (crossed line) marital benefits. For instance, the number 1 on the $x$-axis represents 66-year-old married women that are in the lowest decile of their own Social Security contributions. At that decile, household Social Security benefits for those women and their husbands are $\$ 32,000$ under marital benefits and about $\$ 22,000$ without marital benefits. The comparison of the two lines in this picture reveals that about $50 \%$ of married households benefit from Social Security marital benefits while their husband is alive and that these benefits can be very large. The right graph of Figure 2 takes the same married women and plots what their yearly Social Security benefits would be after their husband's death with and without survivor's benefits. For instance, a 66 -year old widow at the lowest $10 \%$ of Social Security contributions would receive less than $\$ 500$ a month based on her own contributions only, while she would receive $\$ 22,000$ with survivorship benefits. 
Because in this cohort most women have lower wages than men's, participate less, and work fewer hours, survivorship benefits are large for over $80 \%$ of married women. This last set of graphs highlights that Social Security marital benefits are large and can also reduce married women's incentives to work.

\section{Life-cycle patterns for single and married people}

We pick the 1945 cohort because their entire adult life is first covered by the PSID, which starts in 1968 and has rich information for the working period, and then by the HRS, which starts with people age 50 and older in 1994 and has rich information for the retirement period. We pick our 1955 cohort to be as young as possible to maximize changes in their participation, conditional on having an almost complete working period. ${ }^{2}$

The top panels of Figure 3 refer to the 1945 cohort. ${ }^{3}$ The left one shows that married men have the highest participation rate and only slowly decrease their participation starting from age 45, whereas single men decrease their participation much faster. The participation of single women starts about 10 percentage points lower than that of single men and gradually increases until age 50. Married women have the lowest participation rate. It starts around $50 \%$ at age 25 , increases to $78 \%$ between ages 40 and 50, and gradually declines at a rate similar to that of the other three groups. The top right panel highlights that married men on average work more hours than everyone else. Women not only have a participation rate lower than men on average but also display lower average hours, even conditional on participation.

The middle panels display the same information for the 1955 cohort. Comparing the top and bottom panels shows a large increase in participation and hours worked conditional on working for married women across these two cohorts. Finally, annual hours worked by married men conditional on working are lower, which underscores the importance of also modeling men's labor supply.

The bottom panel in Figure 3 shows average wealth (or net worth), which we assume to be the same for both cohorts because wealth data in the PSID is limited.

\footnotetext{
${ }^{2}$ Appendix A details our computations and shows that the majority of men and women are married in both cohorts. Appendix L validates our labor market outcomes from the PSID with those from the Current Population Survey (CPS).

${ }^{3}$ These profiles are obtained from the data by fitting a fourth-order polynomial in age fully interacted with marital status and cohort dummies, separately for each gender.
} 

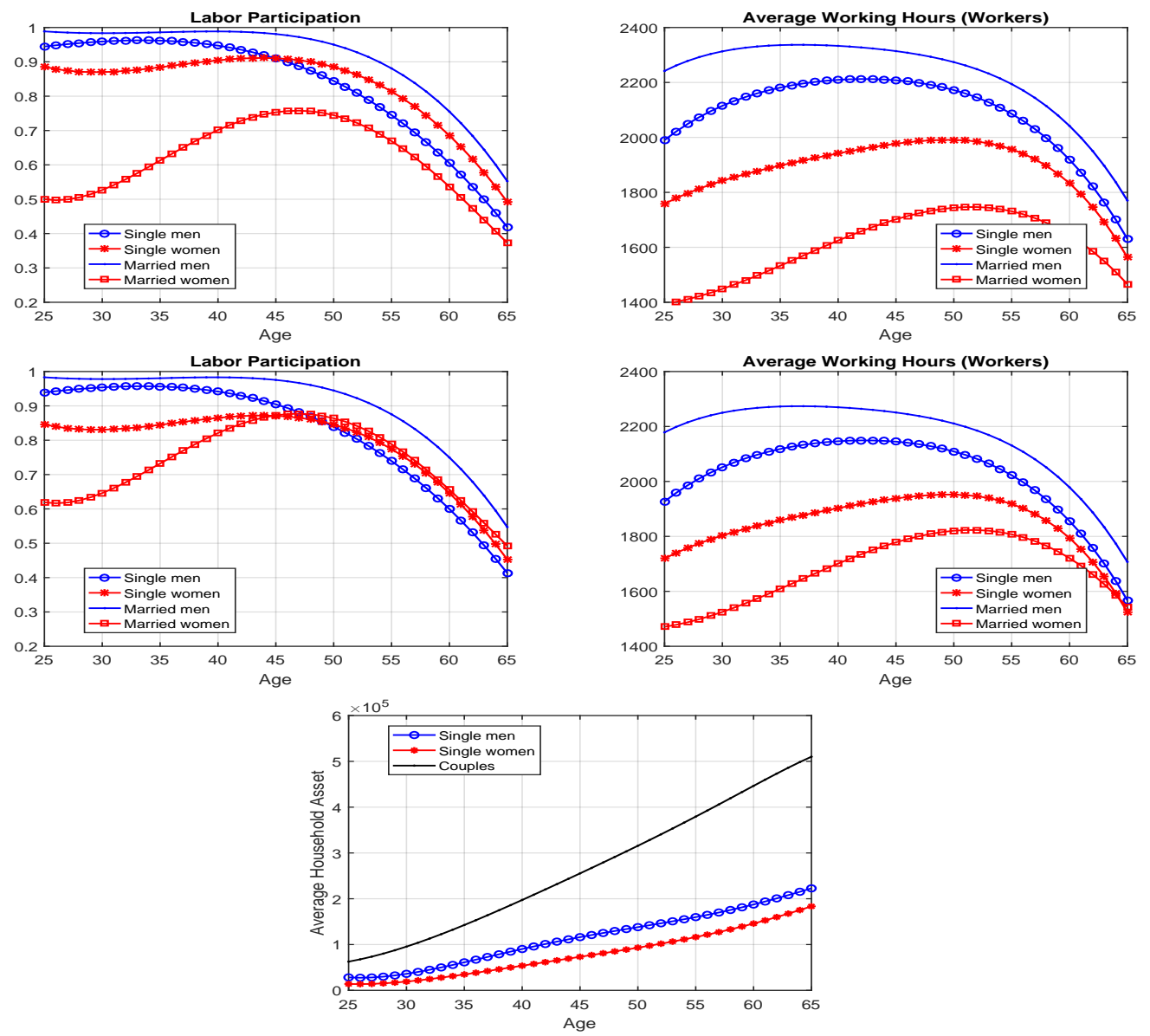

Figure 3: Life-cycle profiles by gender and marital status, 1945 cohort (top two graphs), 1955 cohort (middle two graphs), and both cohorts (bottom graph), PSID.

Despite the fact that couples enjoy economies of scale, the wealth of couples is over twice that of singles at all ages.

\section{The model}

Net worth $a_{t}$, earns a rate of return $r$. Our model period is one year long. There are three stages in one's life: a working stage (ages 25 to 61), an early retirement stage (ages 62 to 65), and a retirement stage (age 66 to the maximum age of 99).

During the working stage, single and married individuals choose how much to work and save and face wage shocks. Married people face divorce shocks, and single people might meet partners and get married. Wages are a function of one's human capital (which is endogenously accumulated while working) and are affected by shocks. 
We model (and estimate) available time to be split between working and leisure and allow it to depend on one's gender and marital status. We interpret it as net of home production, child care, and elderly care that one has to perform whether working or not (and that is not easy to outsource). All workers have to pay a fixed cost of working, which depends on their age, gender, and marital status. It represents the cost of commuting, getting ready for work, making arrangements for being able to work, and so on.

Single women and married people have children, and the number of their children depends on maternal age and marital status. We allow for both time costs and monetary costs of raising children. The time costs affect one's available time for working and enjoying leisure. The monetary costs enter our model in two ways: they affect consumption through equivalent scales, and working mothers have to pay child care costs that depend on the age and number of their children and on their own earnings. Hence, child care costs are a normal good: women with higher earnings pay for more expensive child care.

During the early retirement stage, people still experience wage shocks but single people don't get married anymore and couples no longer divorce. ${ }^{4}$ If they claim Social Security, they can no longer work. Couples claim Social Security jointly.

During the first year of the retirement stage, those who have not already claimed Social Security do so and stop working. People face health shocks, out-of-pocket medical expenses, and mortality shocks. Thus, each married person faces the risk of his or her spouse dying, in addition to their own. Mortality risk and medical expenses depend on gender, age, health status, and marital status.

Given that we explicitly model labor participation and hours of husbands and wives, savings, and medical expenses in old age, our model is computationally intensive (see Appendix E for more details). For tractability, we assume the following. First, marriage and divorce are exogenous processes that we estimate from the data. Second, the amount of time spent in home production is fixed. Third, fertility is exogenous, women have an age-varying number of children that depends on their age and marital status (that we estimate from the data), and we do not model children quality. Fourth, people who are married to each other are of the same age. Lastly, divorced and never married people face the same problem (we thus abstract from So-

\footnotetext{
${ }^{4}$ Only $1 \%$ of couples get divorced and $4 \%$ of singles get married between ages 62 and 72 in the HRS data for our 1945 cohort.
} 
cial Security benefits entitlement for divorcees). We discuss our model's limitations and perform robustness checks in Section 8.

\subsection{Preferences}

Let $t$ be age, with people entering at age 25 and dying by age 99 . For simplicity of notation, we write our model for one cohort, hence $t$ indexes both age and time for that cohort. We solve the model for the two cohorts separately and make sure that each cohort has the appropriate time- and age-varying inputs.

Households discount the future at rate $\beta$. The superscript $i$ denotes gender, with $i=1,2$ being a man or a woman, respectively. The superscript $j$ denotes marital status, with $j=1,2$ being single or in a couple, respectively.

Each single person has preferences over consumption and leisure, and the period flow of utility is given by the standard CRRA utility function

$$
v^{i}\left(c_{t}, l_{t}, \eta_{t}^{i, 1}\right)=\frac{\left(\left(c_{t} / \eta_{t}^{i, 1}\right)^{\omega} l_{t}^{1-\omega}\right)^{1-\gamma}-1}{1-\gamma},
$$

$c_{t}$ is consumption, $\eta_{t}^{i, j}$ is its equivalent scale for couples and $\eta_{t}^{i, 1}$ is the one for singles, $l_{t}^{i, j}$ is leisure, which is given by

$$
l_{t}^{i, j}=L^{i, j}-n_{t}^{i}-\Phi_{t}^{i, j} I_{n_{t}^{i}}
$$

where $L^{i, j}$ is available time, net of home production which can be different for single and married men and women. The functional form we use for it is

$$
L^{i, j}=\frac{L}{1+\exp \left(F L^{i, j}\right)},
$$

where we normalize $L$ to 112 hours a week and estimate $F L^{i, j}$ using our structural model. The term $n_{t}^{i}$, is hours worked, $I_{n_{t}^{i}}$ is an indicator function that equals 1 when hours worked are positive.

The term $\Phi_{t}^{i, j}$ is the fixed time cost of working, which depends on gender, marital status, and age. It assumes the following functional form, whose parameters we 
estimate using our structural model

$$
\Phi_{t}^{i, j}=\frac{\exp \left(\phi_{0}^{i, j}+\phi_{1}^{i, j} t+\phi_{2}^{i, j} t^{2}\right)}{1+\exp \left(\phi_{0}^{i, j}+\phi_{1}^{i, j} t+\phi_{2}^{i, j} t^{2}\right)}
$$

We assume that couples maximize their joint utility function

$$
w\left(c_{t}, l_{t}^{1}, l_{t}^{2}, \eta_{t}^{i, j}\right)=\frac{\left(\left(c_{t} / \eta_{t}^{i, j}\right)^{\omega}\left(l_{t}^{1}\right)^{1-\omega}\right)^{1-\gamma}-1}{1-\gamma}+\frac{\left(\left(c_{t} / \eta_{t}^{i, j}\right)^{\omega}\left(l_{t}^{2}\right)^{1-\omega}\right)^{1-\gamma}-1}{1-\gamma}
$$

Note that for couples, $\eta_{t}^{i, j}$ does not depend on gender and $j=2$.

\subsection{Human capital and wages}

We define human capital, $\bar{y}_{t}^{i}$, as one's average past earnings at each age (see Equation (12) for a formal definition). It is therefore a function of one's initial wages (and schooling to the extent that it is reflected in one's wages) and subsequent labor market experience and wages, and not just of experience measured as the amount of time one has previously worked. Our definition has two important benefits. First, it respects the previous findings that the returns to experience depend on one's education, and thus human capital and earnings (Blundell, Dias, Meghir and Shaw (2016) and Costa Dias, Joyce and Parodi (2018). Second, it allows us to use only one state variable to keep track of both human capital and Social Security contributions, which maintains our framework manageable.

Wages have two components. A deterministic function of age, gender, and human capital: $e_{t}^{i}\left(\bar{y}_{t}^{i}\right)$ and a persistent shock $\epsilon_{t}^{i}$ that evolves as follows

$$
\ln \epsilon_{t+1}^{i}=\rho_{\varepsilon}^{i} \ln \epsilon_{t}^{i}+v_{t}^{i}, v_{t}^{i} \sim N\left(0,\left(\sigma_{v}^{i}\right)^{2}\right)
$$

The product of $e_{t}^{i}(\cdot)$ and $\epsilon_{t}^{i}$ determines one's effective hourly wage per hour.

\subsection{Marriage and divorce}

During the working period, the probability that a single person gets married at the beginning of next period depends on age, gender, and wage shock: $\nu_{t+1}(\cdot)=\nu_{t+1}\left(i, \epsilon_{t}^{i}\right)$.

To allow for assortative mating, conditional on meeting a partner, the probability 
of meeting with a partner $p$ with wage shock $\epsilon_{t+1}^{p}$ is

$$
\xi_{t+1}(\cdot)=\xi_{t+1}\left(\epsilon_{t+1}^{p} \mid \epsilon_{t+1}^{i}, i\right)
$$

We assume random matching over wealth $a_{t+1}$ and average accumulated earnings of the partner $\bar{y}_{t+1}^{p}$, conditional on the partner's wage shock. Thus, we have

$$
\theta_{t+1}(\cdot)=\theta_{t+1}\left(a_{t+1}^{p}, \bar{y}_{t+1}^{p} \mid \epsilon_{t+1}^{p}\right)
$$

A working-age couple can be hit by a divorce shock that depends on age and the wage shock of both partners: $\zeta_{t+1}(\cdot)=\zeta_{t+1}\left(\epsilon_{t}^{1}, \epsilon_{t}^{2}\right)$. If the couple divorces, they split their wealth equally (we experimented with different asset splits with very similar results). We abstract from alimony.

\subsection{Costs of raising children and running a household}

We keep track of both the total number of children and their age as a function of mothers' age and marital status. The term $f^{0,5}(i, j, t)$ is the number of children age $0-5$ and $\tau_{c}^{0,5}$ is the child care cost for each child in that age group. Similarly, $f^{6,11}(i, j, t)$ is the number of children age $6-11$ and $f^{0,5}(i, j, t)$ is the corresponding child care cost for each child. We use our structural model to estimate these costs.

\subsection{Medical expenses and death}

At age 66, we endow people with a distribution of health that depends on their marital status and gender. After that, they face survival, medical expenses, and health shocks. Health status $\psi_{t}^{i}$ can be either good or bad and evolves according to a Markov process $\pi_{t}^{i, j}\left(\psi_{t}^{i}\right)$ that also depends on age, gender, and marital status. Medical expenses $m_{t}^{i, j}\left(\psi_{t}^{i}\right)$ are a function of age, gender, marital status, and health. Survival probabilities $s_{t}^{i, 1}\left(\psi_{t}^{i}\right)$ are a function of age, gender, marital status, and health.

\subsection{Initial conditions}

We take the fraction of single and married people at age 25 and their distribution over the relevant state variables (wealth, human capital, and wage shocks, with the 
latter two being for each of the spouses in the case of couples) from the PSID for each of our two cohorts.

\subsection{Government}

Each cohort in our model faces the effective time-varying tax rates that it experienced in the data and that we estimate from the PSID. As Benabou (2002), we adopt a functional form that allows for negative tax rates and thus incorporates the EITC. We allow our effective tax rates to depend on marital status, gender, and age for each cohort (and thus time). Taxes paid are a function of total income $Y$

$$
T(Y, i, j, t)=\left(1-\lambda_{t}^{i, j} Y^{-\tau_{t}^{i, j}}\right) Y
$$

The government uses a proportional payroll tax $\tau_{t}^{S S}$, up to a Social Security cap $\widetilde{y}_{t}$, to help finance old-age Social Security benefits, which are a function of average past earnings (or human capital as discussed in Section 4.2). We also allow the payroll tax and the Social Security cap to change over time for each cohort as in the data. We thus assume that the tax changes were anticipated by the households. The insurance provided by Medicaid and SSI in old age is represented by a means-tested consumption floor, $\underline{\mathrm{c}}(j)$, as in Hubbard, Skinner and Zeldes (1995). ${ }^{5}$

\subsection{Recursive formulation}

We compute nine value functions for the following groups and stages of life.

\subsubsection{The value function of working-age singles}

The value function of a working-age single depends on ones' age $t$, gender $i$, wealth $a_{t}^{i}$, persistent earnings shock $\epsilon_{t}^{i}$, and human capital $\bar{y}_{t}^{i}$

$$
\begin{gathered}
W^{s}\left(t, i, a_{t}^{i}, \epsilon_{t}^{i}, \bar{y}_{t}^{i}\right)=\max _{c_{t}, a_{t+1}, n_{t}^{i}}\left(v^{i}\left(c_{t}, l_{t}, \eta_{t}^{i, 1}\right)+\beta\left(1-\nu_{t+1}(i)\right) E_{t} W^{s}\left(t+1, i, a_{t+1}^{i}, \epsilon_{t+1}^{i}, \bar{y}_{t+1}^{i}\right)+\right. \\
\left.\beta \nu_{t+1}(i) E_{t}\left[\hat{W}^{c}\left(t+1, i, a_{t+1}^{i}+a_{t+1}^{p}, \epsilon_{t+1}^{i}, \epsilon_{t+1}^{p}, \bar{y}_{t+1}^{i}, \bar{y}_{t+1}^{p}\right)\right]\right)
\end{gathered}
$$

\footnotetext{
${ }^{5}$ Borella, Nardi and French (2018) discuss Medicaid rules and observed outcomes after retirement.
} 
subject to Equation (1) and

$$
\begin{gathered}
Y_{t}^{i}=e_{t}^{i, j}\left(\bar{y}_{t}^{i}\right) \epsilon_{t}^{i} n_{t}^{i}, \\
\tau_{c}(i, j, t)=\tau_{c}^{0,5} f^{0,5}(i, j, t)+\tau_{c}^{6,11} f^{6,11}(i, j, t), \\
T(\cdot)=T\left(r a_{t}+Y_{t}, i, j, t\right), \\
c_{t}+a_{t+1}=(1+r) a_{t}^{i}+Y_{t}^{i}\left(1-\tau_{c}(i, j, t)\right)-\tau_{t}^{S S} \min \left(Y_{t}^{i}, \widetilde{y}_{t}\right)-T(\cdot), \\
\bar{y}_{t+1}^{i}=\left(\bar{y}_{t}^{i}\left(t-t_{0}\right)+\left(\min \left(Y_{t}^{i}, \widetilde{y}_{t}\right)\right)\right) /\left(t+1-t_{0}\right), \\
a_{t+1} \geq 0, \\
n_{t}^{i} \geq 0 .
\end{gathered}
$$

The expectation of the value function for next period if one remains single integrates over one's wage shock next period. If one gets married, it also integrates over the distribution of the partner's state variables. The value function $\hat{W}^{c}$ is the person's discounted present value of utility once he or she is in a married relationship with someone with given state variables (see Appendix C). Equation (12) describes the evolution of human capital, measured as average accumulated earnings (up to the Social Security earnings cap $\widetilde{y}_{t}$ ) and in which $t_{0}=25$.

\subsubsection{The value function of singles during the early retirement stage}

The recursive problem for someone who has claimed Social Security at age $t r$ is

$$
S^{s}\left(t, i, a_{t}^{i}, \bar{y}_{r}^{i}, t r\right)=\max _{c_{t}, a_{t+1}}\left(v^{i}\left(c_{t}, L^{i, j}, \eta_{t}^{i, 1}\right)+\beta E_{t} S^{s}\left(t+1, i, a_{t+1}^{i}, \bar{y}_{r}^{i}, t r\right)\right),
$$

subject to equations (10), (13), and

$$
\begin{gathered}
Y_{t}=S S\left(\bar{y}_{r}^{i}, t r\right) \\
c_{t}+a_{t+1}=(1+r) a_{t}+Y_{t}-T(\cdot) .
\end{gathered}
$$

The term $S S\left(\bar{y}_{r}{ }^{i}, t r\right)$ is a function of the income that the single person earned during his or her working life, $\bar{y}_{r}^{i}$ and claiming age $t r$. Let $N^{s}\left(t, i, a_{t}^{i}, \epsilon_{t}^{i}, \bar{y}_{t}^{i}\right)$ denote the value function of a person during the early retirement period who has not yet claimed 
benefits

$$
N^{s}\left(t, i, a_{t}^{i}, \epsilon_{t}^{i}, \bar{y}_{t}^{i}\right)=\max _{c_{t}, a_{t+1}, n_{t}^{i}}\left(v^{i}\left(c_{t}, l_{t}^{i, j}, \eta_{t}^{i, 1}\right)+\beta E_{t} V^{s}\left(t+1, i, a_{t+1}^{i}, \epsilon_{t+1}^{i}, \bar{y}_{t+1}^{i}\right)\right),
$$

subject to equations (1), (8), (10), (12), (13), (14), and

$$
c_{t}+a_{t+1}=(1+r) a_{t}^{i}+Y_{t}^{i}-\tau_{t}^{S S} \min \left(Y_{t}, \widetilde{y}_{t}\right)-T(\cdot) .
$$

Let $V^{s}\left(t, i, a_{t}^{i}, \epsilon_{t}^{i}, \bar{y}_{t}^{i}\right)$ denote the value function for a person during the early retirement stage who has not yet claimed and who, at the beginning of each period, chooses whether to claim or not, where $D_{t}^{i}$ is an indicator function for claiming

$$
V^{s}\left(t, i, a_{t}^{i}, \epsilon_{t}^{i}, \bar{y}_{t}^{i}\right)=\max _{D_{t}^{i}}\left(\left(1-D_{t}^{i}\right) N^{s}\left(t, i, a_{t}^{i}, \epsilon_{t}^{i}, \bar{y}_{t}^{i}\right)+D_{t}^{i} S^{s}\left(t, i, a_{t}^{i}, \bar{y}_{t}^{i}, t\right)\right) .
$$

\subsubsection{The value function of retired singles}

The value function of a retired single with health $\psi_{t}^{i}$, average realized lifetime earnings $\bar{y}_{r}^{i}$, and Social Security claiming age $t r$ is

$R^{s}\left(t, i, a_{t}, \psi_{t}^{i}, \bar{y}_{r}^{i}, t r\right)=\max _{c_{t}, a_{t+1}}\left(v^{i}\left(c_{t}, L^{i, j}, \eta_{t}^{i, 1}\right)+\beta s_{t}^{i, j}\left(\psi_{t}^{i}\right) E_{t} R^{s}\left(t+1, i, a_{t+1}, \psi_{t+1}^{i}, \bar{y}_{r}^{i}, t r\right)\right)$,

subject to equations (10), (13), (16), and

$$
\begin{gathered}
B\left(a_{t}, Y_{t}, \psi_{t}^{i}, \underline{\mathrm{c}}(j)\right)=\max \left\{0, \underline{\mathrm{c}}(j)-\left[(1+r) a_{t}+Y_{t}-m_{t}^{i, j}\left(\psi_{t}^{i}\right)-T(\cdot)\right]\right\} \\
c_{t}+a_{t+1}=(1+r) a_{t}+Y_{t}+B\left(a_{t}, Y_{t}, \psi_{t}^{i}, \underline{\mathrm{c}}(j)\right)-m_{t}^{i, j}\left(\psi_{t}^{i}\right)-T(\cdot) \\
a_{t+1}=0, \quad \text { if } \quad B(\cdot)>0 .
\end{gathered}
$$

The term $B\left(a_{t}, Y_{t}^{i}, \psi_{t}^{i}, \underline{\mathrm{c}}(j)\right)$ represents old-age means-tested government transfers (such as Medicaid and SSI) that ensure a minimum consumption floor $\underline{\mathrm{c}}(j)$.

\subsubsection{The value function of couples during the working period}

The value function of a married couple at this stage depends on both partners' state variables, where 1 and 2 refer to gender, and $j=2$. 


$$
\begin{aligned}
W^{c}\left(t, a_{t}, \epsilon_{t}^{1}, \epsilon_{t}^{2}, \bar{y}_{t}^{1}, \bar{y}_{t}^{2}\right) & =\max _{c_{t}, a_{t+1}, n_{t}^{1}, n_{t}^{2}}\left(w\left(c_{t}, l_{t}^{1, j}, l_{t}^{2, j}, \eta_{t}^{i, j}\right)\right. \\
& +\left(1-\zeta_{t+1}(\cdot)\right) \beta E_{t} W^{c}\left(t+1, a_{t+1}, \epsilon_{t+1}^{1}, \epsilon_{t+1}^{2}, \bar{y}_{t+1}^{1}, \bar{y}_{t+1}^{2}\right) \\
& \left.+\zeta_{t+1}(\cdot) \beta \sum_{i=1}^{2}\left(E_{t} W^{s}\left(t+1, i, a_{t+1} / 2, \epsilon_{t+1}^{i}, \bar{y}_{t+1}^{i}\right)\right)\right)
\end{aligned}
$$

subject to equations (1), (8), (9), (12), and

$$
\begin{gathered}
T(\cdot)=T\left(r a_{t}+Y_{t}^{1}+Y_{t}^{2}, i, j, t\right) \\
c_{t}+a_{t+1}=(1+r) a_{t}+Y_{t}^{1}+Y_{t}^{2}\left(1-\tau_{c}(2,2, t)\right)-\tau_{t}^{S S}\left(\min \left(Y_{t}^{1}, \widetilde{y}_{t}\right)+\min \left(Y_{t}^{2}, \widetilde{y}_{t}\right)\right)-T(\cdot) \\
a_{t} \geq 0, \quad n_{t}^{1}, n_{t}^{2} \geq 0 .
\end{gathered}
$$

The expected value of the couple's value function is taken with respect to the conditional probabilities of the wage shocks for each of the spouses (we assume independent draws). The expected values for the newly divorced people are taken using the appropriate conditional distribution for their own wage shocks. The term $\zeta_{t+1}(\cdot)$ represents the probability of divorce.

\subsubsection{The value function of couples during the early retirement period}

The recursive problem for couples that have claimed Social Security at age $t r$ is

$$
S^{c}\left(t, a_{t}, \bar{y}_{r}^{1}, \bar{y}_{r}^{2}, t r\right)=\max _{c_{t}, a_{t+1}}\left(w\left(c_{t}, L^{1, j}, L^{2, j}, \eta_{t}^{i, j}\right)+\beta E_{t} S^{c}\left(t+1, a_{t+1}, \bar{y}_{r}^{1}, \bar{y}_{r}^{2}, t r\right)\right)
$$

subject to equations (10), (17), (13), and

$$
Y_{t}=\max \left\{\left(S S\left(\bar{y}_{r}^{1}, t r\right)+S S\left(\bar{y}_{r}^{2}, t r\right), \frac{3}{2} \max \left(S S\left(\bar{y}_{r}^{1}, t r\right), S S\left(\bar{y}_{r}^{2}, t r\right)\right)\right\}\right.
$$

The variable $Y_{t}$ represents Social Security spousal benefit: a married person receives the highest amount between one's own benefit and half of their spouse's benefit. The 
value function of a couple that has not yet claimed benefits is

$$
\begin{aligned}
N^{c}\left(t, a_{t}, \epsilon_{t}^{1}, \epsilon_{t}^{2}, \bar{y}_{t}^{1}, \bar{y}_{t}^{2}\right) & =\max _{c_{t}, a_{t+1}, n_{t}^{1}, n_{t}^{2}}\left(w\left(c_{t}, l_{t}^{1, j}, l_{t}^{2, j}, \eta_{t}^{i, j}\right)\right. \\
& \left.+\beta E_{t} V^{c}\left(t+1, a_{t+1}, \epsilon_{t+1}^{1}, \epsilon_{t+1}^{2}, \bar{y}_{t+1}^{1}, \bar{y}_{t+1}^{2}\right)\right),
\end{aligned}
$$

subject to equations (1), (8), (12), (26), (28), and

$$
c_{t}+a_{t+1}=(1+r) a_{t}+Y_{t}^{1}+Y_{t}^{2}-\tau_{t}^{S S}\left(\min \left(Y_{t}^{1}, \widetilde{y}_{t}\right)+\min \left(Y_{t}^{2}, \widetilde{y}_{t}\right)\right)-T(\cdot) .
$$

The value function of a married couple during the early retirement stage that has not yet claimed Social Security benefits is

$$
V^{c}\left(t, a_{t}, \epsilon_{t}^{1}, \epsilon_{t}^{2}, \bar{y}_{t}^{1}, \bar{y}_{t}^{2}\right)=\max _{D_{t}}\left(\left(1-D_{t}\right) N^{c}\left(t, a_{t}, \epsilon_{t}^{1}, \epsilon_{t}^{2}, \bar{y}_{t}^{1}, \bar{y}_{t}^{2}\right)+D_{t} S^{c}\left(t, a_{t}, \bar{y}_{t}^{1}, \bar{y}_{t}^{2}, t\right)\right)
$$

\subsubsection{The value function of couples during retirement}

During this stage, the married couple's recursive problem $(j=2)$ depends on each of the spouses health shocks $\psi_{t}^{i}$ and there are survival shocks $s_{t}^{i, 2}\left(\psi_{t}^{i}\right)$. We assume that the health shocks of each spouse are independent of each other and that the death shocks of each spouse are also independent of each other.

$$
\begin{aligned}
R^{c}\left(t, a_{t}, \psi_{t}^{1}, \psi_{t}^{2}, \bar{y}_{r}^{1}, \bar{y}_{r}^{2}, t r\right) & =\max _{c_{t}, a_{t+1}}\left(w\left(c_{t}, L^{1, j}, L^{2, j}, \eta_{t}^{i, j}\right)+\right. \\
& \beta s_{t}^{1, j}\left(\psi_{t}^{1}\right) s_{t}^{2, j}\left(\psi_{t}^{2}\right) E_{t} R^{c}\left(t+1, a_{t+1}, \psi_{t+1}^{1}, \psi_{t+1}^{2}, \bar{y}_{r}^{1}, \bar{y}_{r}^{2}, t r\right)+ \\
& \beta s_{t}^{1, j}\left(\psi_{t}^{1}\right)\left(1-s_{t}^{2, j}\left(\psi_{t}^{2}\right)\right) E_{t} R^{s}\left(t+1,1, a_{t+1}, \psi_{t+1}^{1}, \overline{\bar{y}}_{r}^{1}, t r\right)+ \\
& \left.\beta s_{t}^{2, j}\left(\psi_{t}^{2}\right)\left(1-s_{t}^{1, j}\left(\psi_{t}^{1}\right)\right) E_{t} R^{s}\left(t+1,2, a_{t+1}, \psi_{t+1}^{2}, \bar{y}_{r}^{2}, t r\right)\right),
\end{aligned}
$$

subject to equations (10), (13), (24), (30), and

$$
\overline{\bar{y}}_{r}^{i}=\max \left(\bar{y}_{r}^{1}, \bar{y}_{r}^{2}\right)
$$




$$
\begin{gathered}
B\left(a_{t}, Y_{t}, \psi_{t}^{1}, \psi_{t}^{2}, \underline{\mathrm{c}}(j)\right)=\max \left\{0, \underline{\mathrm{c}}(j)-\left[(1+r) a_{t}+Y_{t}-m_{t}^{1, j}\left(\psi_{t}^{1}\right)-m_{t}^{2, j}\left(\psi_{t}^{2}\right)-T(\cdot)\right]\right\} \\
c_{t}+a_{t+1}=(1+r) a_{t}+Y_{t}+B\left(a_{t}, Y_{t}, \psi_{t}^{1}, \psi_{t}^{2}, \underline{\mathrm{c}}(j)\right)-m_{t}^{1, j}\left(\psi_{t}^{1}\right)-m_{t}^{2, j}\left(\psi_{t}^{2}\right)-T(\cdot) .
\end{gathered}
$$

A survivor collects benefits based on the higher amount between their own contributions and those of their deceased spouse (Equation (35)).

\subsubsection{The value functions of individuals in couples}

We have to compute the joint value function of the couple to appropriately compute joint labor supply and savings under the married couples' available resources. However, when computing the value of getting married for a single person, the relevant object for that person is his or her discounted present value of utility in the marriage. We thus compute this object for person of gender $i$ who is married with a specific partner. For more details, see Appendix C.

\section{Estimation}

We estimate our model on our two birth cohorts separately by adopting a two-step estimation strategy (as Gourinchas and Parker (2002)). In the first step, we use data on the initial distributions at age 25 for our model's state variables and estimate or calibrate those parameters that can be cleanly identified outside our model.

In the second step, we use the MSM. For the 1945 cohort, we normalize the time endowment for single men and estimate 19 model parameters $\left(\beta, \omega,\left(\phi_{0}^{i, j}, \phi_{1}^{i, j}, \phi_{2}^{i, j}\right)\right.$, $\left.\left(\tau_{c}^{0,5}, \tau_{c}^{6,11}\right), L^{i, j}\right)$. For the 1955 cohort, we assume that they have the same discount factor $\beta$ and weight on consumption $\omega$ as the 1945 cohort, and thus estimate 17 parameters. The data that inform the estimation of the parameters of our model are composed of the following 448 moments for each cohort:

1. Labor market participation of married and single men and women age 25-65.

2. Hours worked conditional on working for married and single men and women age 25-65.

3. Wealth for couples and single men and women age 26-65.

Appendices B, D, and F discuss our first-step and second-step inputs in detail. 


\subsection{First-step estimation}

\begin{tabular}{clc}
\hline \hline \multicolumn{2}{l}{ Estimated processes } & Source \\
\hline Wages & & \\
$e_{t}^{i, j}(\cdot)$ & Endogenous age-efficiency profiles & PSID \\
$\epsilon_{t}^{i}$ & Wage shocks & PSID \\
Demographics & & \\
$s_{t}^{i, j}\left(\psi_{t}^{i}\right)$ & Survival probability & HRS \\
$\zeta_{t}(\cdot)$ & Divorce probability & PSID \\
$\nu_{t}(\cdot)$ & Probability of getting married & PSID \\
$\xi_{t}(\cdot)$ & Matching probability & PSID \\
$\theta_{t}(\cdot)$ & Partner's wealth and earnings & PSID \\
$f^{0,5}(i, j, t)$ & Number of children ages 0-5 & PSID \\
$f^{6,11}(i, j, t)$ & Number of children ages 6-11 & PSID \\
Health shock & & \\
$m_{t}^{i, j}\left(\psi_{t}^{i}\right)$ & Medical expenses & HRS \\
$\pi_{t}^{i, j}\left(\psi_{t}^{i}\right)$ & Transition matrix for health status & HRS \\
Government policy & \\
$\lambda_{t}^{j}, \tau_{t}^{j}$ & Income tax & See text \\
\hline \hline
\end{tabular}

Table 1: First-step estimated inputs summary.

Table 1 summarizes our first-step estimated model inputs.
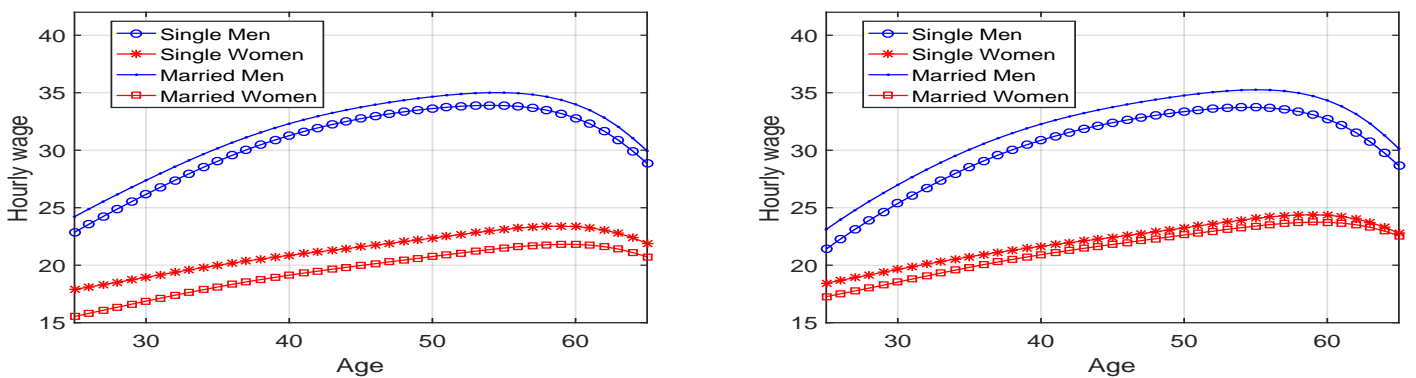

Figure 4: Average wage. Left: 1945 cohort. Right, 1955 cohort. PSID.

Wages. Figure 4 displays the average wage profiles implied by our estimated processes. Consistent with the evidence on the marriage premium, the wages of married men are higher than those of single men. In contrast, the wages of married women are lower than those of single women in our 1945 cohort. Across the two cohorts, the gender gap shrinks because the average wage of married women increases. 
This is due to a combination of different returns to human capital and human capital accumulation. The stagnation of men's wages across cohorts is consistent with the findings by Acemoglu and Autor (2011) and Roys and Taber (2017) on wages over time. Table 11 in Appendix B reports our estimates for the earnings shock processes. ${ }^{6}$

Marriage, divorce, spousal wage shocks, spousal wealth, and Social Security benefits. Men with higher wage shocks are more likely marry and less likely to divorce. In contrasts, these shocks have little effects on the marriage and divorce probabilities of women. In addition, the probability of marrying and divorcing are both smaller for our 1955 cohort (Figures 12 and 13 in Appendix B). Our estimated correlation of the logarithm of initial wage shocks between spouses is 0.22 at age 25$34,0.36$ at age $35-44$, and 0.42 after age $45 .{ }^{7}$ Because of these initial correlations and the high wage shocks persistence that we estimate, spouses also have positively correlated shocks after getting married. Appendix B reports spousal wealth and Social Security earnings.

Children. The number of children has decreased for married women and, to a smaller extent, for single women, from the 1945 cohort to the 1955 cohort (Figure 16 in Appendix B).

Health, mortality, and medical expenses. Due to lack of old-age data for the 1955 cohort, we assume that it faces the same risks as the 1945 one after age 65 . We find that women, married people, and healthy people have longer life expectancies (Figure 18 in Appendix B) and that medical expenses climb fast past age 85 and are highest for single and unhealthy people (Figure 19 in Appendix B).

\subsection{Second-step estimation}

Table 2 presents our estimated preference parameters for both cohorts (see Appendix $\mathrm{G}$ for more details). For the 1945 cohort, our estimated discount factor is 0.990, the same value estimated by De Nardi, French and Jones (2016) for elderly retirees, and our estimated weight on consumption is 0.406 . We assume that the 1955 cohort shares these preference parameters.

We normalize the time endowment of single men to 5,840 hours a year and 112 hours a week. For our 1945 cohort, single women have a weekly time endowment of

\footnotetext{
${ }^{6}$ We discuss the role of education in Appendix B.

${ }^{7} \mathrm{We}$ assume this correlation to be the same for both cohorts because the number of new marriages after age 25 is small during this time period.
} 


\begin{tabular}{lll}
\hline \hline Estimated parameters & 1945 cohort & 1955 cohort \\
\hline$\beta$ : Discount factor & 0.990 & As 1945 cohort \\
$\omega:$ Consumption weight & 0.407 & As 1945 cohort \\
$L^{2,1}$ : Time endowment (weekly hours), single women & 107 & 112 \\
$L^{1,2}$ : Time endowment (weekly hours), married men & 107 & 100 \\
$L^{2,2}$ : Time endowment (weekly hours), married women & 88 & 88 \\
$\tau_{c}^{0,5}$ : Prop. child care cost for children age 0-5 & $28 \%$ & $22 \%$ \\
$\tau_{c}^{6,11}$ : Prop. child care cost for children age 6-11 & $7 \%$ & $19 \%$ \\
$\Phi_{t}^{i, j}:$ Partic. cost & Fig. 21 & Fig. 21 \\
\hline \hline
\end{tabular}

Table 2: Second-step estimated model parameters.

107 hours a week. We interpret this as them having to spend five more hours a week managing their household, rearing children, and taking care of elderly parents. The time endowments for married men and women are 107 and 88 hours. This implies that people in the latter two groups spend 5 and 24 hours a week in home production activities, respectively. These estimates are remarkably similar to those from time diary data in Aguiar and Hurst (2007) and Dotsey, Li and Yang (2014).

Our estimates for the 1945 cohort imply that child care costs for each child age 0-5 and $6-11$ are $28 \%$ and $7 \%$ of a woman's earnings, respectively. The PSID data only reports child care costs for all children in the age range $0-11$. They correspond to $31 \%$ and $20 \%$ of married women's earnings at ages 25 and 30, respectively. These numbers line up well with those from our model, which are $22 \%$ and $17 \%$, respectively.

For the 1955 cohort, we notice two main changes compared with the 1945 cohort. First, to help reconcile the lower hours worked by married men in this cohort, the model estimates that their available time to work and enjoy leisure decreases by seven hours a week. Second, to help reconcile the slopes of hours and participation over the life cycle by married women in the presence of fewer children, the model estimates that the per-child care costs of having younger children goes down, while that of having older children goes up. While decomposing the effects of changing labor supply between the two cohorts is very interesting (see, for instance, Attanasio, Low and Sánchez-Marcos (2008) and Eckstein and Lifshitz (2011)), we abstract from analyzing it further due to space constraints.

Figure 21 in Appendix G reports the age-varying time costs of working by age expressed as fraction of the time endowment of single men. Our estimated participation costs are relatively high when people are younger and, with the exception of 
single men, increase again after 45 . The time costs of going to work might include factors other than commuting time. For instance, they might be higher when children are youngest because during that period parents might need additional time to get their children back and forth from day care. They also show that, conditional on all aspects of our environment, the participation costs of married women are the lowest ones because married women face lower wages, have a smaller time endowment (because of time spent engaging in home production and child care), and tend to have higher-wage husbands who work. Table 19 reports all of our structural model estimates and their standard errors.

\subsection{Model fit}

Figures 5 and 6 report our model-implied moments and the data moments and 95\% confidence intervals from the PSID for our 1945 cohort (for brevity, we report the fit for the 1955 cohort in Appendix H). Our model fits the targeted data well for both cohorts, which is remarkable given that it is tightly parameterized: we have 448 targets for each cohort and we estimate 19 and 17 parameters for the 1945 and 1955 cohorts, respectively.

\subsection{Identification}

In this section, we briefly discuss why our target moments allow us to identify the 19 model parameters that we estimate (see Table 2) for our 1945 cohort. $^{8}$

The discount factor $\beta$ is the only parameter that we estimate that has a large effect on the savings of both couples and singles over much of their life cycle (compare Figure 25 in which we change it, with all of the other figures in Appendix I, which change the other parameters). In contrast, it has relatively small effects on both participation and hours over the life cycle for our four subgroups.

The weight on consumption $\omega$ (Figure 26) is the only parameter that we estimate that affects the participation and hours conditional on participation for all of our four subgroups (single and married men and women). It also has overall minor effects on savings.

\footnotetext{
${ }^{8}$ Given that we only estimate 17 parameters for the 1955 cohort and that we match the same targets, the parameters for the 1955 cohort are identified as well.
} 

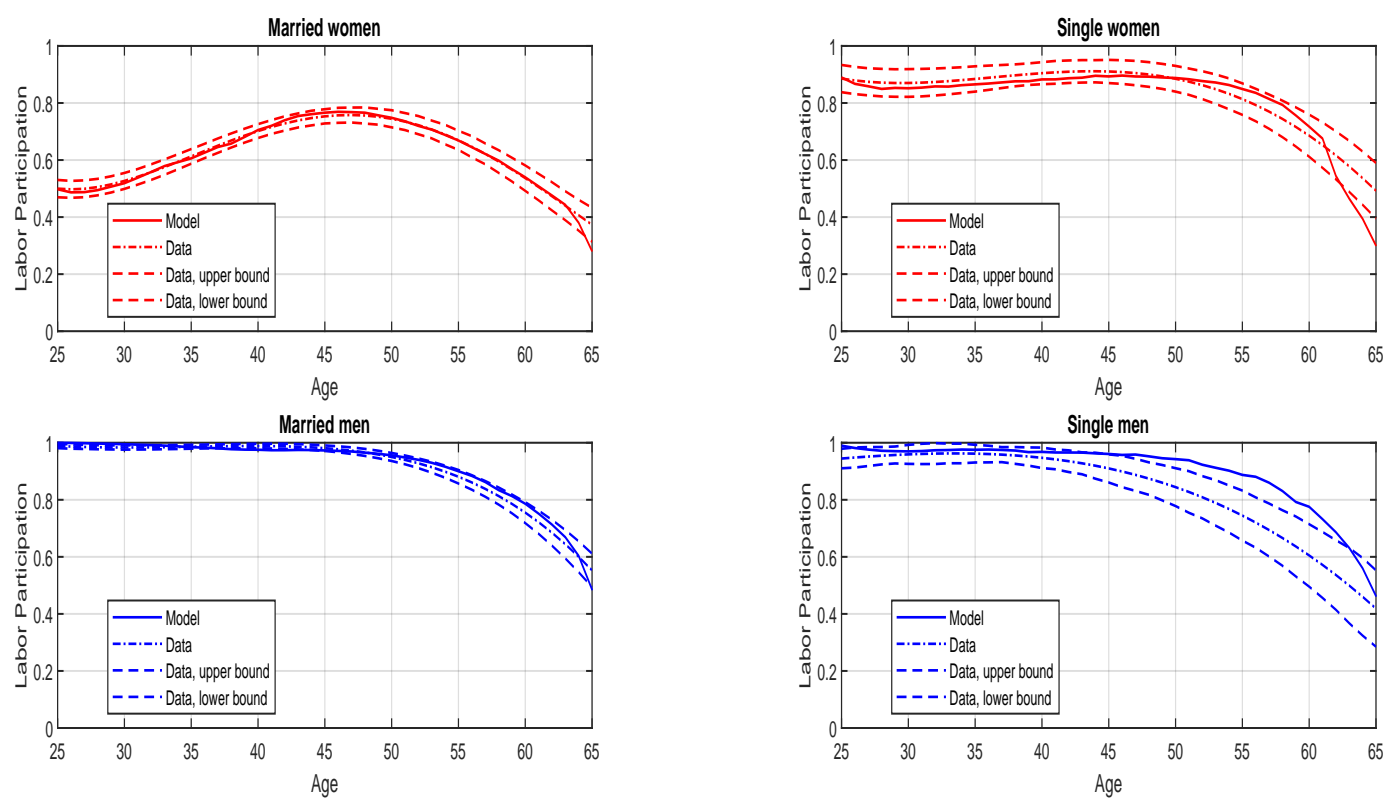

(a) Participation, couples

(b) Participation, singles
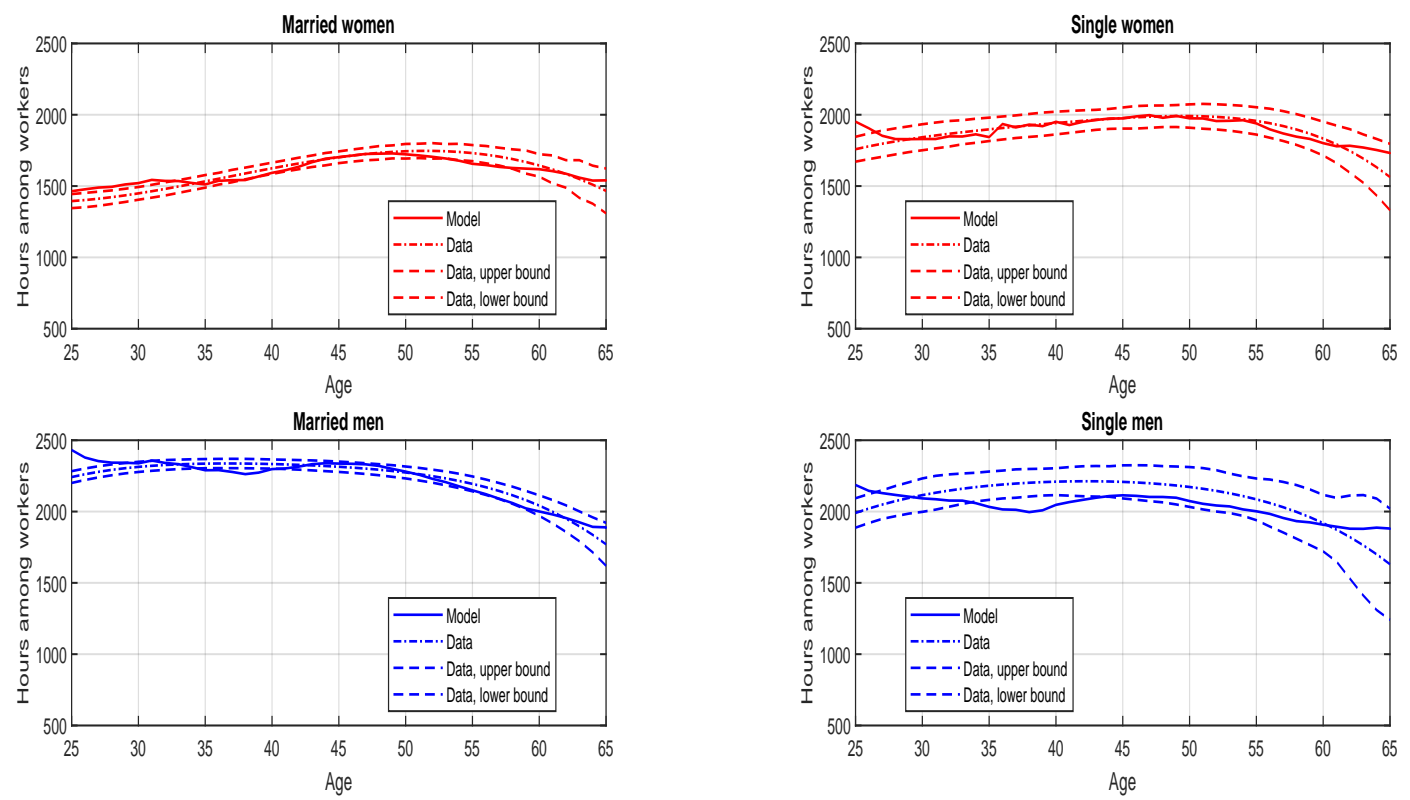

(c) Hours for workers, couples

(d) Hours for workers, singles

Figure 5: Model-implied participation and hours, and average and 95\% confidence intervals from the PSID. 


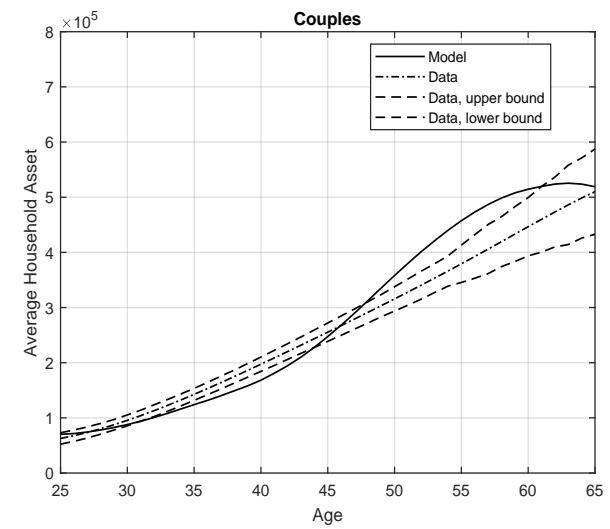

(a) Wealth, couples
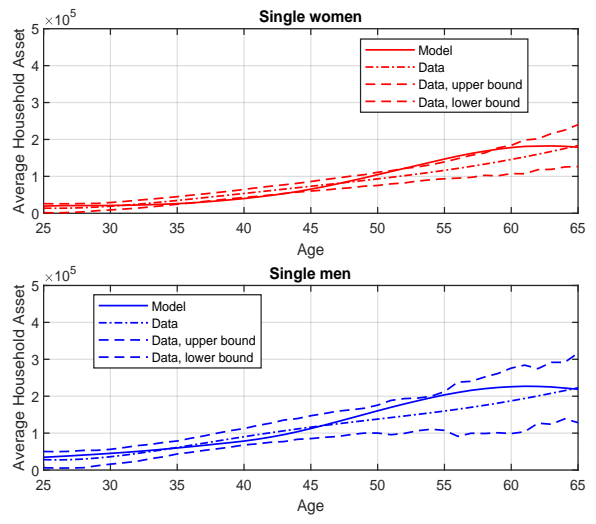

(b) Wealth, singles

Figure 6: Model-implied wealth, and average and 95\% confidence intervals from the PSID.

Our estimated available time for married men and women and for single women (we normalize available time for single men), mostly affect the group they apply to. More specifically, changing the available time of single women mostly affects their hours but does not have much effect on their participation (Figure 27) and has no discernible effects on savings. Reducing available time of married men (Figure 28), who are the breadwinners for these cohorts, marginally decreases the married men's participation later in life, decreases their hours, and reduces couples' savings, but not the savings of singles. Interestingly, it also increases the participation of married women over all of their life cycle, but has no effects on the hours worked by married women conditional on participation. Reducing available time of married women (Figure 29), instead, reduces both their participation and hours, and the participation of married men in middle and late age.

Child care costs mostly affect the participation of the married women, who have more of them. As younger women tend to have younger children, ages 0-5 child care costs mostly affect the participation of very young married women (until age 35, Figure 30). In contrast, age 6-11 child care costs have relatively more of an effect on older married women (Figure 31). Both child care costs have little effects on the rest of our target moments.

The remaining set of parameters that we estimate govern a quadratic function affecting the fixed time cost of working (as a function of age) for each of our four groups of people (see Equation 3). Thus, they comprise 12 additional parameters. We also plot the implied fixed cost of working for each parameter change. 
Decreasing the fixed-time costs of working for single men (Figure 32) increases their participation after age 40, and hours worked during all of the working period, and especially at younger ages. Doing the same for single women goes in the same direction, but single women start increasing their participation at younger ages and adjust by less at each age. For single women, the comparison between Figure 27 and Figure 33 reveals that while the fixed cost of working affects both participation and hours, available time mainly affects their hours worked.

Turning to married men, Figure 34 shows that decreasing the fixed-time cost of participation for married men increases their participation after age 40 and increases their hours worked over all of their life cycle. In contrast, changing available time for married men affects their hours much more than their participation. Decreasing the fixed time cost of participation for married women (Figure 35) increases their labor market participation at all ages but has no effects on hours worked conditional on participation. The comparison with Figure 29 reveals that, in contrast, changing available time of married women changes both their participation and hours worked conditional on participation.

The remaining set of figures change the linear term or the quadratic term fixed time cost of working with age. Consistent with our previous set of results, these changes mostly affect participation rather than hours. In addition, the linear term has a relatively stronger effects in middle age than the constant term, while the quadratic term has the strongest effect on labor market participation closer to retirement age.

Table 21 in Appendix I reports our GMM criterion function disaggregated by group and outcome for our benchmark model and for the experiments that change one parameter at a time and shows that the GMM criterion raises along all of these deviations. This and many other checks that we have run during the estimation stage tell us that our model's parameters are well identified given the target moments that we have chosen.

\section{Model validation}

We start by analyzing the joint distribution of married couple's wages because within-couple relative wages play an important role in generating responses to policy changes. Table 3 shows that the correlation of the wages of working husbands and wives by age group for the 1945 cohort generated by the model broadly replicates 
that found in the data, with the correlation in the model actually being higher than that in the data. Table 20 in Appendix $\mathrm{H}$ shows that our model also matches well the joint distribution of husband's and wife's wages by wage tercile.

\begin{tabular}{lcc}
\hline \hline Age group & Model & Data \\
\hline $25-34$ & 0.462 & 0.330 \\
$35-44$ & 0.430 & 0.237 \\
$45-54$ & 0.433 & 0.162 \\
\hline \hline
\end{tabular}

Table 3: Correlation of husbands and wives wages at various ages, workers, model and data, 1945 cohort.
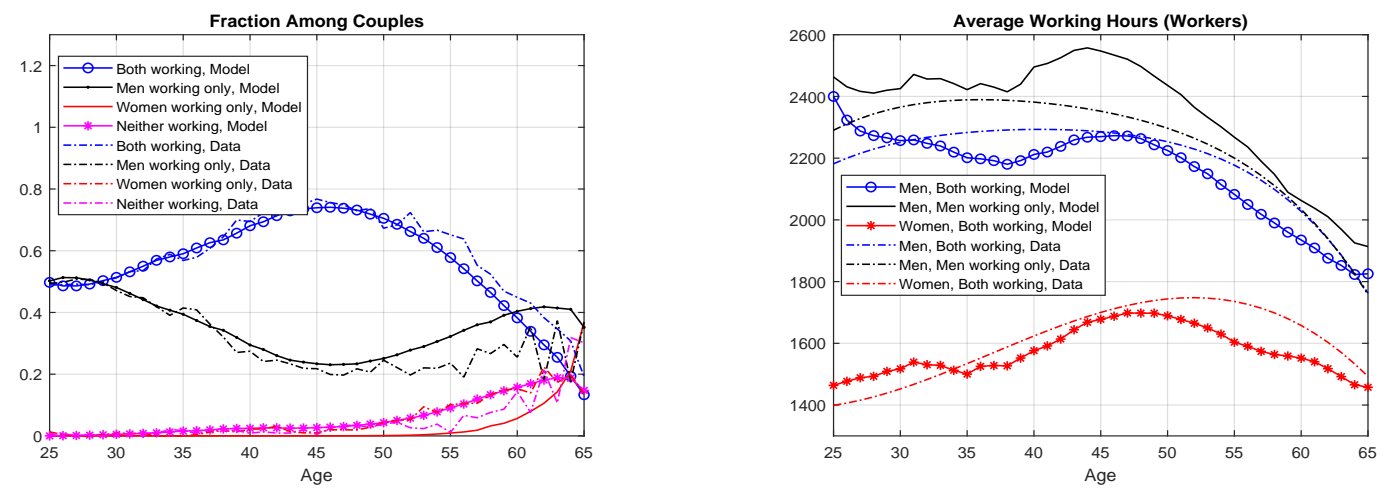

Figure 7: Participation (left) and worker's hours (right) for people in couples. Model (solid) and PSID (dashed). 1945 cohort.

Figure 7 compares additional model implications for couples with those in the data for our 1945 cohort. It shows that our estimated model also matches the fraction of couples with two workers, with only the husband working, with only the wife working, or with none working by age. It also highlights that our model produces reasonable implications for the hours worked over the life cycle for each of these type of couples.

To further build confidence in our model's responses to policy changes, we also evaluate its labor supply elasticities. Table 4 shows the (compensated) elasticities of participation and hours among workers with respect to an anticipated change to their own wage. ${ }^{9}$ It shows that the elasticity of participation of women is larger than that of men, that married men have the lowest elasticity of participation, and

\footnotetext{
${ }^{9}$ For this computation, we temporarily increase the wage for only one age and one group at a time (married men, married women, single men, or single women) by $5 \%$.
} 
that the elasticity of participation for all groups is largest around retirement age (a finding that confirms that of French (2000) for men). Importantly, our elasticities are consistent with those in Liebman, Luttmer and Seif (2009), Blundell and Macurdy (1999), and Attanasio, Levell, Low and Sánchez-Marcos (2018).

\begin{tabular}{c|cccc|cccc}
\hline \hline & \multicolumn{4}{|c}{ Participation } & \multicolumn{4}{c}{ Hours among workers } \\
& \multicolumn{2}{c}{ Married } & \multicolumn{2}{c}{ Single } & \multicolumn{2}{c}{ Married } & \multicolumn{3}{c}{ Single } \\
& W & M & W & M & W & M & W & M \\
\hline 30 & 1.0 & 0.0 & 0.5 & 0.2 & 0.2 & 0.3 & 0.4 & 0.4 \\
40 & 0.7 & 0.1 & 0.4 & 0.2 & 0.4 & 0.5 & 0.4 & 0.5 \\
50 & 0.6 & 0.2 & 0.4 & 0.5 & 0.4 & 0.5 & 0.8 & 0.5 \\
60 & 1.1 & 0.8 & 1.8 & 1.4 & 0.3 & 0.3 & 0.5 & 0.4 \\
\hline \hline
\end{tabular}

Table 4: Model-implied elasticities of labor supply.

However, the compensated wage elasticities are not necessarily indicative of how participation and hours would change as a result of a permanent wage change, which is more relevant given our policy experiments. The left graph of Figure 8 shows that a permanent $5 \%$ increase in the wage of married women implies an elasticity of participation for married women which is U-shaped and peaks at 2.8 at age 25 . It also reports the cross-elasticities of the other groups to changes in the wages of married women. The right graph highlights that permanent wage changes lead to high increases in married women's participation, with participation being 3-7 percentage points higher over all of their life cycle. It also shows that the participation of single women rises because they expect to get married and obtain higher wages (and higher returns to human capital) upon marriage. Married men's participation after age 40 decreases when women's wages increase, a finding that confirms the importance of modeling the labor supply of both spouses when studying couples.

\section{Eliminating marital provisions}

We now evaluate the effects of various policy reforms. We first show the labor supply and savings responses resulting from the elimination of various marital policies and then evaluate their welfare implications. 

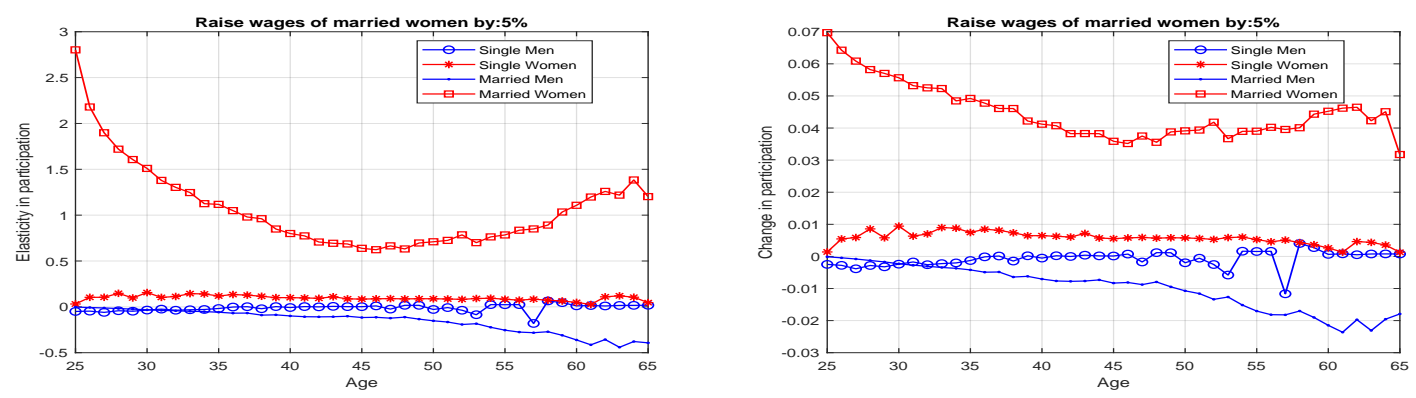

Figure 8: Elasticity of participation (left) and change in participation (right) for a $5 \%$ permanent increase in the wage schedule of married women. Model's implications.

\section{$7.1 \quad$ Outcomes}

For each policy counterfactual, we compute two sets of results. The first one balances the government budget constraint by adjusting the proportional component of the income tax, while the second one keeps the government budget constraint unbalanced. Because of space constraints, we report the latter in Appendix K.

\subsubsection{Eliminating spousal Social Security benefits, 1945 cohort}

According to the current Social Security rules, one's spouse can receive half of his or her partner's contribution while their partner is alive and all of the benefits of their deceased spouse. This provision discourages the labor supply of the secondary earner, given that he or she can benefit from spousal benefits. It also encourages the labor supply of the main earner, who also works to provide Social Security benefits to the secondary earner. In addition, it reduces retirement savings by raising the annuitized income flow of the secondary earner or non-participant.

When eliminating both spousal Social Security benefits, the government runs a budget surplus and can cut the proportional component of the income tax from $4.0 \%$ to $1.8 \%$. The top left panel of Figure 9 shows that the participation of married women is, respectively, 9, 11, and 4 percentage points higher at ages 25, 55-60, and 65 without spousal Social Security benefits. In contrast, married men decrease their participation starting at age 55, and their participation is 6 percentage points lower by age 65 . The participation of single women at ages 25-30 increases by 3 percentage points because, should they marry, they now expect no Social Security benefits coming from their spouse's labor supply. As single women age, the probability that they marry becomes 
negligible, and the effect of the elimination of spousal benefits on their participation fades.
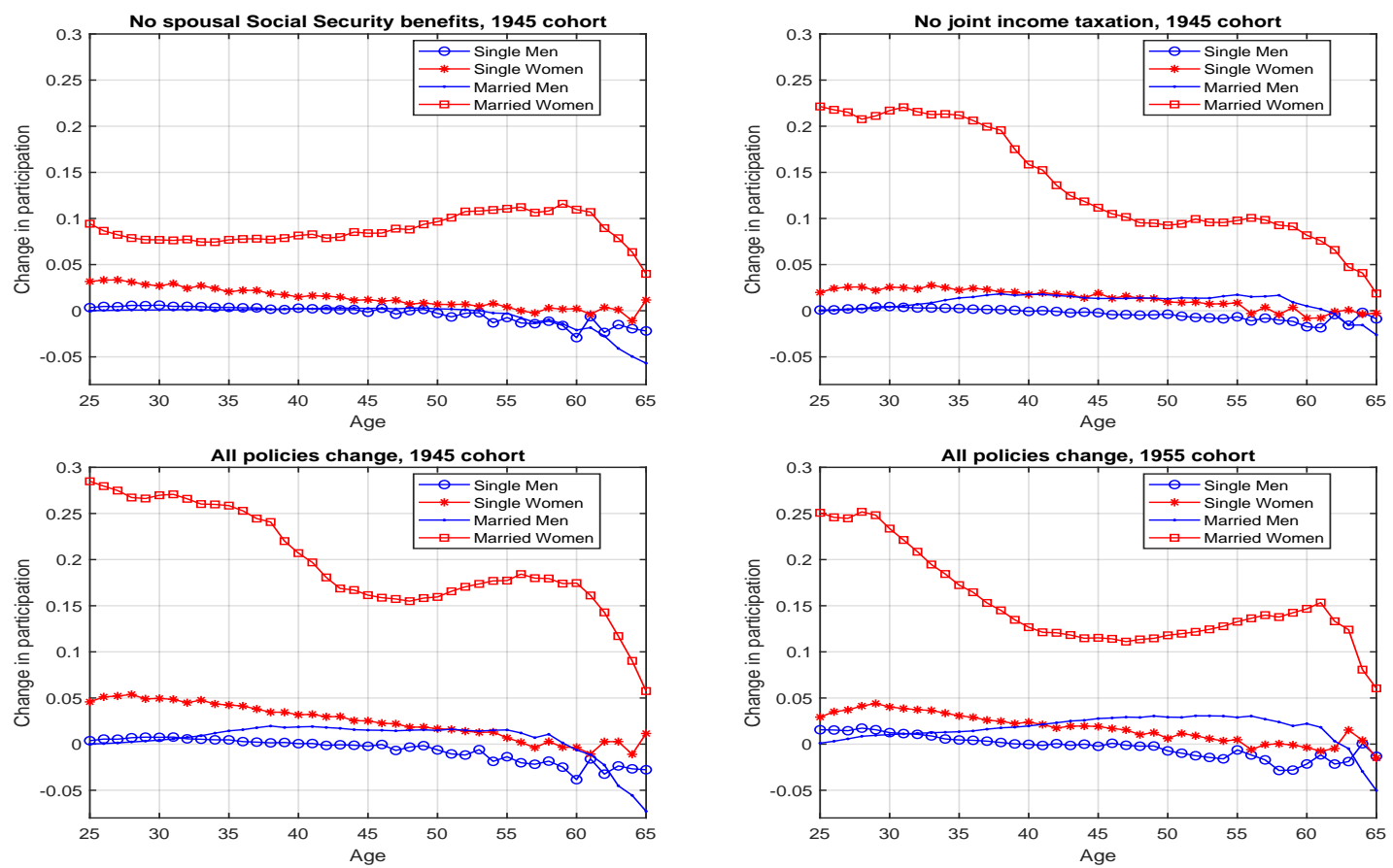

Figure 9: Changes in participation as a result of the elimination of various marriagerelated policies under government budget balance.

An important reason why this reform has such large effects on the labor supply of married women resides in the initial distribution of potential wages of men and women at age 25. The top panel of Table 5 shows that, in the 1945 cohort, $60 \%$ of women and only $20 \%$ of men belong to the bottom two quintiles of wages at age 25 . Thus, most women have low wages and tend to be secondary earners in this cohort. For this reason, they react strongly to the elimination of spousal benefits.

Groneck and Wallenius (forthcoming) and Kaygusuz (2015) study the effects of marital Social Security benefits in simpler models than ours in which, for instance, men cannot change their labor supply and women can do so to a limited extent. ${ }^{10}$ They report that, over all of the working period, their model implies an increase in the participation by married women of 6.4 and 6.1 percentage points, respectively. Because we also allow men to adjust their labor supply, and they choose to reduce it

\footnotetext{
${ }^{10}$ Their models are also less rich along other important dimensions and are calibrated rather than estimated.
} 


\begin{tabular}{l|ccccc}
\hline \hline & \multicolumn{5}{|c}{ Wage quintile } \\
\hline & 1 & 2 & 3 & 4 & 5 \\
\hline 1945 cohort & & & & & \\
Men & $7.9 \%$ & $12.4 \%$ & $21.3 \%$ & $28.2 \%$ & $30.2 \%$ \\
Women & $32.3 \%$ & $27.8 \%$ & $18.7 \%$ & $11.6 \%$ & $9.6 \%$ \\
\hline 1955 cohort & & & & & \\
Men & $10.4 \%$ & $14.0 \%$ & $19.1 \%$ & $26.0 \%$ & $30.4 \%$ \\
Women & $28.1 \%$ & $25.1 \%$ & $20.6 \%$ & $15.1 \%$ & $11.1 \%$ \\
\hline \hline
\end{tabular}

Table 5: Distribution of men and women at age 25 across wage quintiles, 1945 (top) and 1955 cohort (bottom). PSID data.

in older ages, and because women (as in the data) have more flexibility in their hours worked, we find effects that are a bit larger, but in the same ballpark.

Married women work more and accumulate more human capital. As a result, their labor income is over 10\% higher over all of their working period. Row 1 in Table 6 shows the resulting changes in wealth at retirement time. The reform increases savings by reducing government payments to spouses and widows during retirement, and wealth at retirement goes up by $14.6 \%, 8.7 \%$, and $11.2 \%$ for couples, single men, and single women, respectively.

\begin{tabular}{l|ccc}
\hline \hline & Couples & Single men & Single women \\
\hline 1945 cohort, no spousal Social Security benefits & $14.6 \%$ & $8.7 \%$ & $11.2 \%$ \\
1945 cohort, no marital-related policies & $19.5 \%$ & $10.1 \%$ & $15.4 \%$ \\
1955 cohort, no marital-related policies & $17.9 \%$ & $10.0 \%$ & $13.7 \%$ \\
\hline \hline
\end{tabular}

Table 6: Change in wealth at age 66, in percentages, as a result of each policy change when the income tax is reduced to balance the government budget.

\subsubsection{Eliminating joint income taxation, 1945 cohort}

The top right panel of Figure 9 displays the effects on participation of having everyone file as singles (the married men file as single men and the married women as single women) and reducing the proportional component of the income tax to balance the government budget (from $4.0 \%$ to $3.4 \%$ ). As a result of this policy, the participation of married women increases by more than 20 percentage points until age 
35 and by 10 percentage points between ages 45 and 60 . The participation of single women also increases slightly until age 60 . Figure 1 provides the key intuition for this result: the marginal tax rates for married women working are much lower when they do not file jointly with their husbands. Guner, Kaygusuz and Ventura (2012) study the switch from current U.S. taxation to single filer taxation in a calibrated model of a steady state and find that the labor supply of married women goes up by 10-20 percentage points. Our effects on the labor supply of married women are thus close to theirs.

\subsubsection{Eliminating spousal benefits and joint taxation, 1945 cohort}

This policy change implies a reduction in the proportional component of the income tax from $4.0 \%$ to $1.8 \%$. The bottom left panel of Figure 9 shows that, as a result of this reform, the participation of married women is 15-28 percentage points higher until age 62 and that of single women is about 5 percentage points higher until age 40. The participation of married men is higher in middle age, reaching a peak of 2 percentage points higher than in the benchmark, but is 7 percentage points lower than in the benchmark at age 65. Thus, the timing of their participation changes over their life cycle. The effects of increased participation and human capital accumulation imply that average yearly earnings at age 45 are $\$ 6,000$ and $\$ 3,000$ higher for married and single women, respectively. Average earnings of married men are similar until about age 55 and then drop sharply (see left panel of Figure 44 in Appendix J). Row 2 in Table 6 displays the effects on savings at retirement time: Couples now save $19.5 \%$ more for retirement, while single men and women save, $10.1 \%$ and $15.4 \%$ more.

\subsubsection{Eliminating spousal benefits and joint taxation, 1955 cohort}

For brevity, we only report results for the 1955 chort for the case in which we eliminate all three marriage-related provisions at the same time. The bottom right panel of Figure 9 shows that the effects of these policies on a relatively younger cohort with a much higher participation of married women continue to be very large. The effects of increased labor market experience and participation on income are a bit smaller but overall similar to those in the 1945 cohort (right panel of Figure 44 in Appendix J). Row 3 in Table 6 displays the effects on savings at retirement time. 
Couples now save $17.9 \%$ more for retirement, while single men and women save, respectively, $10.0 \%$ and $13.7 \%$ more. Comparing the top and bottom panel of Table 5 highlights that the fraction of women in the lowest wage quintile has decreased and the fraction of women in the highest wage quintile has increased from the 1945 to the 1955 cohort. However, it is still the case that in the 1955 cohort most women tend to have lower wages and to be secondary earners, and hence respond strongly to the elimination of marital provisions.

\subsection{Welfare}

To evaluate welfare changes, we calculate the one-time asset compensation required for each household at age 25 to stay in the benchmark economy and report it as a fraction of average income. Thus, negative asset compensations mean that households are better off in the benchmark economy. Table 7 reports the average welfare gains or losses conditional on one's marital status at age 25, the fraction of households gaining and losing, and average gains and losses in each of these groups.

The top panel refers to the 1945 cohort. The first set of results refers to the economy in which there are no marital Social Security benefits and taxes are unchanged. On average, couples need to be compensated by an asset transfer that is equivalent to 0.24 times average income in the economy, while single women require 0.25 times average income (they expect to marry and lose these benefits after marriage). These welfare costs are not very large because these reforms are anticipated as of age 25 and people have many years to work and save to make up for the loss in benefits. Single men benefit from this policy because their future wives work harder and earn more and they do not take into account their future wife's disutility of doing so. The remaining columns in the table distinguish the effects for winners and losers. The three "winners" columns show that all couples and single women lose from this policy while all single men gain from it.

The second set of results removes marital Social Security provisions and balances the government budget by reducing the proportional component of the income tax from $4.0 \%$ to $1.8 \%$. The first three columns display large welfare gains: couples are willing to pay, on average, an asset amount that corresponds to 0.66 times average income, single women 0.19 times, and single men 1.14 times. The second set of three columns shows that all couples, $92.5 \%$ of single women, and all single men benefit 


\begin{tabular}{lllllllll}
\hline \hline & \multicolumn{3}{c}{ All } & \multicolumn{3}{c}{ Winners } & \multicolumn{3}{c}{ Losers } \\
Couples & SW & SM & Couples & SW & SM & Couples & SW & SM \\
\hline \hline
\end{tabular}

\section{5 cohort}

(1). Remove Social Security spousal benefits, unbalanced budget

$\begin{array}{lccccccccc}\text { Average } & -0.24 & -0.20 & 0.25 & 0.00 & 0.00 & 0.25 & -0.24 & -0.20 & -0.02 \\ \text { Percentage } & & & & 0.0 & 0.0 & 100.0 & 100.0 & 100.0 & 0.0\end{array}$

(2). Remove Social Security spousal benefits, balanced budget

\begin{tabular}{lccccccccc} 
Average & 0.66 & 0.19 & 1.14 & 0.66 & 0.20 & 1.14 & 0.00 & -0.03 & 0.00 \\
Percentage & & & & 100.0 & 92.5 & 100.0 & 0.0 & 7.5 & 0.0 \\
\hline
\end{tabular}

(3). Remove joint income taxation, unbalanced budget

$\begin{array}{llllllllll}\text { Average } & 0.06 & -0.18 & 0.81 & 0.29 & 0.06 & 0.81 & -0.19 & -0.19 & 0.00\end{array}$

$\begin{array}{lllllll}\text { Percentage } & 52.8 & 4.9 & 100.0 & 47.2 & 95.1 & 0.0\end{array}$

(4). Remove joint income taxation, balanced budget

$\begin{array}{lccccccccc}\text { Average } & 0.31 & -0.08 & 1.06 & 0.42 & 0.12 & 1.06 & -0.09 & -0.13 & 0.00 \\ \text { Percentage } & & & & 78.8 & 20.6 & 100.0 & 21.2 & 79.4 & 0.0\end{array}$

(5). Remove all marital related policies, balanced budget

\begin{tabular}{lccccccccc} 
Average & 0.79 & 0.05 & 1.96 & 0.80 & 0.33 & 1.96 & -0.03 & -0.12 & 0.00 \\
Percentage & & & & 98.8 & 37.4 & 100.0 & 1.2 & 62.6 & 0.0 \\
\hline
\end{tabular}

1955 cohort

(6). Remove all marital related policies, balanced budget

$\begin{array}{llllllllll}\text { Average } & 0.70 & 0.20 & 1.10 & 0.72 & 0.29 & 1.10 & -0.04 & -0.04 & -0.03\end{array}$

Percentage

$\begin{array}{llllll}98.2 & 74.1 & 100.0 & 1.8 & 25.9 & 0.0\end{array}$

Table 7: Asset compensation required for staying in the benchmark economy, normalized as a fraction of average income. SM: single men, SW: single women. Top line for each experiment: average welfare gain or loss. Bottom line for each experiment: fraction in that group gaining or losing welfare.

from these changes. The last set of three columns shows that $7.5 \%$ of the single women who lose face very small losses. These are women whose initial human capital is very low and who rely on marital benefits. Thus, this counterfactual suggests that eliminating these benefits while reducing the income tax benefits the vast majority of the young population and has small welfare costs for a minority of single women.

The third set of results makes everyone file as single people without balancing the government budget constraint and shows that the willingness to pay for this policy equals 0.06 and 0.81 times average income for couples and single men, respectively. In contrast, single women require an asset compensation of 0.18 times average income. This happens because they will be working more in the future, especially after mar- 
riage. The winners and losers columns reveal that $52.8 \%$ of couples, $4.9 \%$ of single women, and $100 \%$ of single men favor this policy and that both gains for the winners and losses for the losers are sizable.

The fourth set of results balances the government budget constraint by reducing the income tax (from $4.0 \%$ to $3.4 \%$ ) and generates more winners with larger welfare gains and fewer losers, with smaller welfare losses than in the previous experiment. For instance, $78.8 \%$ of the couples are willing to give up an asset amount corresponding to 0.42 times average income to live under this policy, while the compensation for the remaining $21.2 \%$ amounts to 0.09 times average income.

The fifth set of results for the 1945 cohort eliminates all marriage-related policies and balances the government budget constraint by reducing the income tax from $4.0 \%$ to $1.8 \%$. This policy generates the largest aggregate welfare gains among the set that we consider for the 1945 cohort: $0.79,0.05$, and 1.96 times average income for couples, single women, and single men, respectively. Among couples, $98.8 \%$ gain, compared with $37.4 \%$ of single women and $100 \%$ of single men. The bigger losers coming out of this policy are $62.6 \%$ of single women, who lose, on average, 0.12 times average income.

The results in the bottom panel refer to the 1955 cohort and show that not only there are large aggregate gains from removing marriage-related provisions and reducing the income tax, but also that single women in this cohort are less hurt by this policy than single women in the 1945 cohort. In fact, only $25.9 \%$ of them lose, compared with $62.6 \%$ in the older cohort. In addition, their loss is much smaller (0.04 average income, compared with 0.12 in the 1945 cohort). In both cohorts, only a minority of couples lose and those who do experience a small welfare loss.

Overall, our policy experiments indicate that removing marriage-related taxes and Social Security benefits would increase female labor supply and the welfare of the majority of the populations, whereas the rest would only bear small welfare costs. On this point, it is important to take note that welfare calculations are usually sensitive to all aspects of the environment. In our specific case, they could be especially sensitive to modeling the couple as a collective, rather than unitary, decision making unit. We leave this very interesting extension for future work. 


\section{Limitations, robustness, and future research}

To keep our model tractable, we have made several important assumptions. Marriage, divorce, and home production patterns are estimated from the data and do not change with policy. Fertility is exogenous and we do not model children's human capital accumulation. Couples behave according to the unitary model.

Before we start discussing the robustness of our findings to changes in marriage and divorce, it is worth pointing out that the empirical literature for the United States shows that the effects of marital provisions on marriage and divorce behavior coming from Social Security (Dickert-Conlin and Meghea (2004), Goda, Shoven and Slavov (2007), and Dillender (2016)) and income taxes (Alm and Whittington (1995, 1997, 1999)) are tiny. Turning to welfare programs, Low, Meghir, Pistaferri and Voena (2018) document no effects on marriage and fertility and a decline in divorce rates, from $0.9 \%$ to $0.7 \%$, as a result of the 1996 reform. Persson (2020) finds that, in Sweden, divorce rate increased by $10 \%$ as a result of the elimination of marital survivorship benefits.

We now turn to showing that changes in marriage and divorce patterns of this magnitude have little effect on our results. To do so, we compare the effects of eliminating marital benefits for the 1945 cohort in our benchmark economy with two alternative scenarios. In the first one, the policy decreases marriage rates by $20 \%$ and increases divorce rates by $20 \%$. In the second one, the policy increases marriage rates by $20 \%$ and decreases divorce rates by $20 \%$ (in both, we also balance the government budget). These changes are large compared with those that have been documented in the empirical literature. Figure 10 shows that changes in participation are similar
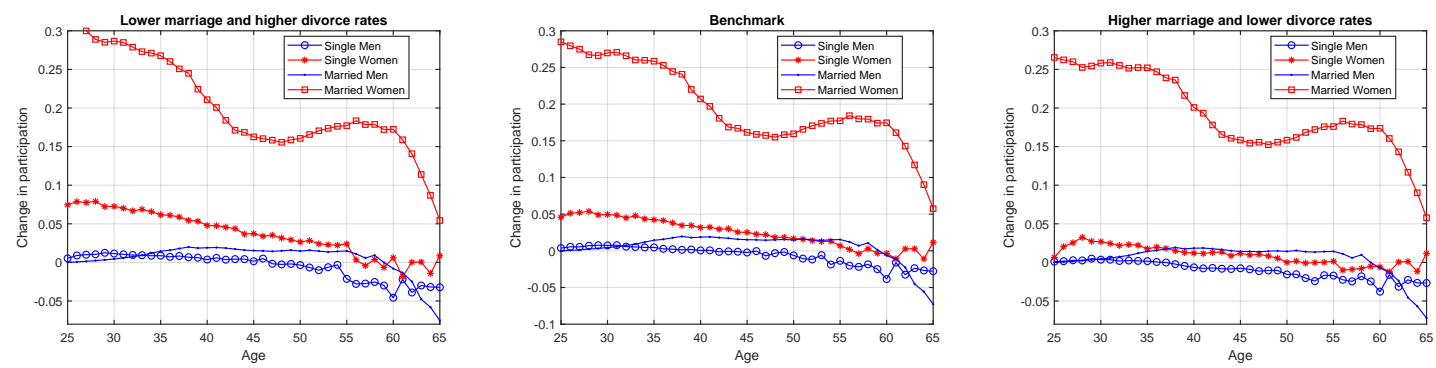

Figure 10: Changes in participation as a result of the elimination of all marriage-related policies when marriage and divorce patterns also change with policy. Government budget balance, 1945 cohort. 
whether marriage and divorce patterns change or not. Comparing the middle panel (no marriage and divorce changes) and the left panel highlights that a reform that lowers the probability of marriage and raises the probability of divorce makes women more self-reliant on their own labor supply. Married women work more to edge against divorce risk. Single women are less likely to marry and also work more. Both accumulate more human capital as a result. Comparing the middle and right panel, shows that the opposite changes (increasing the marriage rate and lowering the divorce rate) have the opposite effect on participation, but that this effect is small. The effects on savings at retirement time are also robust to changes in expected marital patterns.

Because we fix the amount of time that single and married men and women have to split between work and leisure, we also implicitly fix the amount of time that they spend in home production. To evaluate the effects of this assumption on our results, in addition to changing policy, we exogenously change available time. More specifically, we assume that as women's incentives to work more on the labor market increase, they make more time available for labor and leisure. In this robustness check, as all policies change, the available time of married women increases by three hours a week. Hence, if they decide to work longer hours, they also have to pay for more childcare. Figure 11 shows that the increase in female labor supply would be even larger in this case. Consistent with participation, Table 8 shows that savings by couples, who

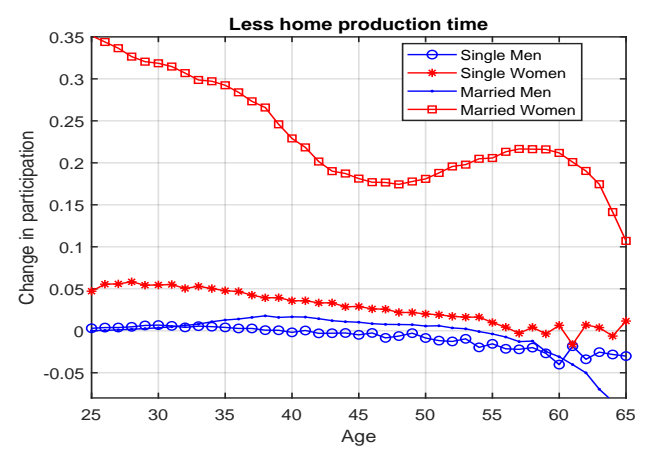

Figure 11: Changes in participation as a result of the elimination of all marriage-related policies when available time increases by 3 hours each week as policy changes. Government budget balance, 1945 cohort.

make up the vast majority of the population, also go up in this robustness check and that they do so by a little more than in our benchmark policy experiment. While this is a very stylized and suggestive experiment, if we were to add a cost for women to 


\begin{tabular}{l|ccc}
\hline \hline & Couples & Single men & Single women \\
\hline Benchmark & $19.5 \%$ & $10.1 \%$ & $15.4 \%$ \\
Reduce home production & $21.5 \%$ & $10.8 \%$ & $16.8 \%$ \\
\hline \hline
\end{tabular}

Table 8: Change in wealth at age 66 after removing all marriage-related policies when available time increases by 3 hours each week as policy changes. Government budget balance, 1945 cohort.

out-source some of their home production (for instance to pay a cleaning person, in addition to paying for additional child care), those who choose not to pay this cost would exhibit an increase in labor market participation very similar to that in our benchmark because their available time does not change. Those who choose to pay this cost, would have a negative wealth effect as a result, and would increase their labor at least as much as they do in our robustness exercise. Thus, the increase in female labor market participation would be at least as large as in our benchmark policy experiment.

Our behavioral responses to marital policy changes have proven to be robust to all of the checks that we have performed. Turning to their welfare implications, if we were to give households more choices, including for instance time spent in home production, we would provide more levers for households to optimize over. Hence, it should be the case that, in presence of home production, the welfare benefits from policy reforms should be no smaller (and possibly larger) in presence of more choices than in our benchmark economy.

While our results are robust to marriage and divorce patterns and changes in home production activities, exploring marriage and divorce decisions are very important avenues to understand the decisions of couples more generally. Furthermore, we do not model investment in children's human capital, marital happiness, and the collective model of the households, which are also very important and promising avenues that we leave for future research.

\section{Conclusions}

We estimate a model of labor supply and savings for single and married people that allows for a rich representation of the risks that people face over their entire 
life cycle and for the important provisions of taxes and Social Security benefits for couples and singles. We do so for both the 1945 and the 1955 birth cohorts, and we show that our model fits the data very well, including along important dimensions that we do not match by construction.

We use our model to evaluate the effects of marriage-based Social Security benefits and taxation. We find that these marriage-based provisions act as a strong disincentive on the labor supply of both married women and single women. This lower participation also reduces their labor market experience, which, in turn, reduces their wages over all of their life cycle. These provisions also induce married men to work longer and depress the savings of couples.

Our findings are very similar for the 1945 and 1955 birth cohorts, even though the labor market participation of young married women in the 1955 cohort is over 10 percentage points higher than that of the 1945 cohort. They thus suggest that these marital provisions have large negative effects on female labor supply, including in recent cohorts. If the government surplus resulting from the elimination of marriagerelated provisions were used to lower income taxation, there would be large welfare gains for the vast majority of the population and the few losing would experience small welfare losses.

Our paper provides several contributions. First, it is the first paper studying all marriage-related taxes and benefits in a unified framework. Second, it does so by allowing for the large observed changes in the labor supply of married women over time by studying two different cohorts. Third, it is the first estimated structural model of couples and singles that allows for participation and hours decisions of both men and women, including those in couples, in a dynamic framework with savings. Fourth, our framework is very rich along other dimensions that are important in the study of our problem, including labor market experience affecting wages and carefully modeling survival, health, and medical expenses in old age, and their heterogeneity by marital status and gender. 


\section{References}

Acemoglu, D. and Autor, D. (2011). Skills, tasks and technologies: Implications for employment and earnings, Vol. 4 of Handbook of Labor Economics, Elsevier, pp. $1043-1171$.

Aguiar, M. and Hurst, E. (2007). Measuring trends in leisure: The allocation of time over five decades, Quarterly Journal of Economics 122(3): 969-1006.

Alm, J. and Whittington, L. A. (1995). Income taxes and the marriage decision, Applied Economics 27(1): 25-31.

Alm, J. and Whittington, L. A. (1997). 'til death or taxes do us part: The effect of income taxation on divorce, The Journal of Human Resources 32(2): 388-412.

Alm, J. and Whittington, L. A. (1999). For love or money? the impact of income taxes on marriage, Economica 66: 297-316.

Altonji, J. G. and Segal, L. M. (1996). Small sample bias in gmm estimation of covariance structures, Journal of Business and Economic Statistics 14(3): 353-366.

Attanasio, O., Levell, P., Low, H. and Sánchez-Marcos, V. (2018). Aggregating elasticities: Intensive and extensive margins of women's labor supply, Econometrica 86(6): 2049-2082.

Attanasio, O., Low, H. and Sánchez-Marcos, V. (2008). Explaining changes in female labor supply in a life-cycle model, American Economic Review 98(4): 1517-1552.

Benabou, R. (2002). Tax and education policy in a heterogeneous-agent economy: What levels of redistribution maximize growth and efficiency?, Econometrica 70(2): 481-517.

Bick, A. and Fuchs-Schündeln, N. (2018). Taxation and labor supply of married couples across countries: A macroeconomic analysis, Review of Economic Studies 85(3): 1543-1576.

Blundell, R., Dias, M. C., Meghir, C. and Shaw, J. (2016). Female Labor Supply, Human Capital, and Welfare Reform, Econometrica 84: 1705-1753. 
Blundell, R., Jack Britton, M. C. D. and French, E. (2017). The impact of health on labour supply near retirement. working paper.

Blundell, R. and Macurdy, T. (1999). Labor supply: A review of alternative approaches, in O. Ashenfelter and D. Card (eds), Handbook of Labor Economics, 1 edn, Vol. 3, Part A, Elsevier, chapter 27, pp. 1559-1695.

Borella, M., Nardi, M. D. and French, E. (2018). Who Receives Medicaid in Old Age? Rules and Reality, Fiscal Studies 39(1): 65-93.

Butrica, B. and Burkhauser, R. (1997). Estimating federal income tax burdens for panel study of income dynamics (PSID) families using the national burea of economic research taxsim model. Maxwell Center for Demography and Economics of Aging.

Citro, C. and Michael, R. (1995). Adjusting poverty thresholds, Measuring Poverty and New Approach, National Academic Press, Washington .

Costa Dias, M., Joyce, R. and Parodi, F. (2018). The gender pay gap in the uk: Children and experience in work. IFS Working Paper W18/02.

David, M., Little, R. J. A., Samuhel, M. E. and Triest, R. K. (1986). Alternative methods for CPS income imputation, Journal of the American Statistical Association 81(393): 29-41.

De Nardi, M., French, E. and Jones, J. B. (2010). Why do the elderly save? the role of medical expenses, Journal of Political Economy 118(1): 39-75.

De Nardi, M., French, E. and Jones, J. B. (2016). Medicaid insurance in old age, American Economic Review 106(11): 3480-3520.

Dickert-Conlin, S. and Meghea, C. (2004). The effect of social security on divorce and remarriage behavior. Working paper no. 9, Center for Retirement Research.

Dillender, M. (2016). Social security and divorce, B. E. Journal of Economic Analysis and Policy 16(2): 931-971.

Dotsey, M., Li, W. and Yang, F. (2014). Consumption and time use over the life cycle, International Economic Review 55(3): 665-692. 
Duffie, D. and Singleton, K. J. (1993). Simulated moments estimation of markov models of asset prices, Econometrica 61(4): 929-952.

Eckstein, Z., Keane, M. and Lifshitz, O. (2019). Career and family decisions: Cohorts born 1935-1975, Econometrica 87(1): 217-253.

Eckstein, Z. and Lifshitz, O. (2011). Dynamic female labor supply, Econometrica 79(6): 1675-1726.

French, E. (2000). The effects of health, wealth and wages on labor supply and retirement behavior. Manuscript, Federal Reserve Bank of Chicago.

French, E. and Jones, J. B. (2011). The effects of health insurance and self-insurance on retirement behavior, Econometrica 79(3): 693-732.

Gayle, G.-L. and Shephard, A. (2019). Optimal taxation, marriage, home production, and family labor supply, Econometrica 87(1): 291-326.

Goda, G. S., Shoven, J. B. and Slavov, S. N. (2007). Social security and the timing of divorce. NBER Working Paper 13382.

Gourinchas, P.-O. and Parker, J. A. (2002). Consumption over the life cycle, Econometrica 70(1): 47-89.

Groneck, M. and Wallenius, J. (forthcoming). It sucks to be single! marital status and redistribution of social security, Economic Journal .

Guner, N., Kaygusuz, R. and Ventura, G. (2012). Taxation and household labour supply, Review of Economic Studies 79: 1113-1149.

Heckman, J. (1979). Sample selection bias as a specification error, Econometrica 47(1): 153-161.

Hubbard, R. G., Skinner, J. and Zeldes, S. P. (1995). Precautionary saving and social insurance, Journal of Political Economy 103(2): 360-399.

Hubener, A., Maurer, R. and Mitchell, O. S. (2016). How family status and social security claiming options shape optimal life cycle portfolios, Review of Financial Studies 29(4): 937-978. 
Judson, R. A. and Owen, A. L. (1999). Estimating dynamic panel data models: a guide for macroeconomists, Economics Letters 65(1): 9-15.

Kaygusuz, R. (2015). Social security and two-earner households, Journal of Economic Dynamics and Control 59: 163-178.

Kimberlin, S., Kim, J. and Shaefer, L. (2015). An updated method for calculating income and payroll taxes from PSID data using the NBER's TAXSIM, for PSID survey years 1999 through 2011. University of Michigan manuscript.

Kleven, H. J., Kreiner, C. T. and Saez, E. (2009). The optimal income taxation of couples, Econometrica 77(2): 537-560.

Liebman, J. B., Luttmer, E. F. and Seif, D. G. (2009). Labor supply responses to marginal social security benefits: Evidence from discontinuity, Journal of Public Economics 93(11-12): 1208-1223.

Low, H., Meghir, C., Pistaferri, L. and Voena, A. (2018). Marriage, labor supply and the social safety net. Working Paper.

Nickell, S. (1981). Biases in dynamic models with fixed effects, Econometrica 49(6): 1417-1426.

Nishiyama, S. (2017). The joint labor supply decision of married couples and the social security pension system, Review of Economic Dynamics 31: 277-304.

Pakes, A. and Pollard, D. (1989). Simulation and the asymptotics of optimization estimators, Econometrica 57(5): 1027-1057.

Persson, P. (2020). Social insurance and the marriage market, Journal of Political Economy 128(1): 252-300.

Roys, N. and Taber, C. (2017). Skills prices, occupations and changes in the wage structure for low skilled men. Working Paper.

Wooldridge, J. (1995). Selection corrections for panel data models under conditional mean independence assumptions, Journal of Econometrics 68(1): 115-132. 


\section{Appendix A. Data: The PSID and the HRS}

We use the Panel Study of Income Dynamics (PSID) to estimate the wage processes, the marriage and divorce probabilities, the initial distribution of couples and singles, taxes, and the sample moments that we match using our structural model. The PSID is a longitudinal study of a representative sample of the U.S. population starting in 1968. We select all individuals in the main sample who are interviewed at least twice during the years 1968-2013 (that is 30,586 individuals), only heads and their wives, if present (18,304), people born between 1931 and 1955 (5,153), and between age 20 to $70(5,129)$. The resulting sample includes 103,434 observations. The vast majority of people in it is already married at age 25 (86\% in the 1945 cohort and $83 \%$ in the 1955 one).

We use the Health and Retirement Study (HRS) for the retirement period because it is a longitudinal data set collecting information on people age 50 and older and includes high quality data on health, medical expenses, demographics, and economic characteristics. It started collecting information in 1992 on people born between 1931 and 1941, the so-called initial HRS cohort, which was then reinterviewed every two years. Other cohorts were introduced over the years. Our data set is based on the RAND HRS files for the period 1995-2012, to which we add the EXIT files to include information on the wave right after death. Our sample selection is as follows. Of the 37,317 people initially present, we drop people for whom marital status is not observed (1,548 people). This yields 35,769 people and 185,255 observations. We then select people in the age range 66-100 born in 1900 to 1945, obtaining a sample of 21,512 people and 99,077 observations. As we cannot observe people born after 1945 and older than age 66 in the HRS, for the 1955 cohort we use the same estimates obtained for the 1945 one.

\section{Appendix B. First step estimation}

\section{Wages}

Our initial conditions, assortative matching in marriage, and marriage and divorce probabilities depend on the realized values of wage shocks. Therefore, we need to estimate not only wages as a function of human capital, age, and gender, and the stochastic processes for wage shocks, but also the realized wage shocks for all men 
and women of working age in our sample. To do so, we proceed as follows. First, we impute potential wages for people who are not working by running fixed effect regressions (our results are robust to performing a Heckman selection correction as shown in Table 12 below). Second, we use wages for both participants and nonparticipants to estimate our wage function as a function of age, gender, and human capital. Third, we estimate the persistence and variance of the wage unobserved component. Finally, we obtain the realized wage shocks using Kalman smoothing.

Missing wages imputation. The observed wage rate is computed as annual earnings divided by annual hours worked. Gross annual earnings are defined as labor income during the previous year. Annual hours are given by annual hours spent working for pay during the previous year. We set to missing observations with an hourly wage rate below half the minimum wage and above $\$ 368$ (in 2016 values).

We impute missing wages by using the estimated parameters from fixed effects regressions that we run separately for men and women as follows: $\ln w a g e_{k t}=f_{k}+$ $Z_{k t}^{\prime} \beta_{z}+\varsigma_{k t}$. The dependent variable is the logarithm of the observed hourly wage rate, $f_{k}$ is an individual-specific fixed effect, and $\varsigma_{k t}$ is an error term. We include a rich set of explanatory variables in $Z_{k t}$ : a fifth-order polynomial in age, a third-order polynomial in experience (measured in years of labor market participation), marital status (a dummy for being single), family size (dummies for each value), number of children (dummies for each value), age of youngest child, and an indicator of partner working if married. As an indicator of health, we use a variable recording whether bad health limits the capacity of working (this is the only health indicator available in the PSID for all years and is not collected for wives. Thus, we do not include it in the regression for married women). Both regressions also include interaction terms between the explanatory variables. Variables that do not vary over time are captured by the individual effect $f_{k}$. To avoid endpoint problems with the polynomials in age, we include people ages 24 to 70 in the sample.

We define potential wage $\ln w \overline{a g} e_{k t}$ as actual wage whenever it is observed and imputed wage whenever it is not.

Wage function estimation. The wage function in our structural model depends on age, gender, and human capital (measured as average realized earnings accrued up to the beginning of age $t, \bar{y}_{t}$ ). To estimate it, we proceed in two stages. First, we 
run the following fixed-effect regression for the logarithm of potential wages

$$
\ln \overline{w a g} e_{k t}=d_{k}+f^{i}(t)+\sum_{g=1}^{G} \beta_{g} D_{g} \ln \left(\bar{y}_{k t}+\delta_{y}\right)+u_{k t},
$$

on a fixed effect $d_{k}$, a gender-specific fifth-order polynomial in age $f^{i}(t)$, and gendercohort dummies $D_{g}$, where $g$ refers to gender-cohort cells. Because we do not observe the complete age profile for the wages of the 1955 cohort, in this equation the 1940s cohort includes the generations born in 1931-1945, and the 1950s cohort those born in 1946-1955. The shifter $\delta_{y}$ is set to $\$ 5,000$ to avoid taking the logarithm of values that are too small. ${ }^{11}$ We also experimented by adding marital status dummies to capture the effect of changing marital status on wages, but they did not turn out to be statistically different from zero, conditional on average earnings. Second, to fix the constant of the wage profile for our cohorts of interest, we regress the sum of the residuals and fixed effects, that is,

$$
w_{k t+1}=d_{k}+u_{k t+1}
$$

on cohort dummies to compute the average effects for the cohorts born in 19411945 and in 1951-1955, respectively. Table 9 reports the coefficients of the estimated equation from the first stage, while Table 10 reports those from the second stage.

The shock in log wages is modeled, for each gender, as the sum of a persistent component plus white noise, which we assume captures measurement error

$$
\begin{gathered}
\tilde{w}_{k t+1}=\ln \epsilon_{k t+1}+\xi_{k t+1} \\
\ln \epsilon_{k t+1}=\rho_{\epsilon} \ln \epsilon_{k t}+v_{k t+1},
\end{gathered}
$$

where $\tilde{w}_{k t+1}$ are the residuals from the second stage regression in our wage equation, and $\xi_{k t+1}$ and $v_{k t+1}$ are independent white-noise processes with zero mean and variances $\sigma_{\xi}^{2}$ and $\sigma_{v}^{2}$. Using the system composed by equations (40) and (41), we estimate not only the persistence and variance of the shocks, but also the realized values of the wages shocks for each person. We need these wage shocks to compute the marriage and divorce probabilities, and the joint distribution of initial wealth, human capital,

\footnotetext{
${ }^{11}$ While we use earnings subject to the Social Security cap to compute average earnings, estimating this wage regression by using uncapped previous average earnings yields very similar estimates.
} 


\begin{tabular}{|c|c|c|}
\hline & Coefficient & Standard Error \\
\hline $\ln \left(\bar{y}_{t}+\delta_{y}\right)$ & $0.305^{* * *}$ & $(0.0172)$ \\
\hline $\ln \left(\bar{y}_{t}+\delta_{y}\right) *$ female & 0.0312 & $(0.0212)$ \\
\hline $\ln \left(\bar{y}_{t}+\delta_{y}\right) *$ born in $1950 \mathrm{~s}$ & $0.130^{* * *}$ & $(0.0202)$ \\
\hline $\ln \left(\bar{y}_{t}+\delta_{y}\right) *$ born in 1950 s*female & $-0.0850^{* * *}$ & $(0.0252)$ \\
\hline Age & $-0.724^{* * *}$ & $(0.108)$ \\
\hline $\mathrm{Age}^{2} /\left(10^{2}\right)$ & $3.469^{* * *}$ & $(0.508)$ \\
\hline $\mathrm{Age}^{3} /\left(10^{4}\right)$ & $-8.014 * * *$ & $(1.171)$ \\
\hline $\mathrm{Age}^{4} /\left(10^{6}\right)$ & $9.066^{* * *}$ & $(1.317)$ \\
\hline $\mathrm{Age}^{5} /\left(10^{8}\right)$ & $-4.058 * * *$ & $(0.580)$ \\
\hline Age*female & -0.0023 & $(0.0375)$ \\
\hline $\mathrm{Age}^{2} /\left(10^{2}\right) *$ female & -0.131 & $(0.199)$ \\
\hline $\mathrm{Age}^{3} /\left(10^{4}\right) *$ female & 0.541 & $(0.532)$ \\
\hline Age $^{4} /\left(10^{6}\right) *$ female & -0.830 & $(0.688)$ \\
\hline Age $^{5} /\left(10^{8}\right) *$ female & 0.468 & $(0.342)$ \\
\hline Constant & $4.820 * * *$ & $(0.867)$ \\
\hline $\mathrm{N}$ & 91208 & \\
\hline R-sq & 0.078 & \\
\hline
\end{tabular}

Table 9: Dependent variable: $\ln \overline{w a g} e_{k t}$. Coefficients from fixed effects regressions. PSID data. Robust standard errors in parentheses, clustered at the individual level. * $\mathrm{p}<0.10, * * \mathrm{p}<0.05, * * * \mathrm{p}<0.01$.

and wage shocks, as described later in this appendix. To do so, we first estimate persistence and variances by maximum likelihood (which can be constructed assuming that the initial state of the system and the shocks are Gaussian) and standard Kalman filter recursions. Given those estimates, we then obtain the smoothed estimate for the entire state, that is, $\ln \epsilon_{k t}$, for $t=1, \ldots T .^{12}$

Table 11 reports our estimates for the AR component of earnings.

Sample selection and control function estimation. We now turn to comparing the results from our approach with those resulting from two other approaches commonly used in the literature. The first approach differs from ours in that it runs fixed effects on wages for labor market participants rather than on all potential wages (imputed and not, like we do). The second approach runs fixed effects on wages for labor market participants and applies a control function approach to correct for sample selection. The control function approach corrects for sample selection by modeling labor market participation as a probit, computing the Mills ratio (which is the probability that a person is working given his or her characteristics), and then using the inverse Mills ratio as an additional regressor to the main fixed effect (or demeaned) regression for wages. This approach was pioneered by Heckman (1979) and extended

\footnotetext{
${ }^{12}$ We limit the age range between 25 and 65 and drop the largest $0.5 \%$ residuals for both men and women. While this trimming avoids the possibility that large outliers inflate the estimated variances, it has negligible effects on our estimates.
} 


\begin{tabular}{lcc}
\hline \hline & Men & Women \\
\hline Born in 1931-35 & $0.0199^{* *}$ & $-0.0561^{* * *}$ \\
& $(0.00966)$ & $(0.00817)$ \\
Born in 1936-40 & 0.000483 & $-0.0525^{* * *}$ \\
& $(0.00946)$ & $(0.00826)$ \\
Born in 1946-50 & $-1.353^{* * *}$ & $-0.419^{* * *}$ \\
& $(0.00775)$ & $(0.00691)$ \\
Born in 1951-55 & $-1.399^{* * *}$ & $-0.430^{* * *}$ \\
& $(0.00787)$ & $(0.00678)$ \\
Constant & $0.579 * * *$ & $0.431^{* * *}$ \\
& $(0.00603)$ & $(0.00534)$ \\
\hline $\mathrm{N}$ & 44575 & 46624 \\
$\mathrm{R}-\mathrm{sq}$ & 0.605 & 0.139 \\
\hline
\end{tabular}

Table 10: Dependent variable: $w_{k t+1}$. Coefficients from fixed effects regressions. PSID data. Robust standard errors in parentheses, clustered at the individual level. $* \mathrm{p}<0.10,{ }^{*} * \mathrm{p}<0.05, * * * \mathrm{p}<0.01$.

\begin{tabular}{l|cc}
\hline Parameter & Men & Women \\
\hline Persistence & 0.9491 & 0.9493 \\
Variance prod. shock & 0.0260 & 0.0159 \\
Initial variance & 0.1187 & 0.1042 \\
\hline
\end{tabular}

Table 11: Estimated parameters for the wage shock processes for men and women, PSID data.

by Wooldridge (1995) to panel data. To apply the control function approach, we include the following variables to explain the participation decision: home ownership (dummy), age of the youngest child, total number of children, number of children age 0-5, and completed grades of education, all interacted with gender, cohort, and marital status. In addition, we include an age polynomial interacted with gender and the time average of all the explanatory variables. As Table 12 shows, the inverse Mills ratio is not significantly different from zero, indicating no selection bias is present in the fixed effects estimates. The table also shows that our estimated coefficients are very similar when using these three approaches and thus are robust to the specific approach used. If anything, our approach is conservative because our estimated coefficient on human capital is slightly lower compared with alternative approaches.

Consistency of our estimator. The presence of average past earnings, which is a nonstrictly exogenous variable, in our wage regression (Equation (38)) may raise some econometrics concerns and deserves discussion. The first concern is that the inclusion of a nonstrictly exogenous variable in a demeaned regression might give rise to biased estimates in short panels (small $T$, Nickell (1981)). However, it has 


\begin{tabular}{lccc}
\hline \hline & $(1)$ & $(2)$ & $(3)$ \\
& BASELINE & $\mathrm{FE}$ & $\mathrm{W} 95$ \\
\hline$\hat{\lambda}$ & & & -0.0470 \\
& & & $(0.0301)$ \\
$\ln \left(\bar{y}_{t}+\delta_{y}\right)$ & $0.305^{* * *}$ & $0.345^{* * *}$ & $0.341^{* * *}$ \\
& $(0.0172)$ & $(0.0206)$ & $(0.0402)$ \\
$\ln \left(\bar{y}_{t}+\delta_{y}\right) *$ female & 0.0312 & $0.0541^{* *}$ & 0.0480 \\
& $(0.0212)$ & $(0.0273)$ & $(0.0476)$ \\
$\ln \left(\bar{y}_{t}+\delta_{y}\right) *$ born in 1950s & $0.130^{* * *}$ & $0.138^{* * *}$ & $0.139^{* *}$ \\
& $(0.0202)$ & $(0.0236)$ & $(0.0562)$ \\
$\ln \left(\bar{y}_{t}+\delta_{y}\right) *$ born in 1950s female & $-0.0850^{* * *}$ & $-0.0562^{*}$ & -0.0555 \\
& $(0.0252)$ & $(0.0312)$ & $(0.0688)$ \\
\hline $\mathrm{N}$ & 91208 & 73909 & 73909 \\
$\mathrm{R}-\mathrm{sq}$ & 0.078 & 0.073 & 0.073 \\
\hline
\end{tabular}

Table 12: Comparing our estimates (column 1) with two alternative procedures controlling for sample selection. Column 2: FE on actual wages for participants, column 3: FE plus inverse Mills ratio $\lambda$ on actual wages for participants. Robust standard errors in parentheses, clustered at the individual level. In (3), bootstrapped standard errors (500 replications). ${ }^{*} \mathrm{p}<0.10,{ }^{* *} \mathrm{p}<0.05,{ }^{* * *} \mathrm{p}<0.01$.

been shown that this bias is inversely proportional to the number of time periods. Indeed, Judson and Owen (1999) use Monte Carlo simulations to show that this bias is already very small when $T=30$. Because our panel has a very long time dimension (38 time periods, spanning 45 years from 1968 to 2013) and our dependent variable is potential wage (which is imputed when needed), the average number of observations per individual in our sample is not curtailed by missing values, and thus is long enough to generate little to no bias.

The second concern regards the consistency of our estimator, which requires that average past earnings (which we use as an explanatory variable) does not correlate with our error term. This correlation could arise if our error term is autoregressive and correlates with average past earnings, rather than just past earnings. To check for this possibility we first test whether our error is autoregressive. Given that we find that its correlation coefficient is 0.32 (with an estimated variance of the disturbance equal to 0.11), we further evaluate the effects of this correlation on our estimates by comparing them with those from an unbiased estimator which we can only run on part of our sample period. This is because, unlike our baseline estimator, it requires yearly data (and the PSID becomes biennial in 1997). Let us now introduce some notation to make this point. Assume that $u_{k t}$ follows an $\mathrm{AR}(1)$ process with parameter $\rho$

$$
u_{k t}=\rho u_{k t-1}+e_{k t}
$$


with $e_{k t}$ uncorrelated with all past $u_{k t-j}$ and $\left\{\ln \left(\bar{y}_{k t}+\delta_{y}\right)\right\}$. We then substitute our error term from the previous equation in our wage equation (Equation (38)) to obtain

$$
(1-\rho L) \ln w \overline{a g} e_{k t}=(1-\rho L) d_{k}+(1-\rho L) f^{i}(t)+\sum_{g=1}^{G}(1-\rho L) \beta_{g} D_{g} \ln \left(\bar{y}_{k t}+\delta_{y}\right)+e_{k t},
$$

and rewrite as

$\ln w \overline{a g} e_{k t}=\rho \ln \overline{w a g} e_{k t-1}+d_{k}^{\prime}+f^{i \prime}(t)+\sum_{g=1}^{G} \beta_{g} D_{g} \ln \left(\bar{y}_{k t}+\delta_{y}\right)-\sum_{g=1}^{G} \rho \beta_{g} D_{g} \ln \left(\bar{y}_{k t-1}+\delta_{y}\right)+e_{k t}$,

Thus, in Equation (44), if $u_{k t}$ is an $\mathrm{AR}(1)$ process the residuals are i.i.d. and the coefficient on $\ln \left(\bar{y}_{t}+\delta_{y}\right)$ is unbiased and consistent. ${ }^{13}$ Table 13 compares the main results from this version of our estimator and the robust one on the shorter subsample until 1997 (on which we can use both methods). The estimated coefficient on $\ln \left(\bar{y}_{t}+\delta_{y}\right)$ are very similar under the two estimators. Thus, this check supports our methodology and shows that the correlation between $\ln \left(\bar{y}_{k t}+\delta_{y}\right)$ and $u_{k t}$ is negligible and does not bias our estimates. The intuition is that, while past earnings and past shocks are correlated, average past earnings and past shocks are not very correlated.

\begin{tabular}{lcc}
\hline \hline $\ln \overline{w a g}_{k t-1}$ & $(1)$ & $(2)$ \\
$\ln \left(\bar{y}_{t}+\delta_{y}\right)$ & & $0.272^{* * *}$ \\
& $0.514^{* * *}$ & $(0.00385)$ \\
$\ln \left(\bar{y}_{t-1}+\delta_{y}\right)$ & $(0.0152)$ & $(0.0299)$ \\
& & $-0.210^{* * *}$ \\
$\ln \left(\bar{y}_{t}+\delta_{y}\right)^{*}$ female & $-0.144^{* * *}$ & $(0.0199)$ \\
& $(0.0179)$ & $\left(0.0371^{* * *}\right.$ \\
$\ln \left(\bar{y}_{t-1}+\delta_{y}\right) *$ female & & 0.0119 \\
& & $(0.0287)$ \\
\hline $\mathrm{N}$ & 71744 & 71744 \\
$\mathrm{R}-$ sq & 0.065 & 0.138 \\
\hline \hline
\end{tabular}

Table 13: Checking our estimator's consistency by comparing its results with those obtained allowing for AR(1) residuals. Both run on yearly data (until 1997).

The effect of education. While one might worry that we miss out on the role of education in our wage function, this is not the case because human capital, measured as average past earnings, soaks up more heterogeneity in wages than education. In

\footnotetext{
${ }^{13}$ Given the much shorter time period, we do not try to estimate the wage equation by cohort and thus do not interact the coefficient of $\bar{y}$ with cohorts.
} 
fact, our baseline specification yields an R-square of 0.078. In contrast, a fixed effects regression of potential wage on a polynomial in age, interacted with gender and education, yields an R-square of 0.052 only. Also, running a fixed effect regression which adds interactions with education for all of the variables already included in our baseline specification (human capital, age, cohort, and gender) delivers an R-square of 0.085 , which is only slightly higher than the one for our base case. The economic intuition is that education is a rough indicator of earnings capacity that does not take into account, for instance, types of major and college quality. They are, instead, reflected in average past earnings.

\section{Average realized earnings}

In the model we keep track of average past accumulated earnings for each individual at each point in time $\left(\bar{y}_{k t}\right)$ subject to Social Security cap that is applied to yearly earnings and is time varying. To do so, we assume that people start working at age 22 , and we compute individual-level capped average earnings. This computation requires taking a stand on people who appear in our sample of heads and wives after age 22. Among those, we assume that those entering before age 25, have zero average accumulated earnings. For those entering after age 25, we use an imputation procedure to recover average realized earnings at entry. This imputation is performed by running a regression of capped earnings on a fourth-order polynomial in age fully interacted with gender, education dummies, interactions of education and gender, marital status, and race dummies also interacted with gender. Cohort dummies are also included. We use the predicted values of this regression as the entry value for people entering the sample after turning 25. Average earnings are then updated for each individual following his/her observed earnings history (as done in the model).

\section{Wealth}

We define wealth, or net worth, as all assets less all liabilities. Wealth in the PSID is only recorded in 1984, 1989, 1994, and then in each (biennial) wave from 1999 onward. We rely on an imputation procedure to compute wealth in the missing years, starting in 1968. This imputation is based on the following fixed effect regression:

$$
\ln \left(a_{k t}+\delta_{a}\right)=Z_{k t}^{\prime} \beta_{z}+d a_{k}+w a_{k t}
$$


where $k$ denotes the individual and $t$ is age. The parameter $\delta_{a}$ is a shifter for wealth to have only positive values and to be able to take logs, and the variables $\mathrm{Z}$ includes polynomials in age, also interacted with health status, and with average earnings (uncapped), family size, and a dummy for health status. The term $d a_{k}$ is the individual fixed effect and $w a_{k t}$ is a white-noise error term. Equation (45) is estimated separately for single men, single women, and couples, as wealth is measured at the household level, on an enlarged sample of people born between 1931 and 1965. We then use the imputed and the actual observations to estimate the wealth profiles used as target moments and to parameterize the joint distribution of initial wealth, average realized earnings, and wage shocks for single men, single women, and couples.

\section{Initial distributions}

For single men and women, separately, we parameterize the joint distribution of initial wealth, average realized earnings, and wage shocks at each age as a joint lognormal distribution:

$$
\left(\begin{array}{c}
\ln \left(a_{t}^{i}+\delta_{a}^{i}\right) \\
\ln \left(\bar{y}_{t}^{i}\right) \\
\ln \epsilon_{t}^{i}
\end{array}\right) \sim N\left(\begin{array}{c}
\mu_{a t}^{i}+\delta_{a}^{i} \\
\mu_{\bar{y} t}^{i}, \quad, \Sigma_{s t}^{i} \\
\mu_{\epsilon t}^{i}
\end{array}\right)
$$

where $\Sigma_{s}$ is a $3 \times 3$ covariance matrix. We estimate its mean and variance as a function of age $t$. For the mean, we regress the logarithm of wealth plus shift parameter, average earnings, and wage shock $\ln \hat{\epsilon}_{t}^{i}$ on a third-order polynomial in age and cohort dummies. The predicted age profile, relative to cohorts born in 1945 and 1955, is the age-specific estimate of the mean of the lognormal distribution. Taking residuals from the above estimates, we can estimate the elements of the variance-covariance matrix by computing the relevant squares or cross-products. We regress the squares or the cross-products of the residuals on a third-order polynomial in age to obtain, element by element, a smooth estimate of the variance-covariance matrix at each age.

For couples, we compute the initial joint distribution at age 25 of the following variables: 


$$
\left(\begin{array}{c}
\ln \left(a+\delta_{a}\right) \\
\ln \left(\bar{y}^{1}\right) \\
\ln \left(\bar{y}^{2}\right) \\
\ln \left(\epsilon^{1}\right) \\
\ln \left(\epsilon^{2}\right)
\end{array}\right) \sim N\left(\begin{array}{cc}
\mu_{a}+\delta_{a} \\
\mu_{\bar{y} 1} & \\
\mu_{\bar{y} 2} & , \Sigma_{c} \\
\mu_{\epsilon 1} & \\
\mu_{\epsilon 2}
\end{array}\right)
$$

where $\Sigma_{c}$ is a $5 \times 5$ covariance matrix computed on the data for married or cohabiting couples.

\section{Marriage and divorce probabilities}

We model the probability of getting married, $\nu_{t+1}$, as a function of gender, age and the wage shock and perform the estimation separately for men and women using PSID data. Our estimated equation is

$$
\nu_{t+1}^{i}=\operatorname{Prob}\left(\text { Married }_{t+1}=1 \mid \text { Married }_{t}=0, Z_{t}\right)=F\left(Z_{t}^{\prime} \beta_{m}\right)
$$

where $F$ denotes the standard logistic function and $Z_{t}$ includes a polynomial in age, cohort dummies, the logarithm of the wage shock, and the after-1997 dummy ${ }^{14}$. Using the estimated coefficients on the cohort dummies, we then adjust the probability for the 1945 and 1955 cohorts, respectively.

We estimate the probability of divorce as

$$
\zeta_{t}=\operatorname{Prob}\left(\text { Divorced }_{t+1}=1 \mid \text { Married }_{t}=1, Z_{t}\right)=F\left(Z_{t}^{\prime} \beta_{d}\right)
$$

where $Z_{t}$ includes a polynomial in age, husband's wage shock, wife's wage shock, cohort dummies, and an indicator for biennial waves.

Figures 12 and 13 report the resulting marriage and divorce probabilities for both cohorts, while Table 14 reports our estimated coefficients from the marriage and divorce regressions.

Conditional on meeting a partner, the probability of meeting a partner $p$ with wage shock $\epsilon_{t+1}^{p}$ is $\xi_{t+1}(\cdot)=\xi_{t+1}\left(\epsilon_{t+1}^{p} \mid \epsilon_{t+1}^{i}, i\right)$. Using our estimated wage shocks and partitioning households in age groups (25-35, 35-45, 45-65), we compute the variance-

\footnotetext{
${ }^{14}$ The PSID goes from a yearly to a biennial frequency in 1997 . To take this into account, we include an indicator variable taking a value of one from 1997 on in the regression, which we then abstract from when constructing the yearly probabilities.
} 


\begin{tabular}{lccc}
\hline \hline & $\begin{array}{c}\text { Single Men } \\
\text { Marriage }\end{array}$ & $\begin{array}{c}\text { Single Women } \\
\text { Marriage }\end{array}$ & $\begin{array}{c}\text { Couples } \\
\text { Divorce }\end{array}$ \\
\hline Age & $0.0755^{* *}$ & -0.0474 & 0.0512 \\
& $(0.0353)$ & $(0.0366)$ & $(0.0334)$ \\
Age $^{2} / 10^{2}$ & $-0.151^{* * *}$ & -0.0265 & $-0.121^{* * *}$ \\
& $(0.0450)$ & $(0.0456)$ & $(0.0407)$ \\
$\ln \epsilon_{k t}$ & $0.357^{* * *}$ & 0.0466 & $-0.430^{* * *}$ \\
& $(0.132)$ & $(0.149)$ & $(0.100)$ \\
Spouse's ln $\epsilon_{k t}$ & & & -0.0616 \\
& & & $(0.122)$ \\
I year $>1997)$ & $0.590^{* * *}$ & $0.373^{*}$ & $0.542^{* * *}$ \\
& $(0.204)$ & $(0.207)$ & $(0.166)$ \\
Born in 1931-35 & 0.135 & -0.310 & -0.268 \\
& $(0.270)$ & $(0.230)$ & $(0.174)$ \\
Born in 1936-40 & -0.0435 & $-0.566^{* *}$ & -0.131 \\
& $(0.239)$ & $(0.238)$ & $(0.144)$ \\
Born in 1946-50 & -0.228 & -0.268 & -0.146 \\
& $(0.182)$ & $(0.164)$ & $(0.116)$ \\
Born in 1951-55 & $-0.388^{* *}$ & $-0.295^{*}$ & -0.0994 \\
& $(0.177)$ & $(0.158)$ & $(0.124)$ \\
Constant & $-2.319^{* * *}$ & -0.0561 & $-3.589^{* * *}$ \\
& $(0.701)$ & $(0.732)$ & $(0.670)$ \\
\hline N & 4833 & 8507 & 30451 \\
pseudo- $R^{2}$ & 0.026 & 0.057 & 0.023 \\
\hline
\end{tabular}

Table 14: Column 1: Marriage of single men; column 2: marriage of single women; column 3: divorce of couples. Estimated coefficients from logistic regressions. PSID data. Robust standard errors in parentheses, clustered at the individual level. $* \mathrm{p}<0.10,{ }^{* *} \mathrm{p}<0.05,{ }^{* * *} \mathrm{p}<0.01$.
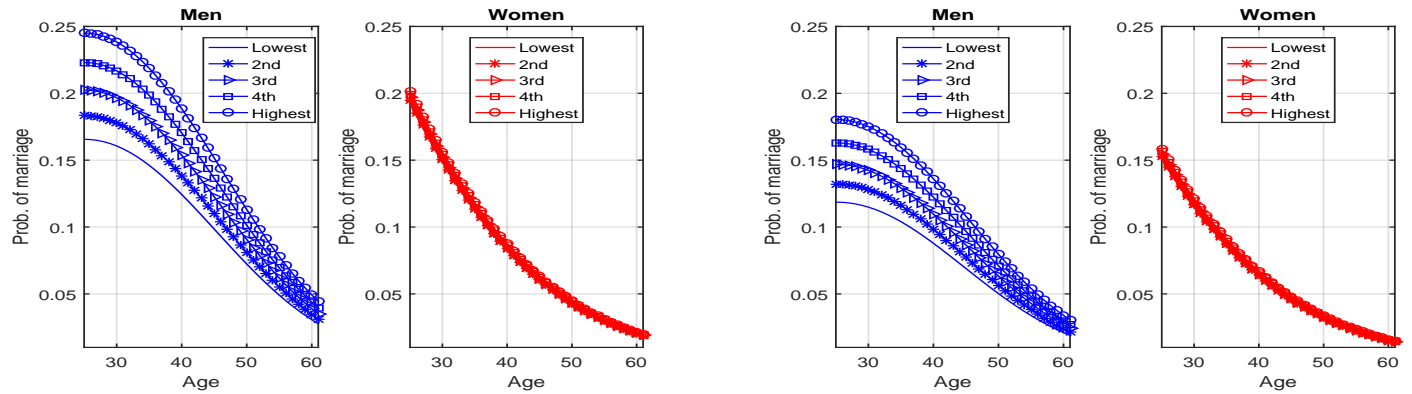

Figure 12: Marriage probabilities by gender, age, and one's wage shock for the 1945 cohort (left panel) and 1955 cohort (right panel), PSID data.

covariance matrix of newly matched partners' wage shocks by age groups. We then derive the conditional distribution of meeting a partner assuming lognormality. In the whole sample we observe only 750 new marriages in the age range $25-65$, thus we do not allow this probability to depend on cohort. 

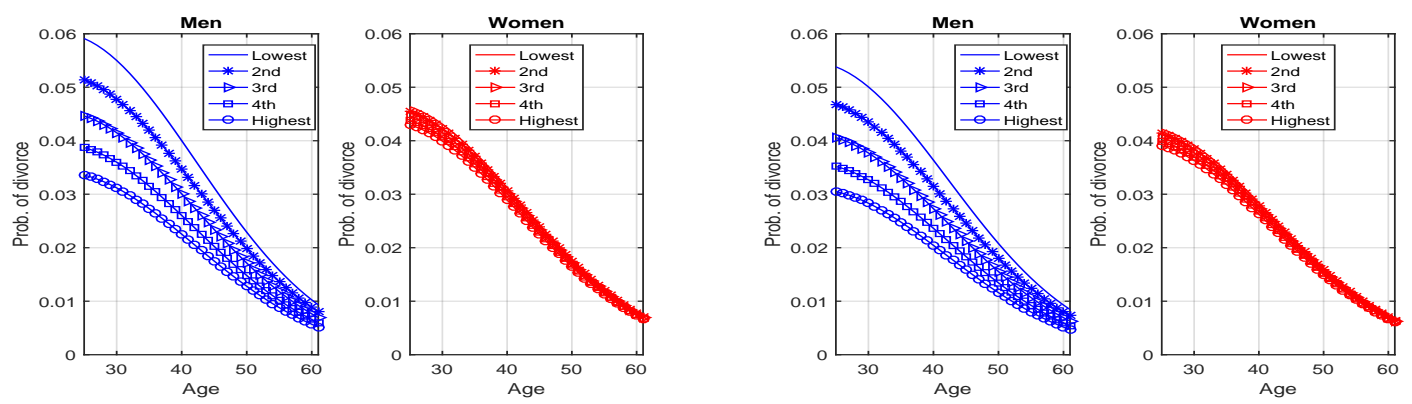

Figure 13: Divorce probabilities by gender, age, and one's wage shock for the 1945 cohort (left panel) and 1955 cohort (right panel), PSID data.

\section{Spousal wealth and Social Security benefits}

We assume random matching over asset and lifetime income of the partner conditional on partner's wage shock. Thus, we compute $\theta_{t+1}(\cdot)=\theta_{t+1}\left(a_{t+1}^{p}, \bar{y}_{t+1}^{p} \mid \epsilon_{t+1}^{p}\right)$ using sample values of wealth, average capped earnings, and wage shocks. More specifically, we assume $\theta_{t+1}$ is lognormally distributed at each age with mean and variance computed from sample values. Wealth include a shifter as described for the computation of the joint distribution at age 25 (see Initial distributions subsection in this Appendix).
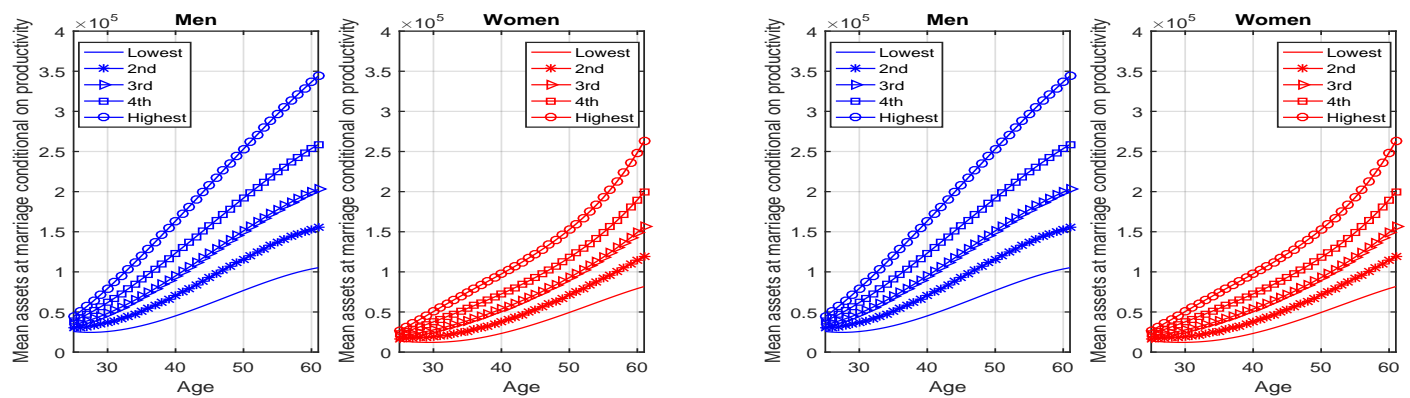

Figure 14: Average spousal wealth by spousal wage shocks in case of marriage for the 1945 cohort (left panel) and 1955 cohort (right panel), PSID data.

Figure 14 reports average spousal wealth by spousal wage shocks in case of marriage next period. Both panels show that both women and men marrying early on in life expect their partner to have relatively low wealth on average, even conditional on the various wage shocks. In contrast, those who marry later experience a much larger variation in their partner's wealth, depending on the wage shock of the partner 
they meet. The gradient in average wealth by wage shocks increases especially fast for male partners and thus exposes women to much more variability in their partner's resources as they marry later and later. The patterns are similar for the two cohorts.
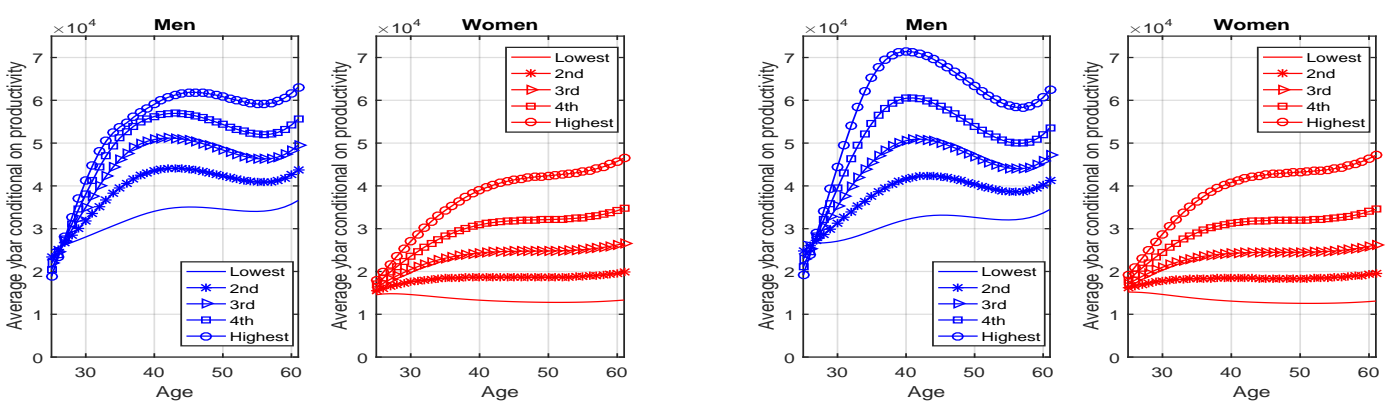

Figure 15: Spousal Social Security earnings by spousal wage shocks in case of marriage for the 1945 cohort (left panel) and 1955 cohort (right panel), PSID data.

Figure 15 reports spousal Social Security earnings by spousal wage shocks in case of marriage next period. Given that male wage shocks are higher on average, Social Security earnings for men are higher than those for women at all levels of wage shocks.

\section{Number of children}

To compute the average number of children by age group, we use the individual information in the PSID and classify as children of the family those in the following categories: sons or daughters of the head, stepsons or stepdaughters of the head, sons or daughters of the cohabiting partner but not of the head, foster sons or foster daughters (not legally adopted), and children of the cohabitor but not of the head. Having done that, we add up the number of children in each age category ( 0 to 5 , 6 to 11 , or 0 to 17 for the total number of children) and run a regression on a fifthorder polynomial in age of the mother, interacted with marital status, and cohort dummies to construct the average age profile of children in each age group for single and married women. We use the profiles for the cohorts of mothers born in 1941-1945 and in 1951-1955 (see Figure 16).

\section{Health status at retirement}

We define health status on the basis of self-reported health. In the HRS, this variable can take five possible values (excellent, very good, good, fair, poor). As 

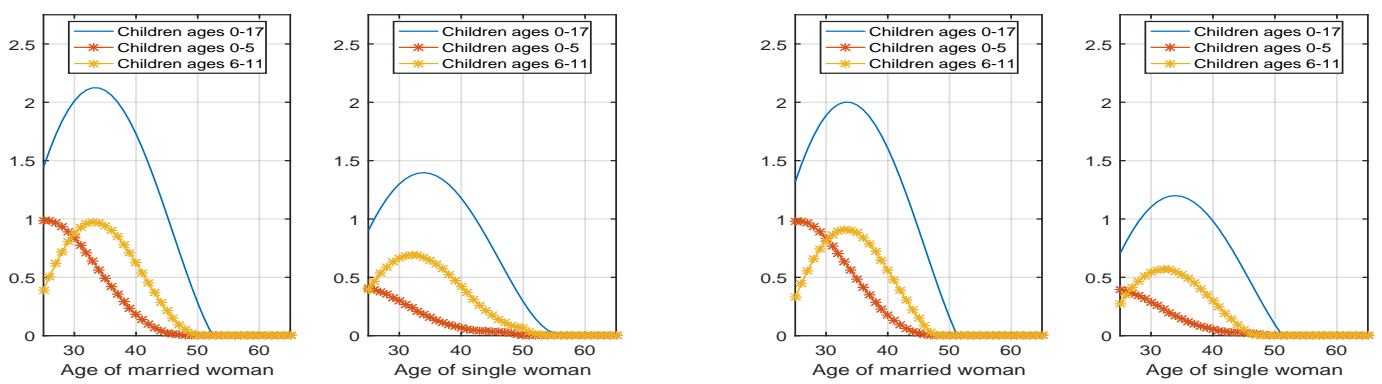

Figure 16: Number of children for married and single women for the 1945 cohort (left panel) and 1955 cohort (right panel), PSID data.

standard, we take health to be a dichotomous variable equal to 1 if self-reported health is fair or poor and 0 otherwise. ${ }^{15}$ We estimate the probability of being in bad health at age 66, using the observed frequencies for the 1941-1945 cohort, which is the youngest cohort that we can observe at age $66+$ in the HRS data. All the inputs estimated from the HRS correspond to the 1941-1945 cohort. For lack of better data, we also use them for our 1951-1955 cohort. For singles, we compute the sample fraction of single men and single women in bad health in the age range 65-67, which ensures that the sample size is big enough. For couples, we compute the sample frequencies for the four possible health states.

\section{Health dynamics after retirement}

We model the probability of being in bad health during retirement as a logistic function, which we estimate on HRS data

$$
\pi_{\psi t}=\operatorname{Prob}\left(\psi_{t}=1 \mid X_{t}^{\psi}\right)=F\left(X_{t}^{\psi \prime} \beta^{\psi}\right)
$$

which we then use to construct the transition matrix at each age, gender, and marital status. The set of explanatory variables $X_{t}^{\psi}$ includes cohort dummies, a second-order polynomial in age, previous health status, gender, marital status, and interactions between these variables when they are statistically different from zero. As the HRS data are collected every two years, we obtain two-year probabilities and convert them into

\footnotetext{
${ }^{15}$ Looking at labor supply behavior around retirement time, Blundell, Jack Britton and French (2017) show that this measure of self-reported health captures health well and about and more involved measures such as using large numbers of objective measures to predict health.
} 
one-year probabilities. Table 15 reports our estimated coefficients, while Figure 17 displays the health transition matrix by gender, age, marital status, and health status that we estimated.

\begin{tabular}{|c|c|c|}
\hline & Coefficient & SE \\
\hline Age & $0.0984^{* * *}$ & $(0.0289)$ \\
\hline$A g e^{2} / 10^{2}$ & $-0.0477 * * *$ & $(0.0181)$ \\
\hline Health $_{t-1}$ & $6.540^{* * *}$ & $(0.244)$ \\
\hline Health $_{t-1} *$ Age & $-0.0521^{* * *}$ & $(0.00310)$ \\
\hline Male & $0.514^{* *}$ & $(0.222)$ \\
\hline Male*Age & $-0.00580 * *$ & $(0.00288)$ \\
\hline Age*Married & $-0.0244^{* * *}$ & $(0.00302)$ \\
\hline $\mathrm{Age}^{2} / 10^{2 *}$ Married & $0.0283^{* * *}$ & $(0.00385)$ \\
\hline Born in $1936-40$ & $0.132^{* * *}$ & $(0.0501)$ \\
\hline Born in 1931-35 & $0.176^{* * *}$ & $(0.0502)$ \\
\hline Born in $1926-30$ & $0.162^{* * *}$ & $(0.0539)$ \\
\hline Born in $1921-25$ & $0.307 * * *$ & $(0.0571)$ \\
\hline Born in $1916-20$ & $0.430 * * *$ & $(0.0612)$ \\
\hline Born in $1900-15$ & $0.567^{* * *}$ & $(0.0678)$ \\
\hline Constant & $-6.432^{* * *}$ & $(1.146)$ \\
\hline $\mathrm{N}$ & 74589 & \\
\hline Pseudo- $R^{2}$ & 0.233 & \\
\hline
\end{tabular}

Table 15: Health dynamics over two-year periods, dependent variable: health status. Logistic regression coefficients. HRS data. Robust standard errors in parentheses, clustered at the individual level. ${ }^{*} \mathrm{p}<0.1,{ }^{* *} \mathrm{p}<0.05,{ }^{* * *} \mathrm{p}<0.01$.
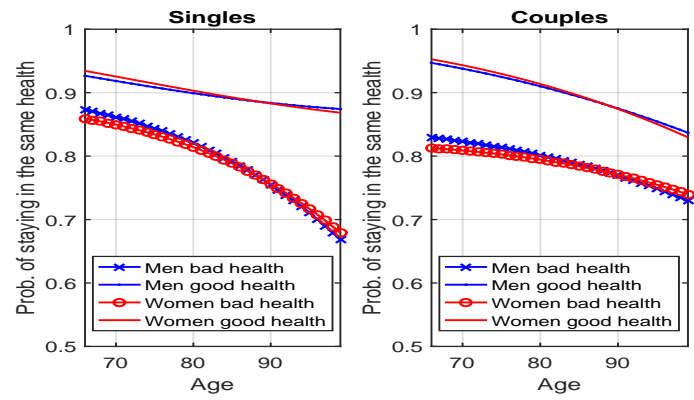

Figure 17: Health transition probabilities for singles and couples by age. HRS data.

\section{Survival probabilities}

We model the probability of being alive at time $t$ as a logistic function

$$
s_{t}=\operatorname{Prob}\left(\text { Alive }_{t}=1 \mid X_{t}^{s}\right)=F\left(X_{t}^{s \prime} \beta^{s}\right) .
$$


which we estimate using the HRS data. Among the explanatory variables, we include a fourth-order polynomial in age, gender, marital status, and health status in the previous wave, and interactions between these variables and age, whenever they are statistically different from zero. As the HRS is collected every two years, we transform the biennial probability of surviving into an annual probability by taking the square root of the biennial probability. Table 16 reports estimated coefficients, and Figure 18 displays the implied survival probability by age, gender, and marital and health status.

\begin{tabular}{|c|c|c|}
\hline & Coefficient & SE \\
\hline Age & $-18.90^{* * *}$ & (6.198) \\
\hline$A g e^{2} / 10^{2}$ & $34.40^{* * *}$ & (11.39) \\
\hline$A g e^{3} / 10^{4}$ & $-27.76^{* * *}$ & (9.263) \\
\hline Age $^{4} / 10^{6}$ & $8.325^{* * *}$ & $(2.812)$ \\
\hline Health $_{t-1}$ & $-3.824^{* * *}$ & $(0.284)$ \\
\hline Health $_{t-1} *$ age & $0.0311^{* * *}$ & $(0.00346)$ \\
\hline Male & $-0.459 * * *$ & $(0.0291)$ \\
\hline Married & $0.103^{* * *}$ & $(0.0307)$ \\
\hline Born in $1936-40$ & -0.0173 & $(0.110)$ \\
\hline Born in $1931-35$ & -0.0597 & $(0.110)$ \\
\hline Born in $1926-30$ & -0.0850 & $(0.113)$ \\
\hline Born in $1921-25$ & -0.0707 & $(0.117)$ \\
\hline Born in $1916-20$ & -0.0989 & $(0.120)$ \\
\hline Born in $1900-15$ & -0.101 & $(0.124)$ \\
\hline Constant & $393.5^{* * *}$ & $(125.9)$ \\
\hline $\mathrm{N}$ & 80807 & \\
\hline Pseudo- $R^{2}$ & 0.162 & \\
\hline
\end{tabular}

Table 16: Dependent variable: survival over a two-year period. Logistic regression coefficients. HRS data. Robust standard errors in parentheses, clustered at the individual level. ${ }^{*} \mathrm{p}<0.1,{ }^{* *} \mathrm{p}<0.05,{ }^{* * *} \mathrm{p}<0.01$.
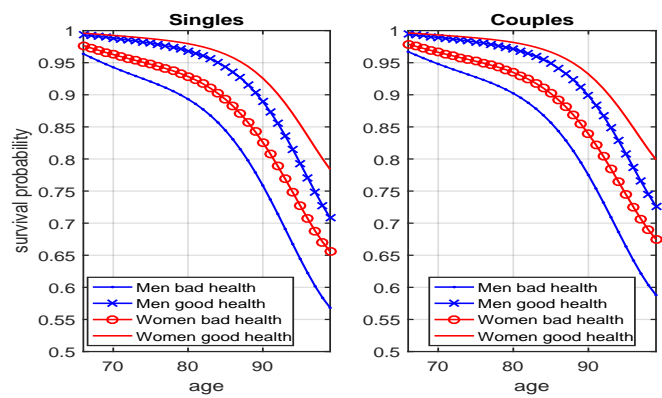

Figure 18: Survival probability by age, gender, and marital and health status, both cohorts. HRS data. 


\section{Out-of-pocket medical expenditures}

Out-of-pocket medical expenses are defined as the total amount that the individual spends out of pocket in hospital and nursing home stays, doctor visits, dental costs, outpatient surgery, average monthly prescription drug costs, home health care, and special facilities charges. They also include medical expenses in the last year of life, as recorded in the exit interviews. In contrast, expenses covered by public or private insurance are not included in our measure, because they are not directly incurred by the individual. The estimated equation is

$$
\ln \left(m_{k t}\right)=\alpha_{k}^{m}+X_{k t}^{m \prime} \beta^{m}+u_{k t}^{m},
$$

where explanatory variables include a fourth-order polynomial in age fully interacted with gender and current health status. We only include these interactions whenever they are statistically different from zero. We estimate the equation on the HRS data using a fixed effects estimator, which takes into account all unmeasured fixed-overtime characteristics that may bias the age profile, such as differential mortality (as discussed in De Nardi, French and Jones (2010)). Marital status (also interacted with other variables) does not turn out to be significantly different from zero in the first step. We then regress the residuals and fixed effects from this equation on cohort, gender, and marital status dummies to compute the average effect for each group of interest. Table 17 reports estimated coefficients, while Figure 19 displays medical expenditure by age, gender, and marital and health status.

Finally, we model the variance of the shocks by regressing the squared residuals from the regression in logs on a third-order polynomial in age fully interacted with gender and current health status, and on cohort, gender, and marital status dummies

and use it to construct average medical expenses as a function of age by adding half of the variance to the average in logs before exponentiating.

\section{Taxes}

We model taxes $T$ on total income $\mathrm{Y}$ as $T(Y)=Y-\lambda Y^{1-\tau}$, where $\tau$ captures the degree of progressivity and $\lambda$ captures the average level of taxation. Since this specification implies $(Y-T(Y))=\lambda Y^{1-\tau}$ and $\ln (Y-T(Y))=\ln (\lambda)+(1-\tau) \ln (Y)$, we estimate $\tau$ and $\lambda$ by regressing the logarithm of after-tax household income on 


\begin{tabular}{lcc}
\hline & Coefficient & SE \\
\hline Age & 2.187 & $(2.217)$ \\
Age $^{2} / 10^{2}$ & -4.255 & $(4.241)$ \\
Age $^{3} / 10^{4}$ & 3.649 & $(3.587)$ \\
Age $^{4} / 10^{6}$ & -1.153 & $(1.132)$ \\
Bad health $_{\text {Bad health* Age }}$ & $3.756^{* * *}$ & $(0.932)$ \\
Bad health*Age $/ 10^{2}$ & $-0.0942^{* * *}$ & $(0.0242)$ \\
Male*Age $^{*}$ & $0.0610^{* * *}$ & $(0.0157)$ \\
Male*Age $/ 10^{2}$ & $-7.053^{* *}$ & $(3.456)$ \\
Male*Age $/ 10^{4}$ & $13.74^{* *}$ & $(6.627)$ \\
Male*Age $/ 10^{6}$ & $-11.76^{* *}$ & $(5.621)$ \\
Constant & $3.734^{* *}$ & $(1.779)$ \\
\hline Second stage & 22.18 & $(33.12)$ \\
\hline Male & & \\
Married & $134.3^{* * *}$ & $(0.0237)$ \\
Male*Married & $0.328^{* * *}$ & $(0.0170)$ \\
Born in 1936-40 & -0.0303 & $(0.0279)$ \\
Born in 1931-35 & -0.00647 & $(0.0244)$ \\
Born in 1926-30 & $-0.0580^{* *}$ & $(0.0238)$ \\
Born in 1921-25 & $-0.0803^{* * *}$ & $(0.0250)$ \\
Born in 1916-20 & $-0.114^{* * *}$ & $(0.0266)$ \\
Born in 1900-15 & $-0.156^{* * *}$ & $(0.0293)$ \\
Constant & $-0.309^{* * *}$ & $(0.0332)$ \\
\hline N & $-57.38^{* * *}$ & $(0.0225)$ \\
$R^{2}$ first stage & 86402 & \\
$R^{2}$ second stage & 0.016 & \\
\hline & 0.99 & \\
\hline & &
\end{tabular}

Table 17: Estimates for the logarithm of medical expenses, first stage (fixed effects) and second stage (OLS). HRS data. Robust standard errors in parentheses, clustered at the individual level. ${ }^{*} \mathrm{p}<0.1,{ }^{*} \mathrm{p}<0.05,{ }^{* * *} \mathrm{p}<0.01$.
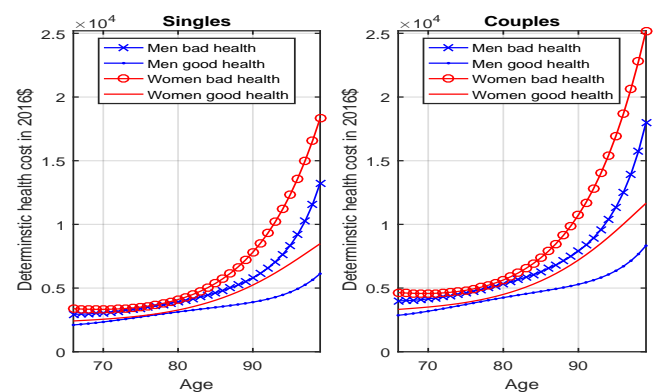

Figure 19: Medical expenditure by age, gender, and marital and health status. HRS data.

a constant and on the logarithm of pre-tax household income by cohort, year, and household type (single man, single woman, and couple).

We use PSID data from 1968 to 2015 to estimate cohort- and time-specific tax functions. Information about federal taxes paid is provided directly by the PSID up to 1991. After that year it is computed using TAXSIM, the NBER simulation program computing taxes. In particular, we extend the program written by Kimberlin, Kim 
and Shaefer (2015) to prepare the input needed by TAXSIM. ${ }^{16}$

Before-tax household income is defined as the sum of all income received by the spouses (or by the individual if single) in a given tax year. It thus includes income of head and wife (if present), that is, labor income, the asset part of income from farm, business, roomers, income from rent, interest dividends, and so on, and wife's income from wealth, plus transfer income, that is, Social Security, pension, annuities, other retirement income, welfare, aid to dependent children, unemployment or worker's compensation, help from relatives, alimony, or child support. After-tax household income is defined as before-tax income minus the federal income tax liability (including capital gains taxes, surtaxes, AMT, and refundable and non-refundable credits, as computed by TAXSIM).

Because couples are much more numerous than singles, we follow a slightly different procedure. For couples, we define two five-year cohorts (one born in 1941-1945, one in 1951-1955). For single men and women, the 1945 cohort includes people born in 1938-1947, while the 1955 one includes those born in 1948-1957. For both, we estimate yearly tax functions using a 5-year moving window to have enough observations and at the same time to capture relevant changes in the legislation.

All of the inputs needed by TAXSIM come from the PSID for the years 19922015. Before 1999, medical expenses and charitable contributions are not available, thus they need to be imputed. We do so by regressing the sum of these two items for pooled years 1999-2015, when they are observed, and predicting their value using our estimated parameters (out-of-sample prediction for the years they are missing). The included explanatory variables are demographic and income variables, such as family size, employment status of the head and the spouse if present, state of residence, wages, pensions, other incomes, education, number of children, age, and marital status. Then, we add an error term to that prediction to tackle the attenuation in the variance of the distribution of the imputed values, following the procedure in David, Little, Samuhel and Triest (1986), and French and Jones (2011). More precisely, first we regress the sum of the two items on the vector of observables for the sample

\footnotetext{
${ }^{16}$ The program by Kimberlin, Kim and Shaefer (2015) prepares the input for TAXSIM for the PSID years 1999-2011 following Butrica and Burkhauser (1997). It differs from more simplified PSID TAXSIM interface approaches in that multiple tax units are identified within each PSID family unit; thus, cohabiting couples are treated as two separate tax units, with children assigned to the appropriate tax unit (head or cohabitor) using relationship codes. We extend their program to include all years between 1992 and 2015.
} 
of heads who choose to itemize, $d e d u c_{i}=z_{i} \beta+\epsilon_{i}$. Second, for each household $i$ for which deduc is observed, we calculate the predicted value $\widehat{\operatorname{deduc}}_{i}=z_{i} \hat{\beta}$ and the residual $\hat{e}_{i}=d e d u c_{i}-\widehat{\operatorname{deduc}}_{i}$. Third, we sort the predicted value $\widehat{\operatorname{deduc}}_{i}$ into deciles and keep track of all values of $\hat{e}_{i}$ within each decile. Next, for every individual $j$ with missing deduc we impute $\widehat{d e d u c}_{j}=z_{j} \hat{\beta}$. Then we impute $\hat{e}_{j}$ for households with missing deduc by finding a random individual $i$ in the non-missing sample with a value of $\widehat{d e d u c}_{i}$ in the same decile as $\widehat{\operatorname{deduc}}_{j}$ and set $\hat{e}_{j}=\hat{e}_{i}$. The imputed value of deduc is $\widehat{\operatorname{deduc}}_{j}+\hat{e}_{j}$.

\section{Appendix C. The value functions of individuals in couples}

Let $\hat{c}_{t}(\cdot), \hat{l}_{t}^{i, j}(\cdot), \hat{a}_{t+1}(\cdot)$, and $\hat{D}_{t}(\cdot)$ denote, respectively, the optimal consumption, leisure, saving, and claiming decision for an individual of gender $i$ in a couple with a given set of state variables. During the working period, we have

$$
\begin{aligned}
\hat{W}^{c}\left(t, i, a_{t}, \epsilon_{t}^{1}, \epsilon_{t}^{2}, \bar{y}_{t}^{1}, \bar{y}_{t}^{2}\right) & =v^{i}\left(\hat{c}_{t}(\cdot), \hat{l}_{t}^{i, j}, \eta_{t}^{i, j}\right)+ \\
& \beta(1-\zeta(\cdot)) E_{t} \hat{W}^{c}\left(t+1, i, \hat{a}_{t+1}(\cdot), \epsilon_{t+1}^{1}, \epsilon_{t+1}^{2}, \bar{y}_{t+1}^{1}, \bar{y}_{t+1}^{2}\right)+ \\
& \beta \zeta(\cdot) E_{t} W^{s}\left(t+1, i, \hat{a}_{t+1}(\cdot) / 2, \epsilon_{t+1}^{i}, \bar{y}_{t+1}^{i}\right) .
\end{aligned}
$$

During the early retirement period, we have

$$
\begin{gathered}
\hat{N}^{c}\left(t, i, a_{t}, \epsilon_{t}^{1}, \epsilon_{t}^{2}, \bar{y}_{t}^{1}, \bar{y}_{t}^{2}\right)=v^{i}\left(\hat{c}_{t}(\cdot), \hat{l}_{t}^{i, j}, \eta_{t}^{i, j}\right) \\
+\beta E_{t} \hat{V}^{c}\left(t+1, i, \hat{a}_{t+1}(\cdot), \epsilon_{t+1}^{1}, \epsilon_{t+1}^{2}, \bar{y}_{t+1}^{1}, \bar{y}_{t+1}^{2}\right) \\
\hat{S}^{c}\left(t, i, a_{t}, \bar{y}_{r}^{1}, \bar{y}_{r}^{2}, t r\right)=v^{i}\left(\hat{c}_{t}(\cdot), L^{i, j}, \eta_{t}^{i, j}\right)+\beta E_{t} S^{c}\left(t+1, i, \hat{a}_{t+1}(\cdot), \bar{y}_{r}^{1}, \bar{y}_{r}^{2}, t r\right) \\
\hat{V}^{c}\left(t, i, a_{t}, \epsilon_{t}^{1}, \epsilon_{t}^{2}, \bar{y}_{t}^{1}, \bar{y}_{t}^{2}\right)=\left(1-\hat{D}_{t}(\cdot)\right) \hat{N}^{c}\left(t, i, a_{t}, \epsilon_{t}^{1}, \epsilon_{t}^{2}, \bar{y}_{t}^{1}, \bar{y}_{t}^{2}\right)+\hat{D}_{t}(\cdot) \hat{S}^{c}\left(t, i, a_{t}, \bar{y}_{r}^{1}, \bar{y}_{r}^{2}, t\right) .
\end{gathered}
$$

During the retirement period, we have

$$
\begin{aligned}
\hat{R}^{c}\left(t, i, a_{t}, \psi_{t}^{1}, \psi_{t}^{2}, \bar{y}_{r}^{1}, \bar{y}_{r}^{2}, t r\right) & =v^{i}\left(\hat{c}_{t}(\cdot), L^{i, j}, \eta_{t}^{i, j}\right)+ \\
& \beta s_{t}^{i, j}\left(\psi_{t}^{i}\right) s_{t}^{p, j}\left(\psi_{t}^{p}\right) E_{t} \hat{R}^{c}\left(t+1, i, \hat{a}_{t+1}(\cdot), \psi_{t+1}^{1}, \psi_{t+1}^{2}, \bar{y}_{r}^{1}, \bar{y}_{r}^{2}, t r\right)+ \\
& \beta s_{t}^{i, j}\left(\psi_{t}^{i}\right)\left(1-s_{t}^{p, j}\left(\psi_{t}^{p}\right)\right) E_{t} R^{s}\left(t+1, i, \hat{a}_{t+1}(\cdot), \psi_{t+1}^{i}, \bar{y}_{r}^{i}, t r\right),
\end{aligned}
$$

where $s_{t}^{p, j}\left(\psi_{t}^{p}\right)$ is the survival probability of the partner of the person of gender $i$. 


\section{Appendix D. Calibrated model parameters}

Table 18 summarizes our first-step calibrated model inputs. We set the interest rate $r$ to $4 \%$ and the utility curvature parameter, $\gamma$, to 2.5. The equivalence scales are set to $\eta_{t}^{i, j}=\left(j+0.7 * f_{t}^{i, j}\right)^{0.7}$, as estimated by Citro and Michael (1995). The term $f_{t}^{i, j}$ is the average total number of children for single and married men and women by age. Our equivalence scale implies that $\$ 1$ spent by a household in a couple with two children gives each household member a consumption of 0.42 cents.

The most recent paper estimating the consumption floor during retirement is by De Nardi, French and Jones (2016). They estimate a utility floor that corresponds to consuming $\$ 4,600$ a year when healthy. However, SSI recipients are guaranteed a minimum income of $\$ 6,670$. As a compromise, we use $\$ 5,900$ as our consumption floor for elderly singles (which is $\$ 8,687$ in 2016 dollars), and the one for couples to be 1.5 the amount for singles, which is the statutory ratio between benefits of couples to singles.

\begin{tabular}{|c|c|c|}
\hline \multicolumn{2}{|c|}{ Calibrated parameters } & Source \\
\hline \multicolumn{3}{|c|}{ Preferences and returns } \\
\hline$r$ & Interest rate & 4\% De Nardi, French and Jones (2016) \\
\hline$\gamma$ & Utility curvature parameter & 2.5 see text \\
\hline$\eta_{t}$ & Equivalence scales & Citro and Michael (1995) \\
\hline \multicolumn{3}{|c|}{ Government policy } \\
\hline$S S\left(\bar{y}_{r}^{i}\right)$ & Social Security benefit & See text \\
\hline$\tau_{t}^{S S}$ & Social Security tax rate & See text \\
\hline$\tilde{y}_{t}$ & Social Security cap & See text \\
\hline$\underline{\mathrm{c}}(1)$ & Minimum consumption, singles & $\$ 8,687$, De Nardi, French and Jones (2016) \\
\hline$\underline{\mathrm{c}}(2)$ & Minimum consumption, couples & $\$ 8,687^{*} 1.5$ Social Security rules \\
\hline
\end{tabular}

Table 18: First-step calibrated inputs summary.

The Social Security benefit at age 66 is calculated to mimic the Old Age and Survivor Insurance component of the Social Security system:

$$
S S\left(\bar{y}_{r}\right)=\left\{\begin{array}{ll}
0.9 \bar{y}_{r}, & \bar{y}_{r}<0.1115 \\
0.1004+0.32\left(\bar{y}_{r}-0.1115\right), & 0.1115 \leq \bar{y}_{r}<0.6725 \\
0.2799+0.15\left(\bar{y}_{r}-0.6725\right), & 0.6725 \leq \bar{y}_{r}<y_{t}^{c a p}
\end{array}\right\}
$$

where the marginal rates and bend points, expressed as fractions of average household 
income, come from the Social Security Administration. ${ }^{17}$ The Social Security tax and Social Security cap shown in Figure 20 have been changing over time.
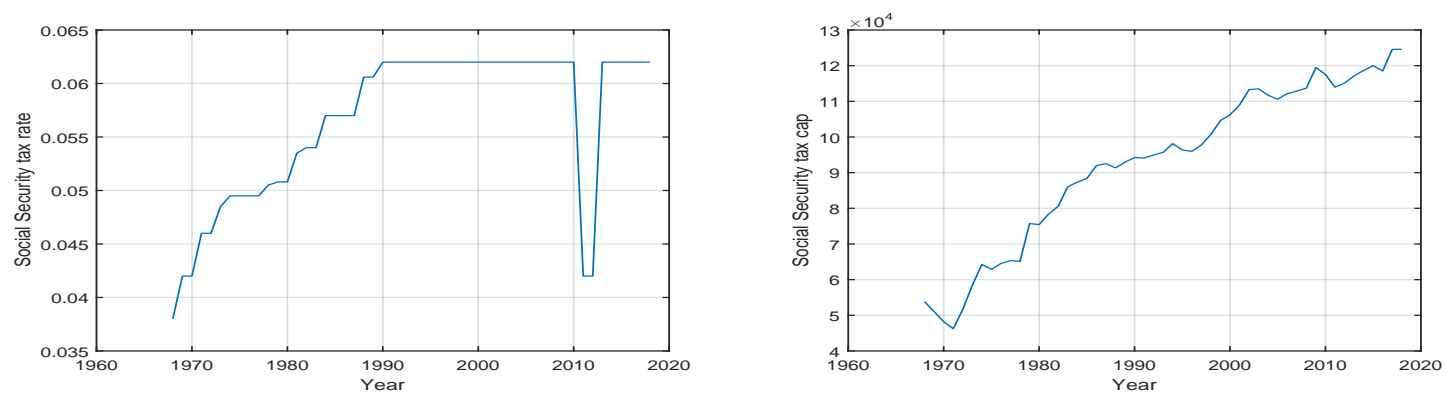

Figure 20: Social Security tax (left) and cap (right) over time, 2016 dollars.

\section{Appendix E. Solution algorithm}

This appendix describes the solution algorithm. We solve for the value functions and policy functions and then we simulate our model economy. In the latter step, we conduct a partial equilibrium analysis of each cohort and we do not impose equilibrium on the marriage market. More specifically, we use our estimated marriage and divorce probabilities to compute both the dynamic programming problem and to generate the distribution of people by state variables that is generated by our policy functions. Finally, we estimate our model parameters following the procedures that we describe in Appendix F.

We optimize over six value functions over multiple time periods, compute three more value functions, and have six continuous state variables. In addition, there can be kinks in the value functions because both husbands and wives choose their participation. Thus, to have reliable solutions, we compute them brute force on a grid. To get a sense of dimensionality, the value function for working couples has the following dimensions in terms of state variables: age ( 41 periods, as we have yearly periods), wealth, wage shocks for each spouse, and human capital for each spouse. Over these grids, we evaluate choices for consumption, savings, and labor supply of both household members and compute all of the relevant expected values at each and marital status for each of the value functions.

\footnotetext{
${ }^{17}$ Social Security Administration: https://www.ssa.gov/oact/cola/bendpoints.html "Benefit Formula Bend Points". We use their values for 2009.
} 
Even parallelizing our model in $\mathrm{C}$ on high-end workstations, the model requires 22 minutes for each set of parameter values to be solved. Estimating the model for one cohort implies solving it thousands of times, which thus requires at least three or four weeks each time. We reestimate our model for each cohort many times to check for local minima, robustness, and so on. The computation time required is substantial.

During the retirement stage, single people do not get married anymore; hence, their value function can be computed independently of the other value functions. The value function of couples depends on their own future continuation value and the one of the singles, in case of death of a spouse. Then there is the value function of the single person being married in a couple, which depends on the optimal policy function of the couple, taking the appropriate expected values. We compute them as follows:

1. Compute the value function of the retired single person for all time periods after retirement by backward iteration starting from the last period.

2. Compute the value function of the retired couple for all time periods after retirement, which uses the value function for the retired single person in case of death of one of the spouses by backward induction starting from the last period.

3. Compute the value function of the single person in a marriage for all time periods after retirement.

During the early retirement stage, single people do not get married, and married people do not divorce or die; hence, the value function of the single person and that of the couple can be computed independently. We compute them as follows:

1. Compute the value function of the single person for all time periods by backward iteration starting from the last period in the early retirement stage.

2. Compute the value function of the couple for all time periods by backward iteration starting from the last period in the early retirement stage.

3. Compute the value function of the single person in a marriage for all time periods in the early retirement stage.

During the working age, the value functions are interconnected; hence, we solve each of them at time $t$, working backward over the life cycle, at each period: 
1. Take as given the value of being a single person in a married couple for next period and the value function of being single next period, which have been previously computed, and compute the value function of being single this period.

2. Given the value function of being single, compute the value function of the couple for the same age.

3. Given the optimal policy function of the couple, use the implied policy functions to compute the value function for a person in a couple.

4. Keep going back in time until the first period.

\section{Appendix F. Estimation strategy}

In this appendix, we review the two-step estimation strategy, the moment conditions, and the asymptotic distribution of our estimator. To simplify notation, we do not include a cohort indicator.

In the first step, we estimate the vector $\chi$, which includes the set of parameters than can be estimated without explicitly using our model. In the second step, we use the method of simulated moments (MSM) to estimate the remaining parameters, which are contained in the $M \times 1$ vector $\Delta$. For the 1945 cohort, the elements of $\Delta$ are the 19 model parameters $\left(\beta, \omega,\left(\phi_{0}^{i, j}, \phi_{1}^{i, j}, \phi_{2}^{i, j}\right),\left(\tau_{c}^{0,5}, \tau_{c}^{6,11}\right), L^{i, j}\right) .{ }^{18}$ For the 1955 cohort, we assume that the households have the same $\beta$ and $\omega$ as the 1945 cohort, and we thus estimate the remaining 17 parameters. Our estimate, $\hat{\Delta}$, of the "true" parameter vector $\Delta_{0}$ is the value of $\Delta$ that minimizes the (weighted) distance between the lifecycle profiles found in the data and the simulated profiles generated by the model.

In a nutshell, in the second step, we use the model to simulate a representative population of people as they age and die, and we find the parameter values that allow our simulated life-cycle profiles to "best match" (as measured by a GMM criterion function) the data for that cohort. The mechanics of our MSM approach draw heavily from De Nardi, French and Jones (2010, 2016) and are as follows. We discretize the asset grid, and, using value function iteration, we solve the model numerically (see Appendix E for details). This yields a set of decision rules that allows us to simulate life-cycle histories for wealth, participation, and hours. We keep track of a large number of artificial people, which are initially endowed with a value of the

\footnotetext{
${ }^{18}$ We normalize the time endowment of single men.
} 
state vector drawn from the data distribution for each cohort at age 25, generate their histories, and use them to construct moment conditions and evaluate the match using our GMM criterion. We search over the parameter space for the values that minimize the criterion.

More specifically, from ages 25 to 65 , we match average wealth for single men, single women, and couples, and working hours and participation for single men, single women, married men, and married women. For the generic variable $z$ equal to hours $(H)$, participation $(I n)$, and wealth $(a)$, we denote $z_{k, t}^{i, j}$ the sample observation relative to person $k$, of gender $i$, marital status $j$, and age $t$. Denoting $z_{t}^{i, j}(\Delta, \chi)$ the modelpredicted expected value of $z$ for age $i$, gender $i$, and marital status $j$, where $\chi$ is the vector of parameters estimated in the first step, we write the moment conditions as

$$
\begin{gathered}
E\left[a_{k, t}^{i, j}-a_{t}^{i, j}\left(\Delta_{0}, \chi_{0}\right)\right]=0, \quad \forall t=2, \ldots, 41 \\
E\left[H_{k, t}^{i, j}-H_{t}^{i, j}\left(\Delta_{0}, \chi_{0}\right)\right]=0, \quad \forall t=1, \ldots, 41 \\
E\left[\operatorname{In}_{k, t}^{i, j}-\operatorname{In}_{t}^{i, j}\left(\Delta_{0}, \chi_{0}\right)\right]=0, \quad \forall t=1, \ldots, 41 .
\end{gathered}
$$

Note that wealth for couples, $a_{k, t}^{i, j}$, do not depend on gender when marital status is $j=2$. Also, as wealth at age $25(t=1)$ is an initial condition, it is matched by construction. Thus, we have a total of $J=448$ moment conditions. In practice, we compute the sample expectations in equations (53), (54), and (55) conditional on a flexible polynomial in age. More specifically, we regress each variable $z$ on a fourthorder polynomial in age and on a set cohort of dummies, fully interacted with marital status and separately for each gender. We then compute the conditional expectations for each cohort in turn using the estimated marital- and gender-specific polynomial in age and coefficients relative to that cohort. These average age profiles, conditional on gender, marital status, and cohort, are those shown in the figures in the main text.

Suppose we have a data set of $K$ persons that are each observed at up to $T$ separate calendar years. Let $\varphi\left(\Delta ; \chi_{0}\right)$ denote the $J$-element vector of our moment conditions, and let $\hat{\varphi}_{K}($.$) denote its sample analog.$

Letting $\widehat{\mathbf{W}}_{K}$ denote a $J \times J$ positive definite weighting matrix, the MSM estimator $\hat{\Delta}$ is given by

$$
\underset{\Delta}{\operatorname{argmin}} \hat{\varphi}_{K}\left(\Delta ; \chi_{0}\right)^{\prime} \widehat{\mathbf{W}}_{K} \hat{\varphi}_{K}\left(\Delta ; \chi_{0}\right)
$$

Note that we also estimate $\chi_{0}$. For tractability reasons, and following much of the 
literature, we treat it as known.

Under the regularity conditions stated in Pakes and Pollard (1989) and Duffie and Singleton (1993), the MSM estimator $\hat{\Delta}$ is both consistent and asymptotically normally distributed:

$$
\sqrt{K}\left(\hat{\Delta}-\Delta_{0}\right) \rightsquigarrow N(0, \mathbf{V}),
$$

with the variance-covariance matrix $\mathbf{V}$ given by

$$
\mathbf{V}=\left(\mathbf{D}^{\prime} \mathbf{W D}\right)^{-1} \mathbf{D}^{\prime} \mathbf{W} \mathbf{S W D}\left(\mathbf{D}^{\prime} \mathbf{W D}\right)^{-1},
$$

where $\mathbf{S}$ is the variance-covariance matrix of the data;

$$
\mathbf{D}=\left.\frac{\partial \varphi\left(\Delta ; \chi_{0}\right)}{\partial \Delta^{\prime}}\right|_{\Delta=\Delta_{0}}
$$

is the $J \times M$ gradient matrix of the population moment vector; and $\mathbf{W}=\operatorname{plim}_{K \rightarrow \infty}\left\{\widehat{\mathbf{W}}_{K}\right\}$. When $\mathbf{W}=\mathbf{S}^{-1}, \mathbf{V}$ simplifies to $\left(\mathbf{D}^{\prime} \mathbf{S}^{-1} \mathbf{D}\right)^{-1}$.

The asymptotically efficient weighting matrix arises when $\widehat{\mathbf{W}}_{K}$ converges to $\mathbf{S}^{-1}$. However, as Altonji and Segal (1996) point out, the optimal weighting matrix is likely to suffer from small sample bias. We thus use a diagonal weighting matrix that is the same as $\mathbf{S}$ along the diagonal and has zeros off the diagonal of the matrix. We estimate $\mathbf{D}$ and $\mathbf{W}$ with their sample analogs.

Appendix G. Parameter Estimates Table 19 reports all of our structural model estimates and their standard errors. Figure 21 reports the age-varying time
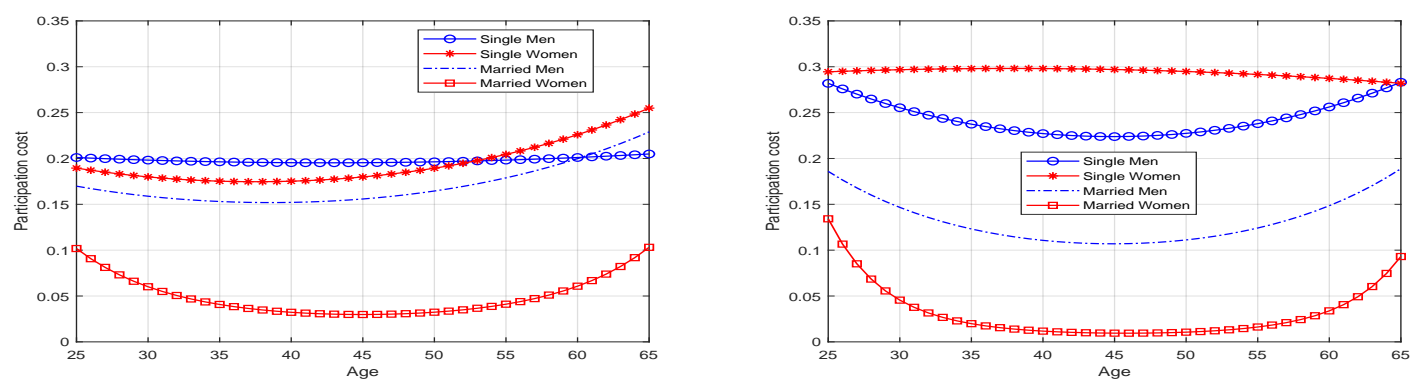

Figure 21: Labor participation costs estimated from the structural model, expressed as a fraction of the time endowment of single men. Left: 1945 cohort. Right: 1955 cohort. 


\begin{tabular}{l|cc|cc}
\hline \hline & \multicolumn{2}{|c|}{ Cohort 1945 } & \multicolumn{2}{c}{ Cohort 1955 } \\
\hline & Coeff. & Std. Err. & Coeff. & Std. Err. \\
\hline$\beta$ & 0.9902 & $(0.00025)$ & & \\
$\omega$ & 0.4067 & $(0.00121)$ & & \\
Participation costs: & & & & \\
$\phi_{2}^{1,1}$ & 0.0001 & $(0.00002)$ & 0.0008 & $(0.00003)$ \\
$\phi_{1}^{1,1}$ & -0.0041 & $(0.00064)$ & -0.0310 & $(0.00128)$ \\
$\phi_{0}^{1,1}$ & -1.3798 & $(0.02479)$ & -0.9350 & $(0.02044)$ \\
$\phi_{2}^{2,1}$ & 0.0006 & $(0.00003)$ & -0.0001 & $(0.00001)$ \\
$\phi_{1}^{2,1}$ & -0.0159 & $(0.00105)$ & 0.0027 & $(0.00034)$ \\
$\phi_{0}^{2,1}$ & -1.4534 & $(0.03154)$ & -0.8736 & $(0.01317)$ \\
$\phi_{2}^{1,2}$ & 0.0007 & $(0.00002)$ & 0.0016 & $(0.00004)$ \\
$\phi_{1}^{1,2}$ & -0.0196 & $(0.00087)$ & -0.0650 & $(0.00162)$ \\
$\phi_{0}^{1,2}$ & -1.5872 & $(0.03430)$ & -1.4770 & $(0.02662)$ \\
$\phi_{2}^{2,2}$ & 0.0033 & $(0.00007)$ & 0.0064 & $(0.00011)$ \\
$\phi_{1}^{2,2}$ & -0.1308 & $(0.00359)$ & -0.2680 & $(0.00644)$ \\
$\phi_{0}^{2,2}$ & -2.1777 & $(0.04321)$ & -1.8645 & $(0.04676)$ \\
Time endowments: & & & & \\
$F L^{2,1}$ & -3.0263 & $(0.08968)$ & -6.2257 & $(0.94085)$ \\
$F L^{1,2}$ & -2.9603 & $(0.07475)$ & -2.0981 & $(0.03211)$ \\
$F L^{2,2}$ & -1.2710 & $(0.01281)$ & -1.2731 & $(0.00775)$ \\
Childcare costs: & & & & \\
$\tau_{c}^{0,5}$ & 0.2790 & $(0.01185)$ & 0.2223 & $(0.01620)$ \\
$\tau_{c}^{6,11}$ & 0.0684 & $(0.00599)$ & 0.1892 & $(0.01063)$ \\
\hline
\end{tabular}

Table 19: Estimated parameters from the structural model. Standard errors in parentheses.

costs of working by age (expressed as a fraction of the time endowment of single men) from our estimated structural model. 


\section{Appendix H. Model fit, additional information}

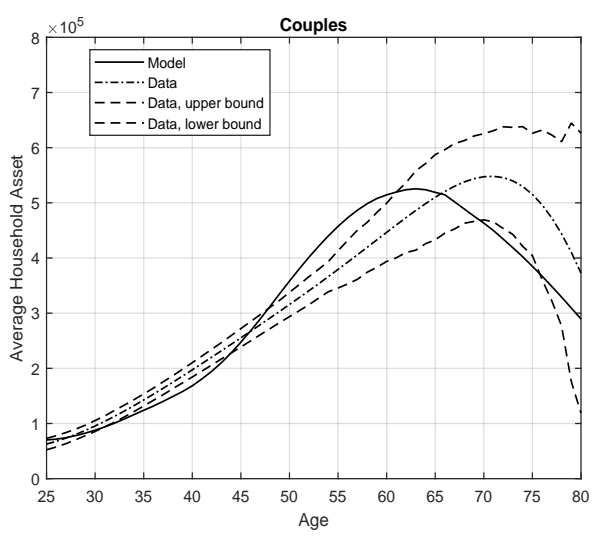

(a) Wealth, couples
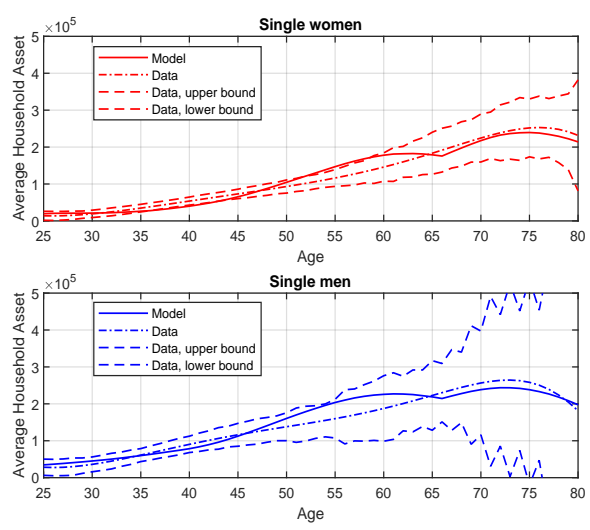

(b) Wealth, singles

Figure 22: Wealth from model, data, and 95\% confidence intervals. PSID, 1945 cohort.

We do not match savings after age 66 because the asset data become very noisy after that. However, the model does fit them well. Figure 22 shows the full profile of wealth generated by the model and those in the data for the 1945 cohort.

Table 20 reports the joint distribution of husband's and wife's wages by wage tercile (where the terciles are conditional on gender), relative to the theoretical number of couples under a uniform distribution. Hence, a number greater than one indicates that marriages in that cell are more likely than under the uniform distribution. Here, too, the pattern computed from the model is broadly consistent with that found in the data. The intuition for this result is the following. At age 25 we match the distribution of wages shocks and initial human capital within married couples. We also estimate the wage shock correlation of those who get married subsequently from the data. Because our wage shocks are persistent (the AR coefficient is 0.95), men with high wage shocks have higher human capital and tend to marry women who have both higher wage shocks and higher human capital. Thus, initial human capital at marriage is correlated. This high wage shock persistence also allows our model to match the assortativeness at various ages.

Figures 23 and 24 report our model-implied moments and target moments and 95\% confidence intervals from the PSID data for our 1955 cohort. They show that our parsimoniously parameterized model also fits the data for the 1955 cohort well. 


\begin{tabular}{|c|c|c|c|c|c|c|}
\hline \multirow{2}{*}{$\begin{array}{l}\text { Wage terciles: } \\
\text { Husband } \backslash W i f e\end{array}$} & \multicolumn{3}{|c|}{ Model } & \multicolumn{3}{|c|}{ Data } \\
\hline & 1 & 2 & 3 & 1 & 2 & 3 \\
\hline Age group & \multicolumn{3}{|c|}{$25-34$} & \multicolumn{3}{|c|}{$25-34$} \\
\hline 1 & 1.626 & 0.808 & 0.575 & 416 & 1.094 & 0.502 \\
\hline 2 & 64 & 1.068 & & .914 & 1.094 & 0.9 \\
\hline 3 & 331 & 1.117 & & .681 & 0.825 & 1.488 \\
\hline Age g & \multicolumn{3}{|c|}{$34-44$} & \multicolumn{3}{|c|}{$34-44$} \\
\hline 1 & .578 & 0.862 & 0.565 & .209 & 1.194 & 0.597 \\
\hline 2 & 1.048 & 0.982 & 0.97 & 0.995 & 1.010 & 0.995 \\
\hline 3 & 391 & 1.151 & 1.453 & 0.796 & 0.796 & 1.408 \\
\hline Age group & \multicolumn{3}{|c|}{$45-54$} & \multicolumn{3}{|c|}{$45-54$} \\
\hline 1 & 1.580 & 0.899 & 0.528 & 1.064 & 1.081 & 0.855 \\
\hline 2 & 1.024 & 0.992 & 0.984 & 1.134 & 1.116 & 0.750 \\
\hline 3 & 0.400 & 1.109 & 1.484 & 0.802 & 0.802 & 1.395 \\
\hline
\end{tabular}

Table 20: Comparing the joint distribution of husbands and wives by gender-specific wage terciles from the model and the data. Row index for husbands, column for wives, relative to the uniform distribution. 

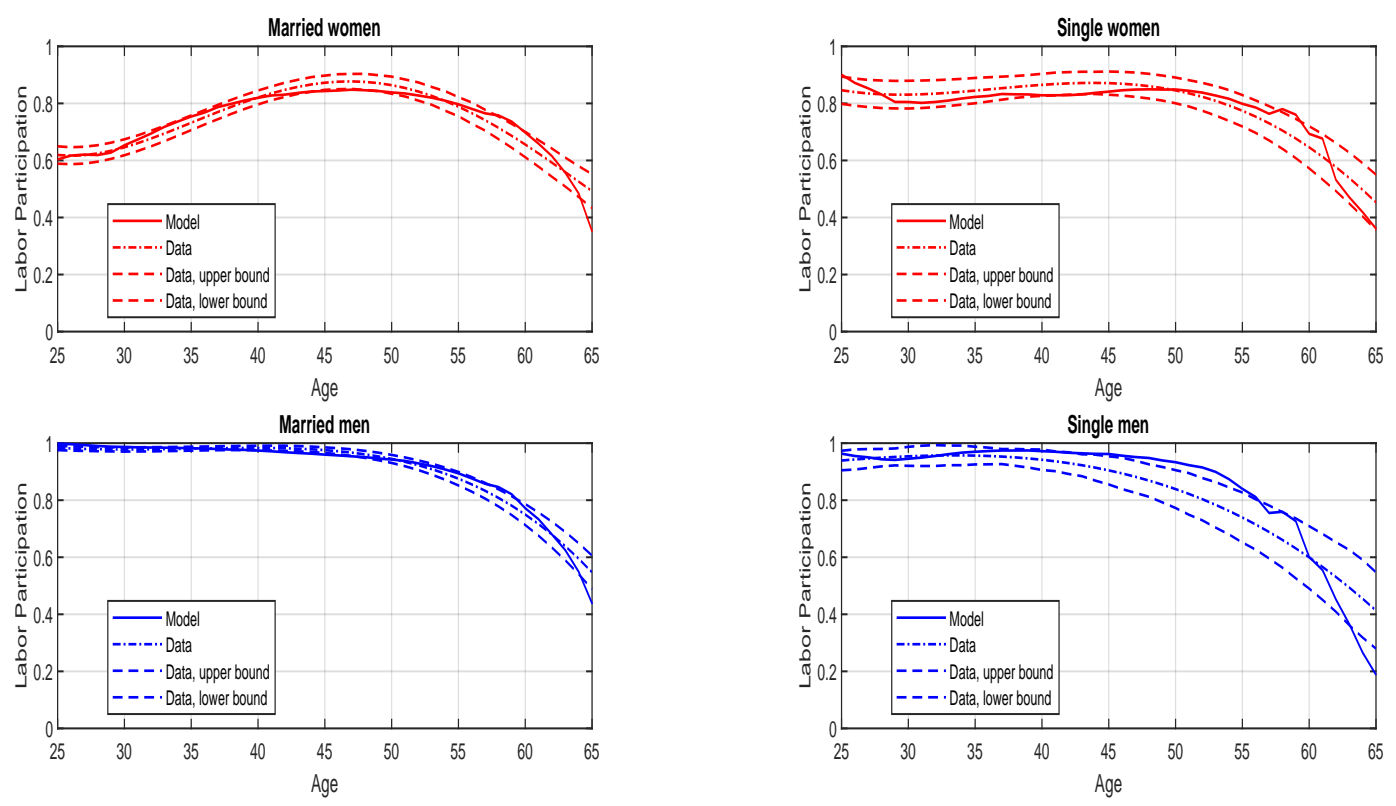

(a) Participation, couples

(b) Participation, singles
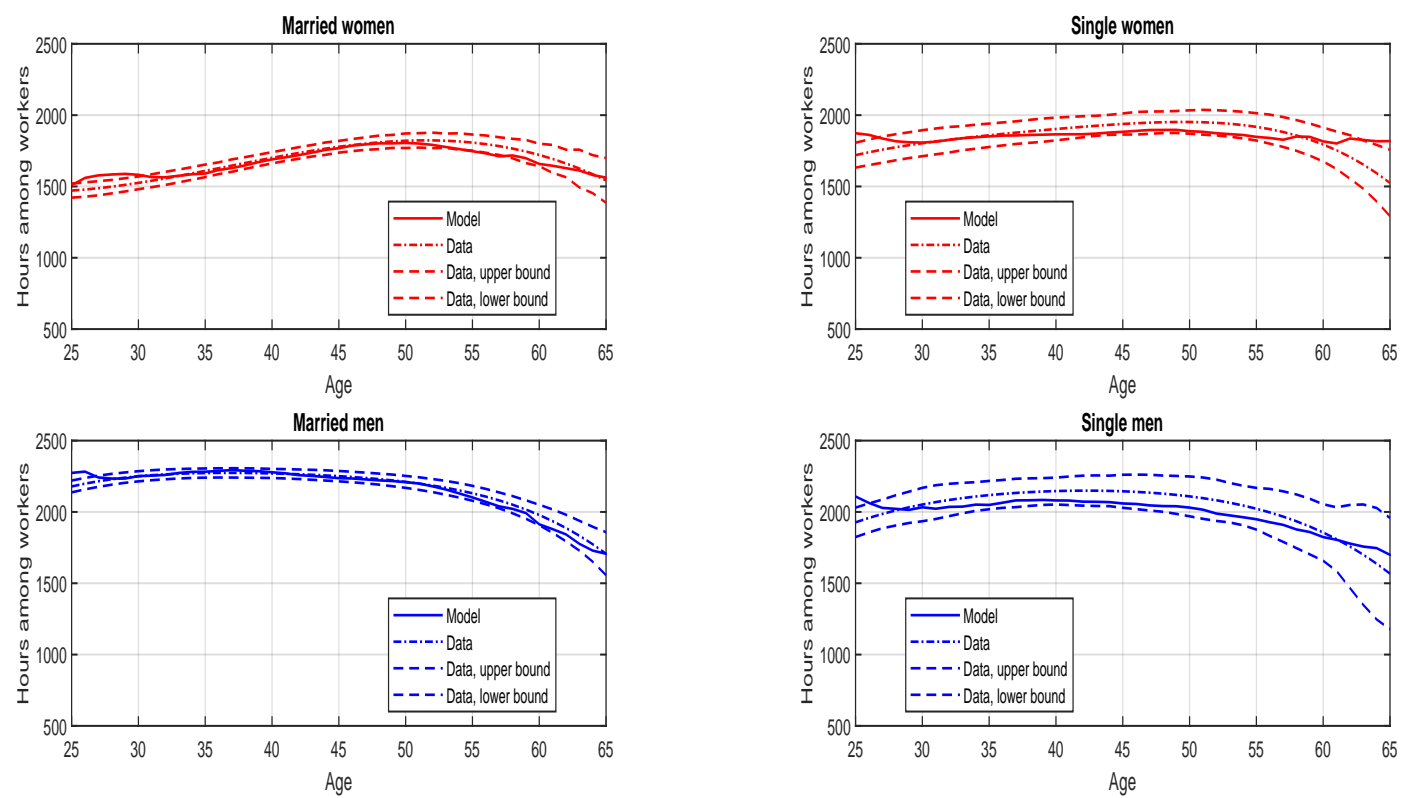

(c) Hours for workers, couples

(d) Hours for workers, singles

Figure 23: Model-implied average wealth, and data and $95 \%$ confidence intervals from the PSID for participation (top graphs) and hours (bottom graphs), 1955 cohort. 


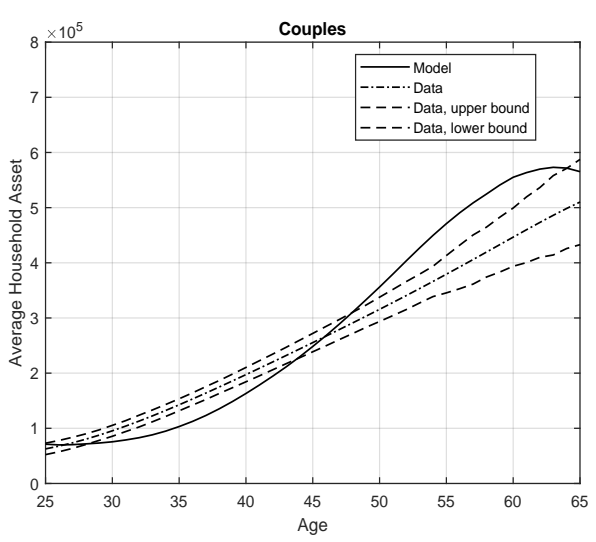

(a) Wealth, couples
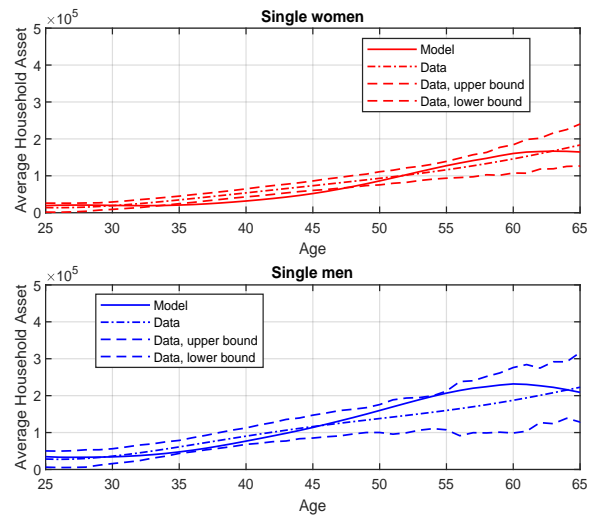

(b) Wealth, singles

Figure 24: Model-implied average wealth, data, and 95\% confidence intervals from the PSID, 1955 cohort. 


\section{Appendix I. Identification and sensitivity}
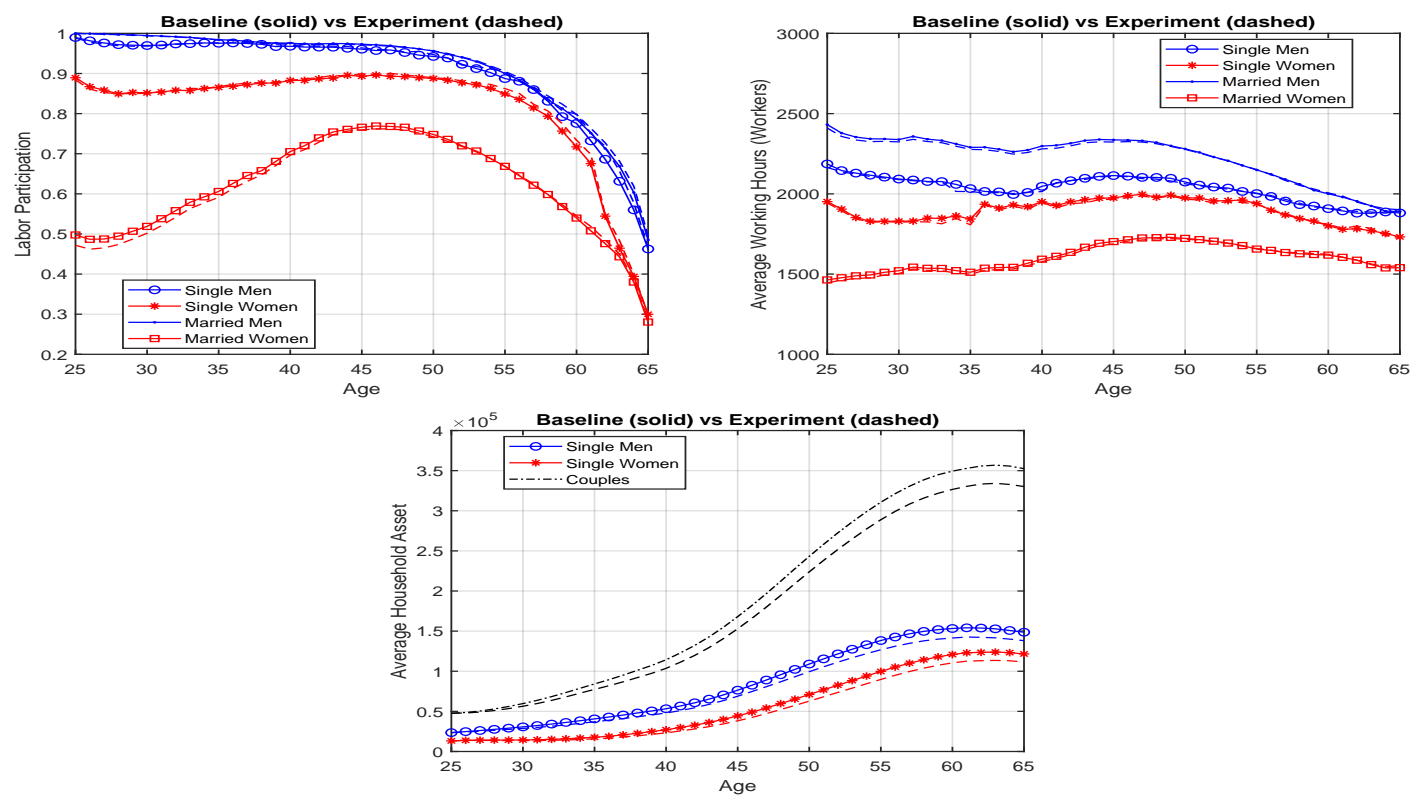

Figure 25: Profiles, 1945 cohort. Benchmark (solid), discount factor decreased $0.25 \%$ (dashed). 

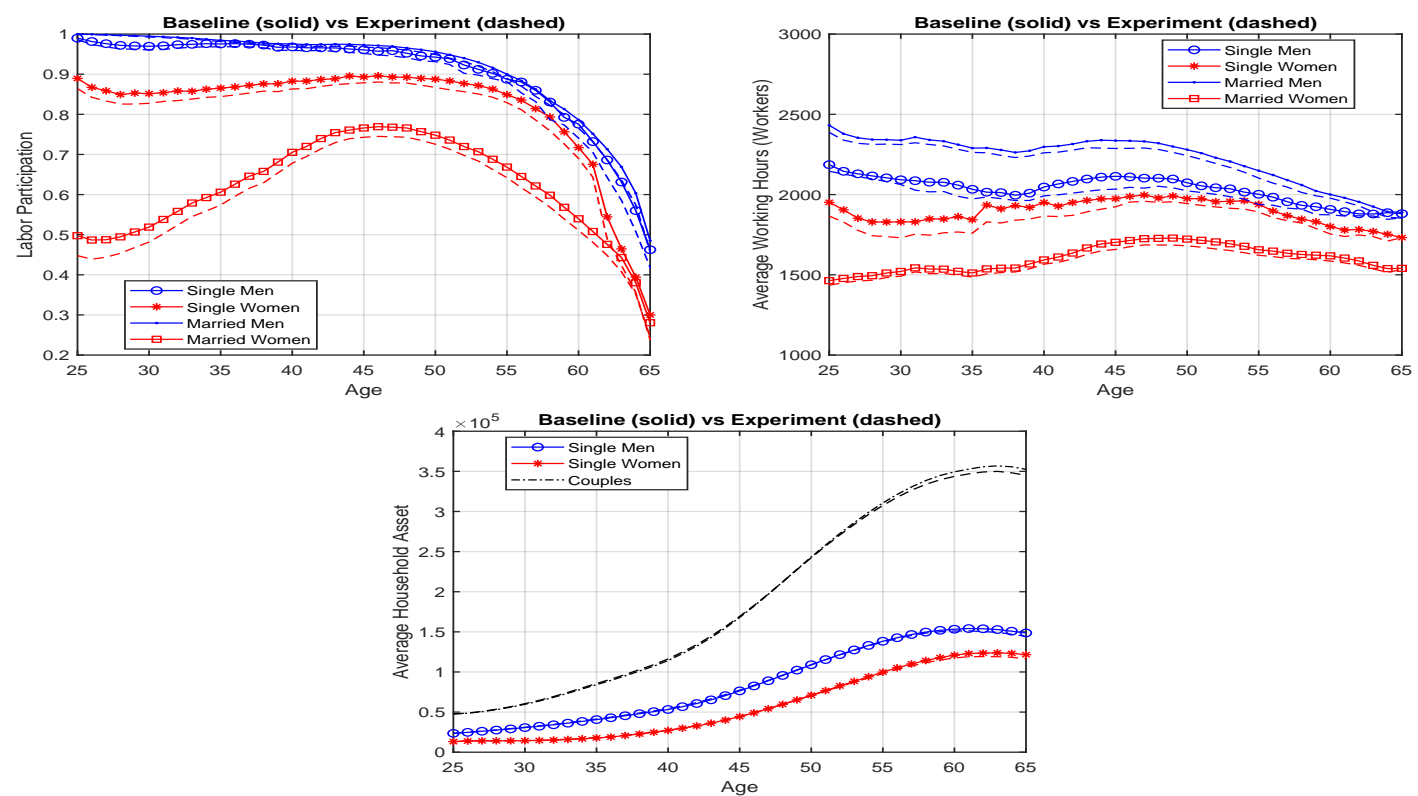

Figure 26: Profiles, 1945 cohort. Benchmark (solid), weight on consumption decreased $2.5 \%$ (dashed).
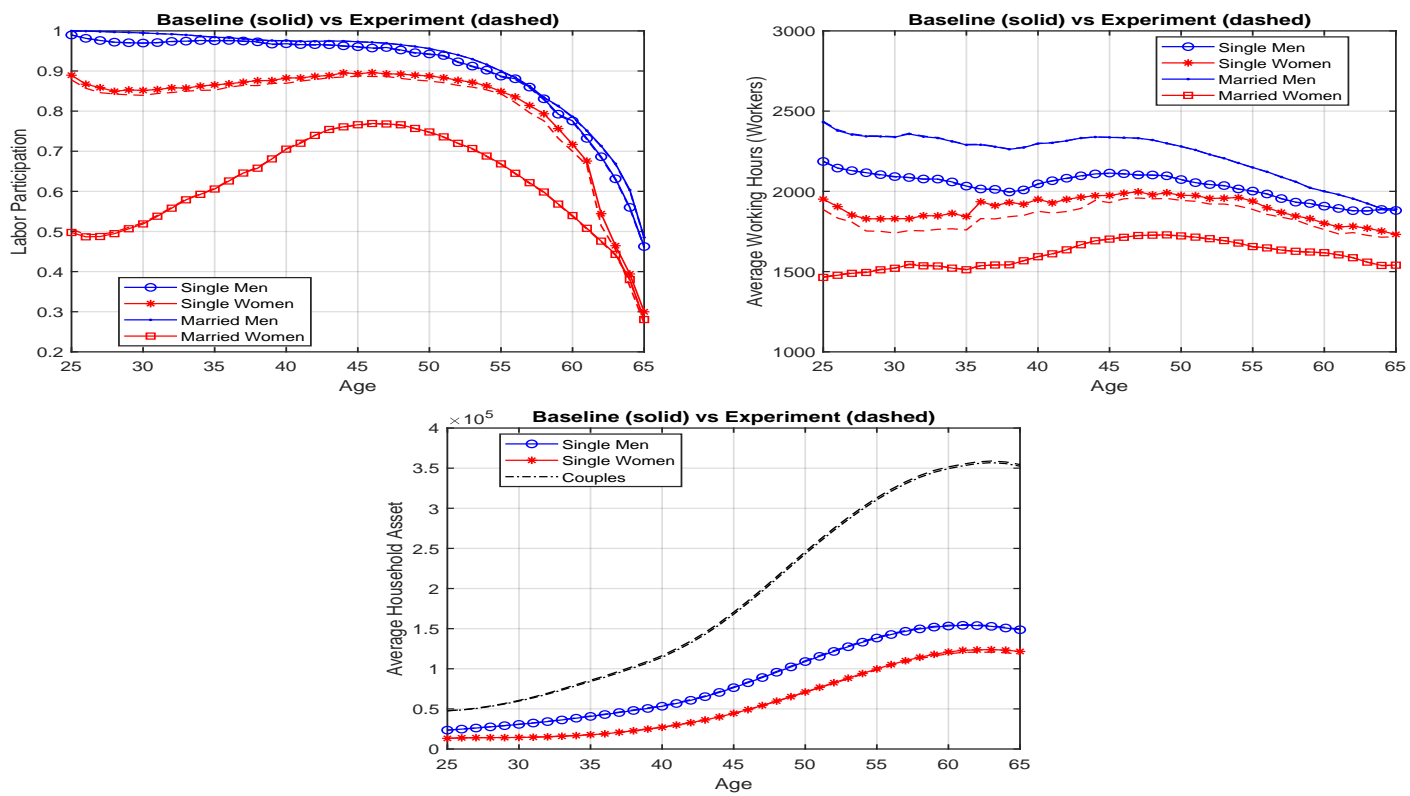

Figure 27: Profiles, 1945 cohort. Benchmark (solid), lower available time for single women by decreasing $F L^{2,1} 10 \%$ (dashed). 

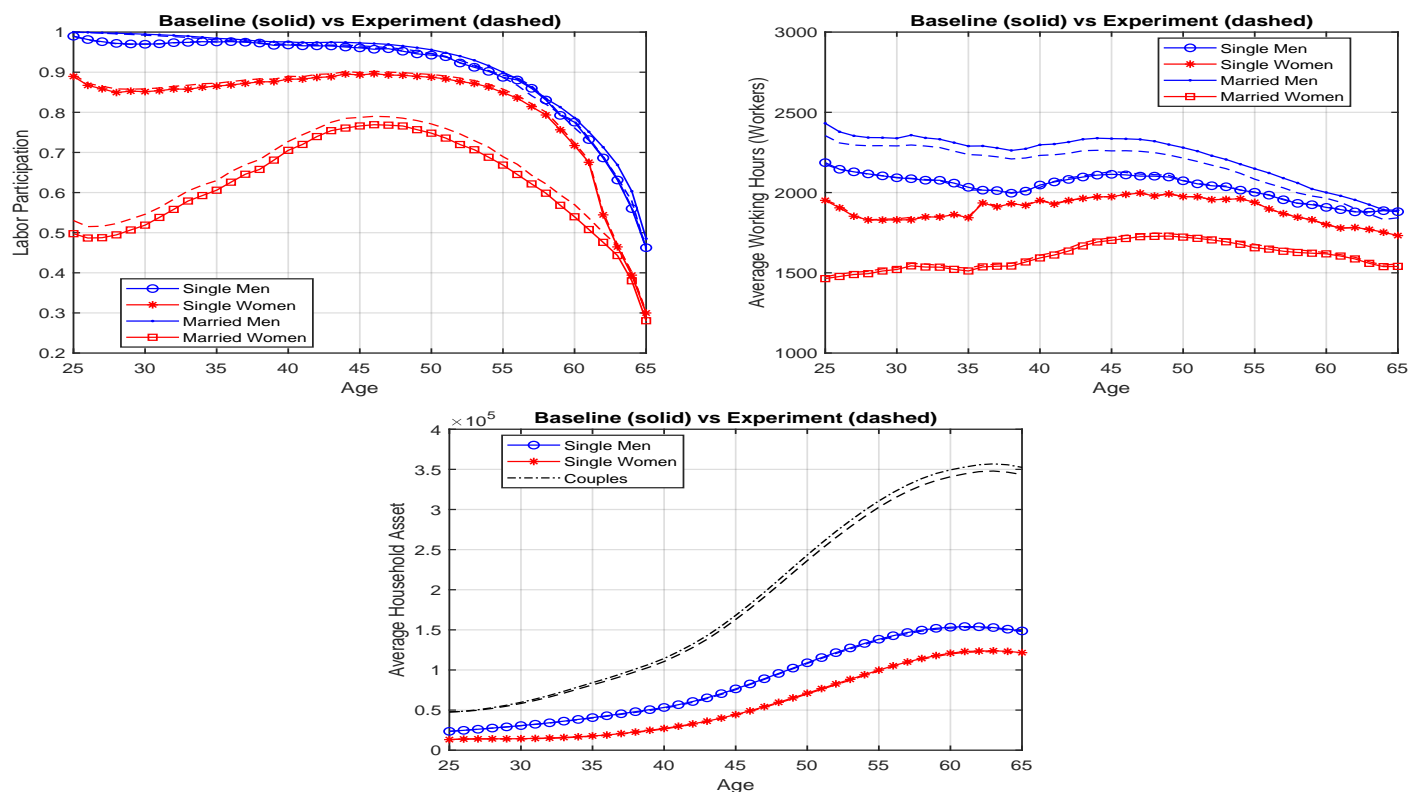

Figure 28: Profiles, 1945 cohort. Benchmark (solid), lower available time for married men by decreasing $F L^{1,2} 10 \%$ (dashed).
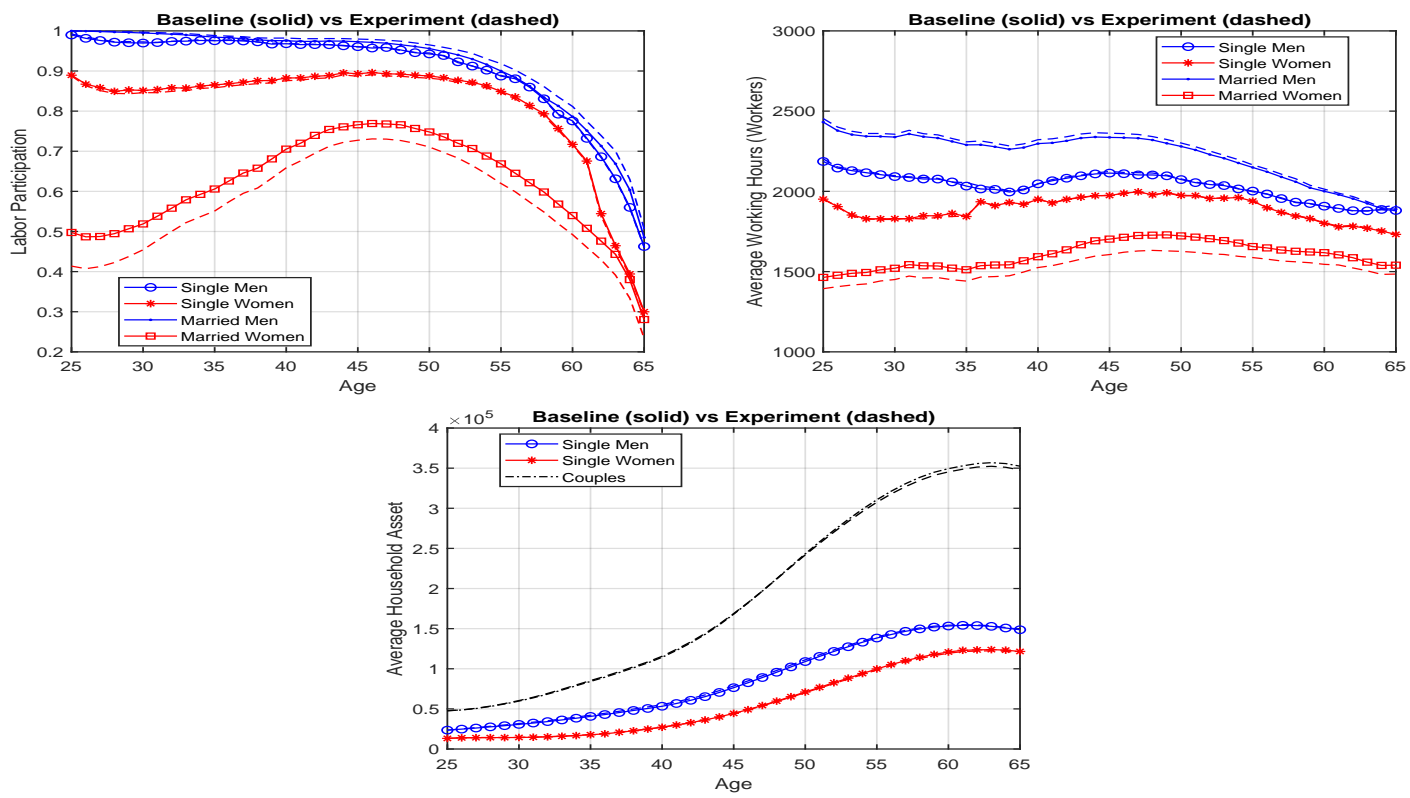

Figure 29: Profiles, 1945 cohort. Benchmark (solid), lower available time for married women by decreasing $F L^{2,2} 10 \%$ (dashed). 

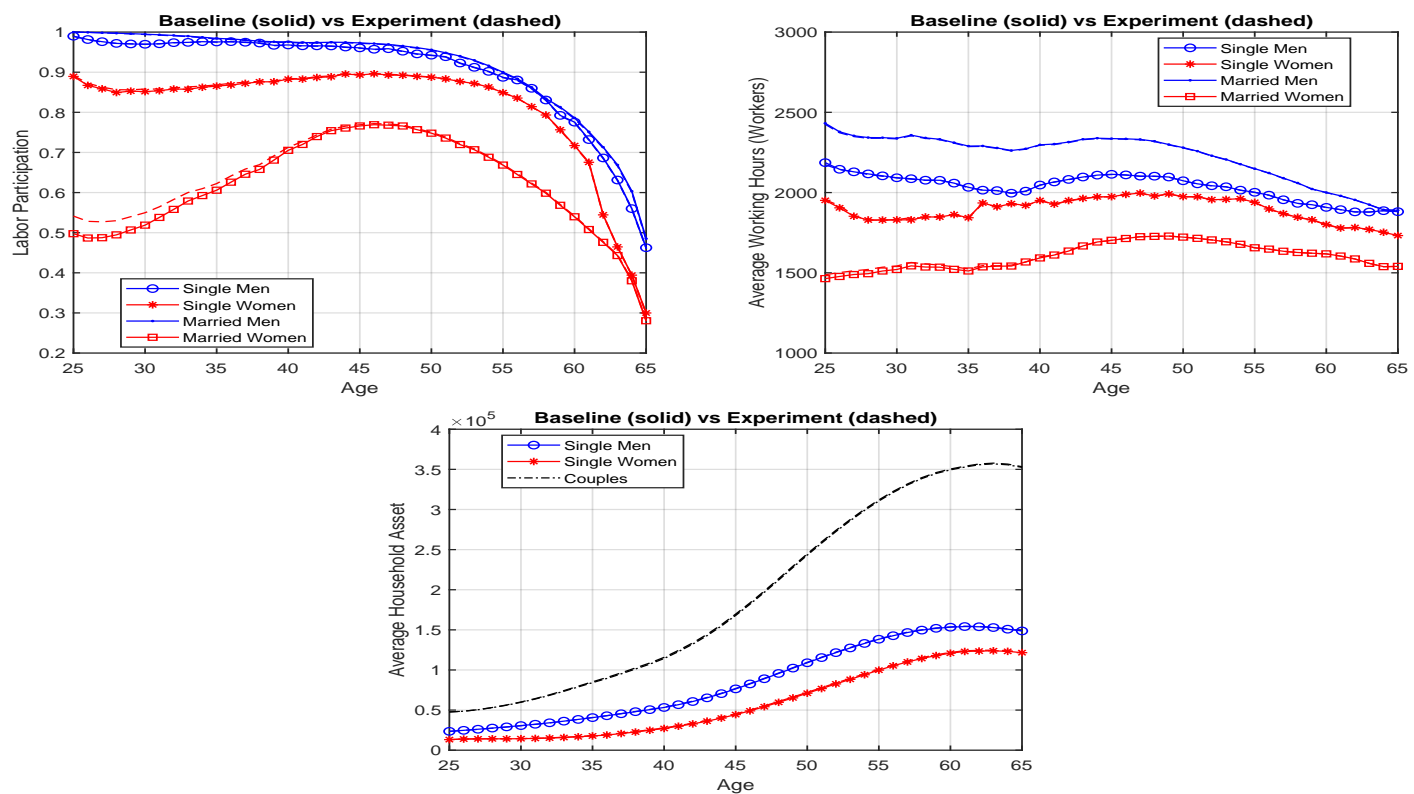

Figure 30: Profiles, 1945 cohort. Benchmark (solid), child care costs for younger children decreased $10 \%$ (dashed).
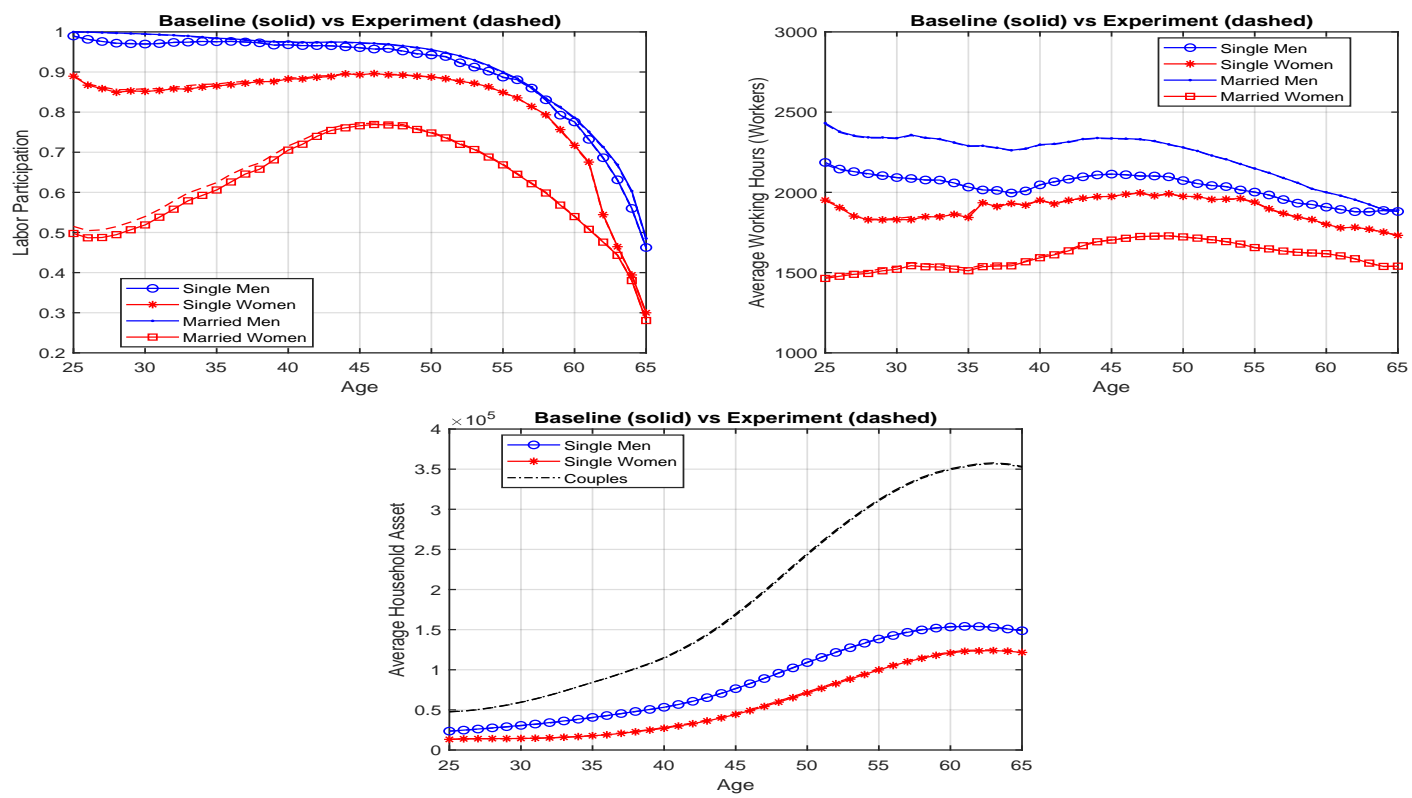

Figure 31: Profiles, 1945 cohort. Benchmark (solid), child care costs for older children decreased $25 \%$ (dashed). 

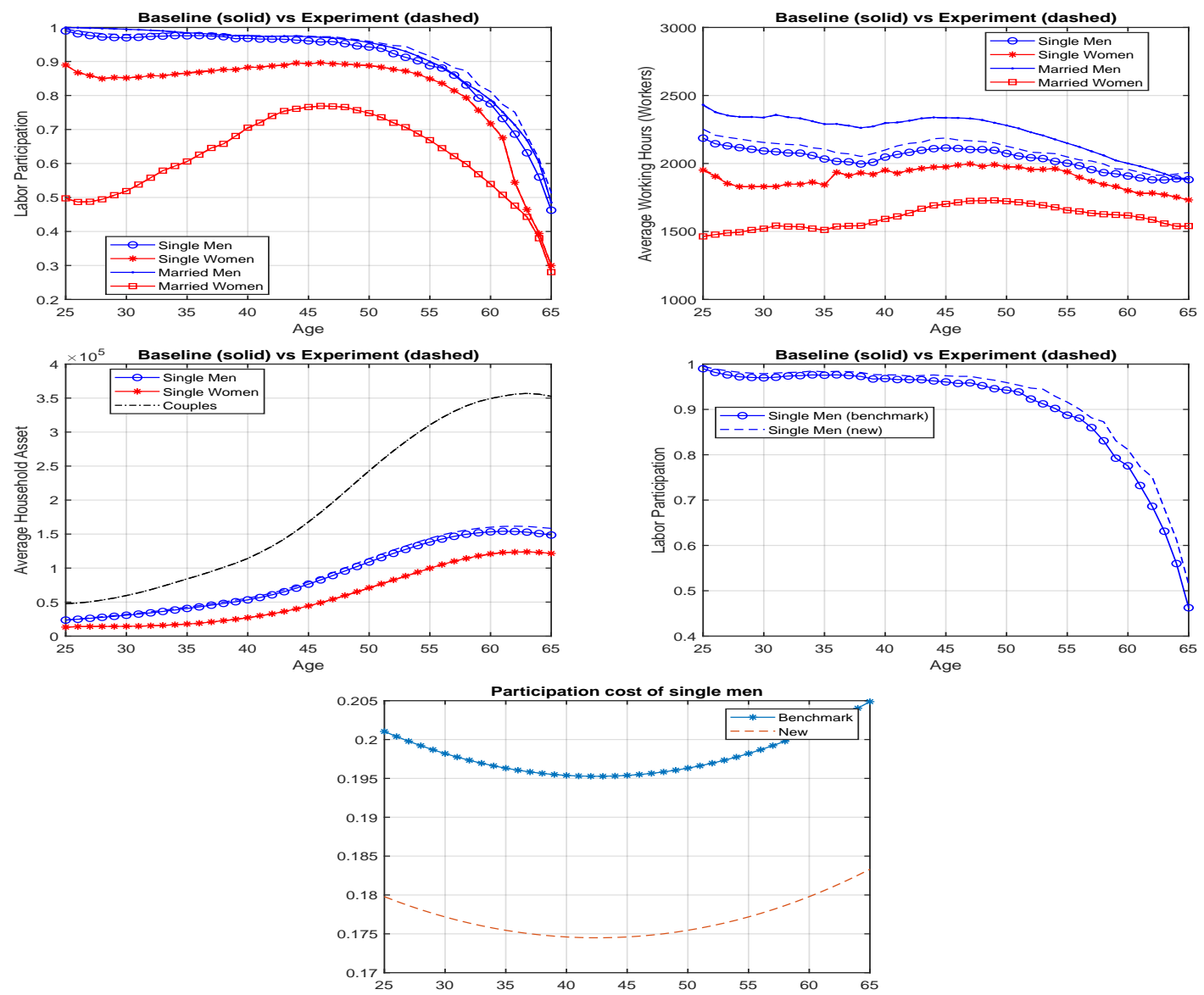

Figure 32: Profiles, 1945 cohort. Benchmark (solid), constant in participation cost for single men changed by $10 \%$ (dashed) to lower participation costs. 

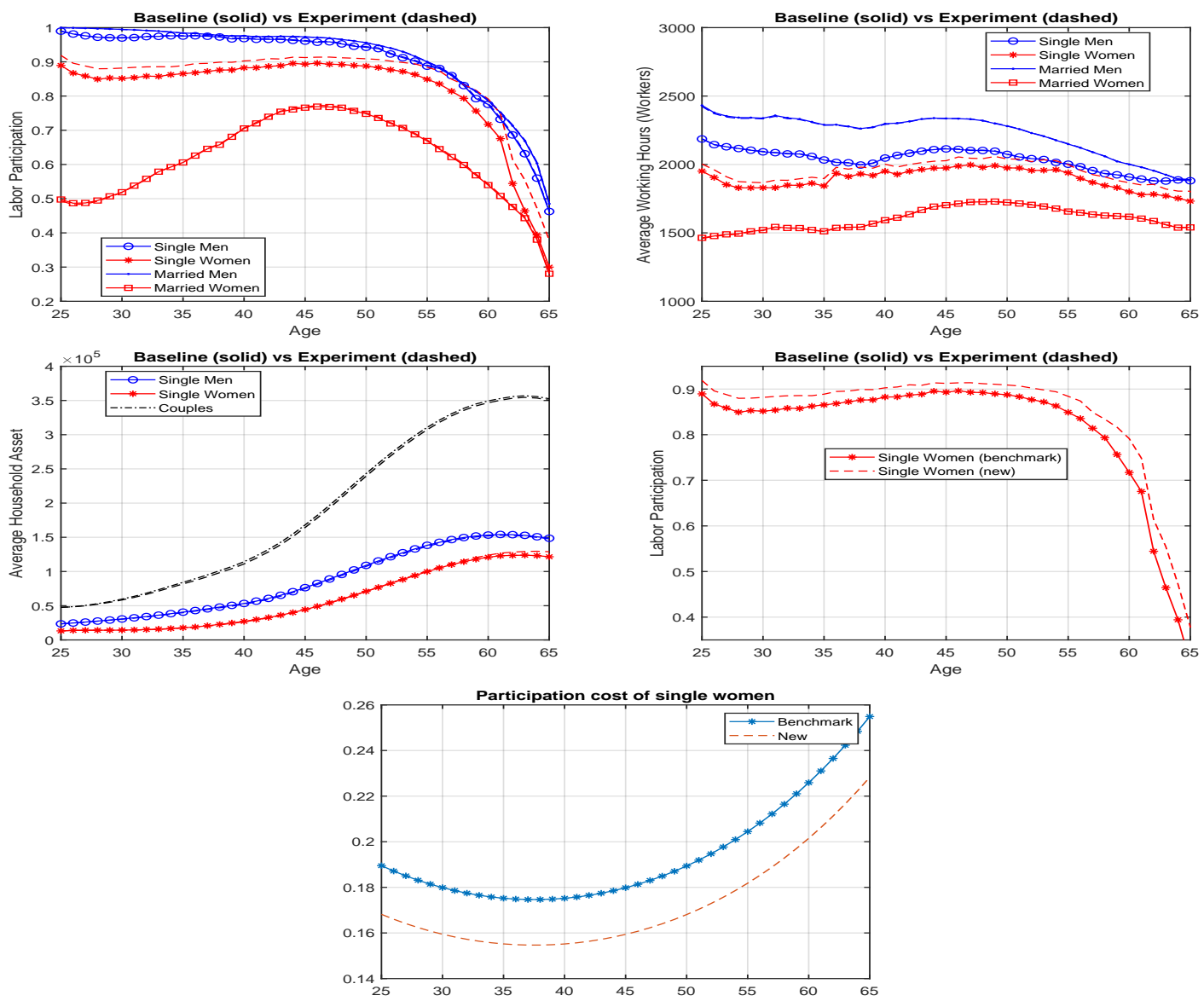

Figure 33: Profiles, 1945 cohort. Benchmark (solid), constant in participation cost for single women changed by $10 \%$ (dashed) to lower participation costs. 

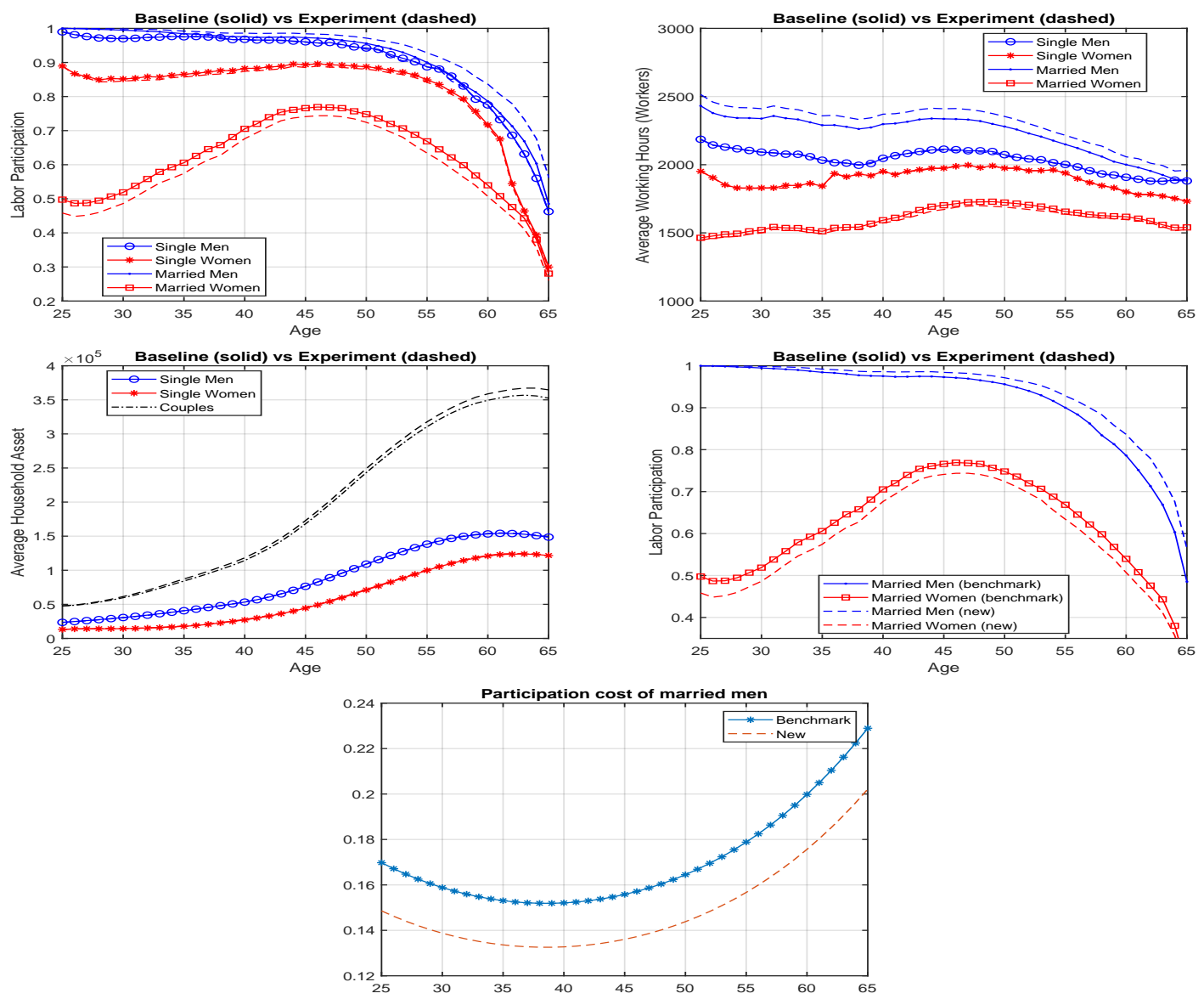

Figure 34: Profiles, 1945 cohort. Benchmark (solid), constant in participation cost for married men changed by $10 \%$ (dashed) to lower participation costs. 

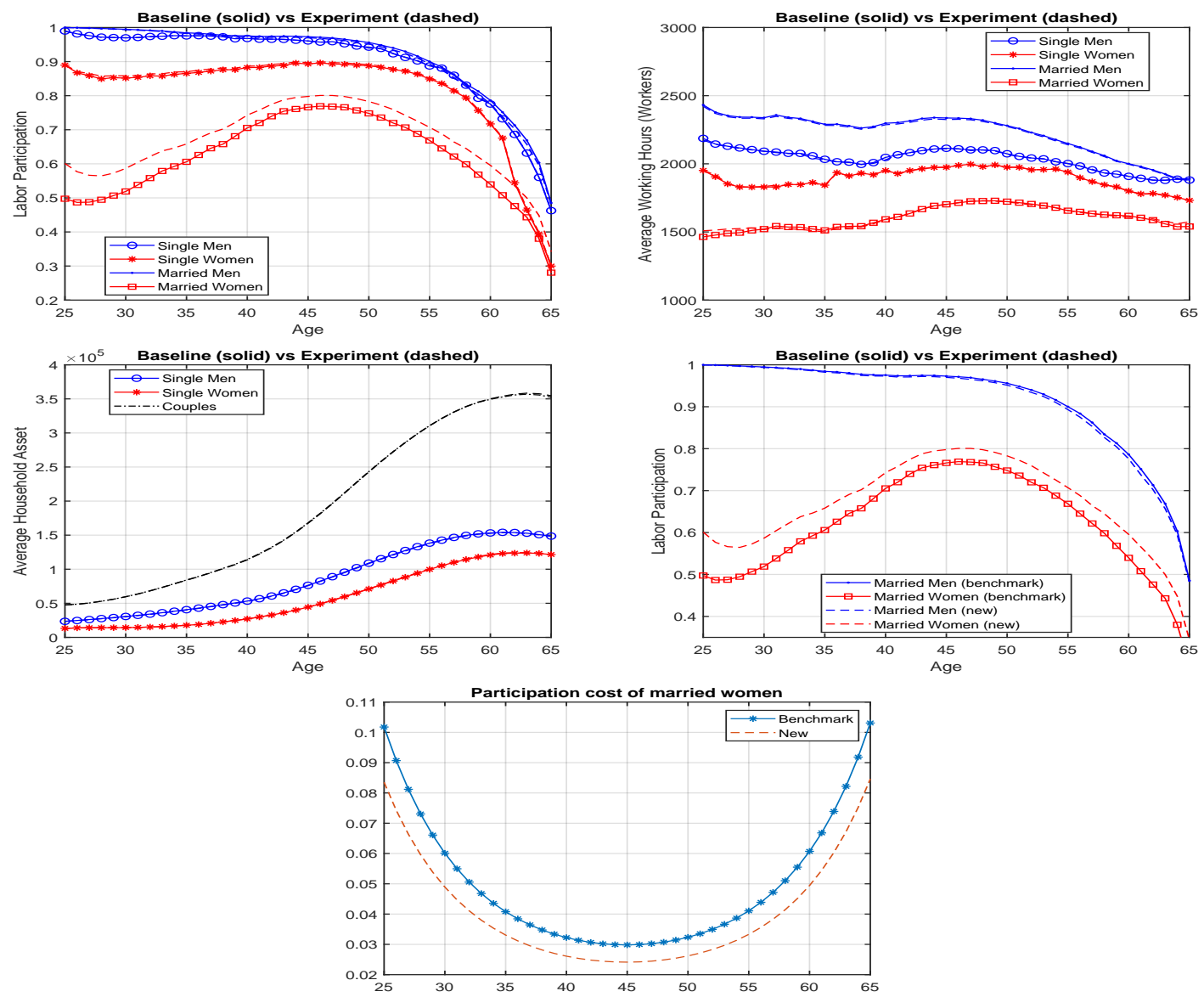

Figure 35: Profiles, 1945 cohort. Benchmark (solid), constant in participation cost for married women changed by $10 \%$ (dashed) to lower participation costs. 

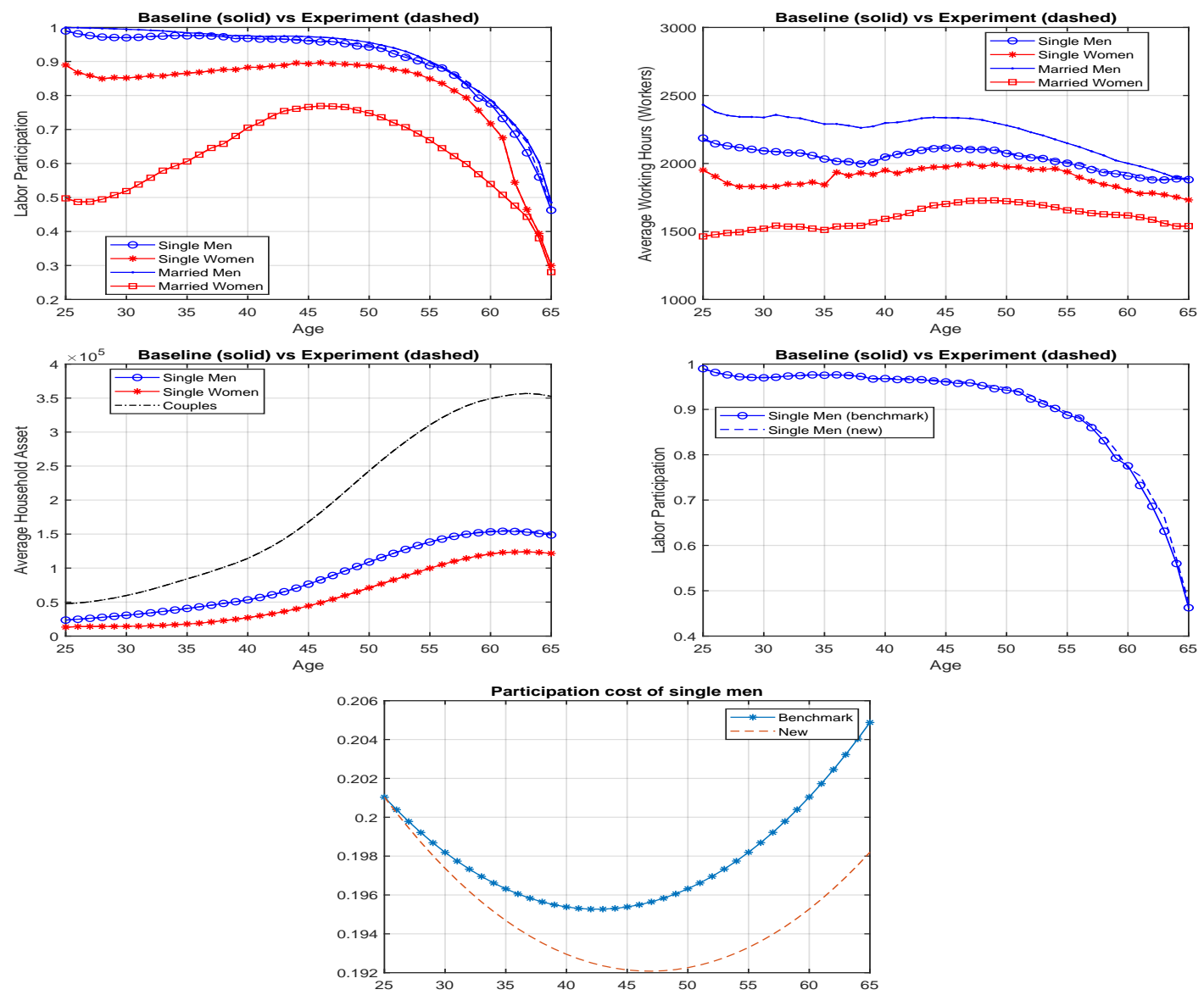

Figure 36: Profiles, 1945 cohort. Benchmark (solid), linear term in age in participation cost for single men $\phi_{1}^{1,1}$ increased $25 \%$ (dashed). 

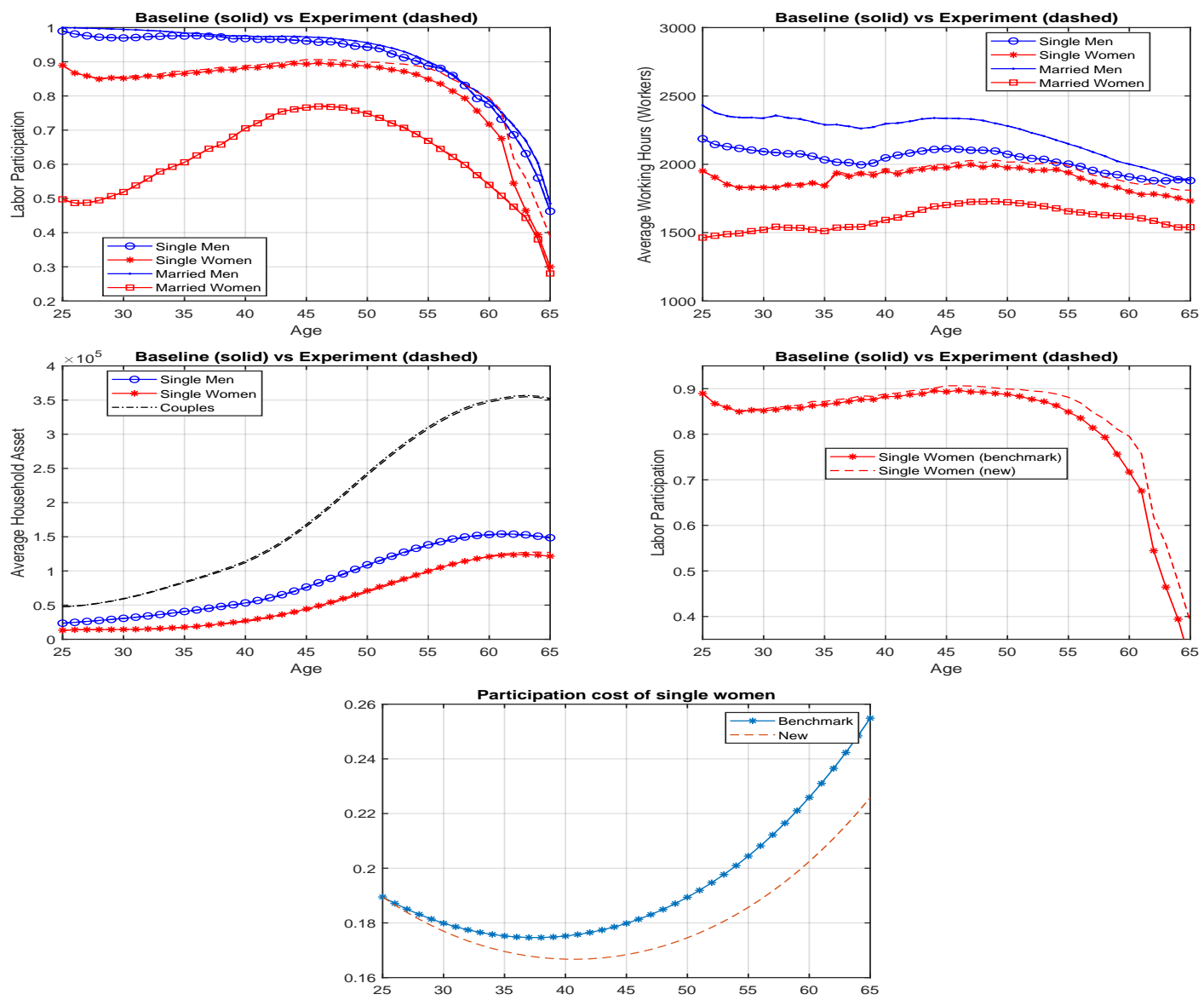

Figure 37: Profiles, 1945 cohort. Benchmark (solid), linear term in age in participation cost for single women $\phi_{1}^{2,1}$ increased $25 \%$ (dashed). 

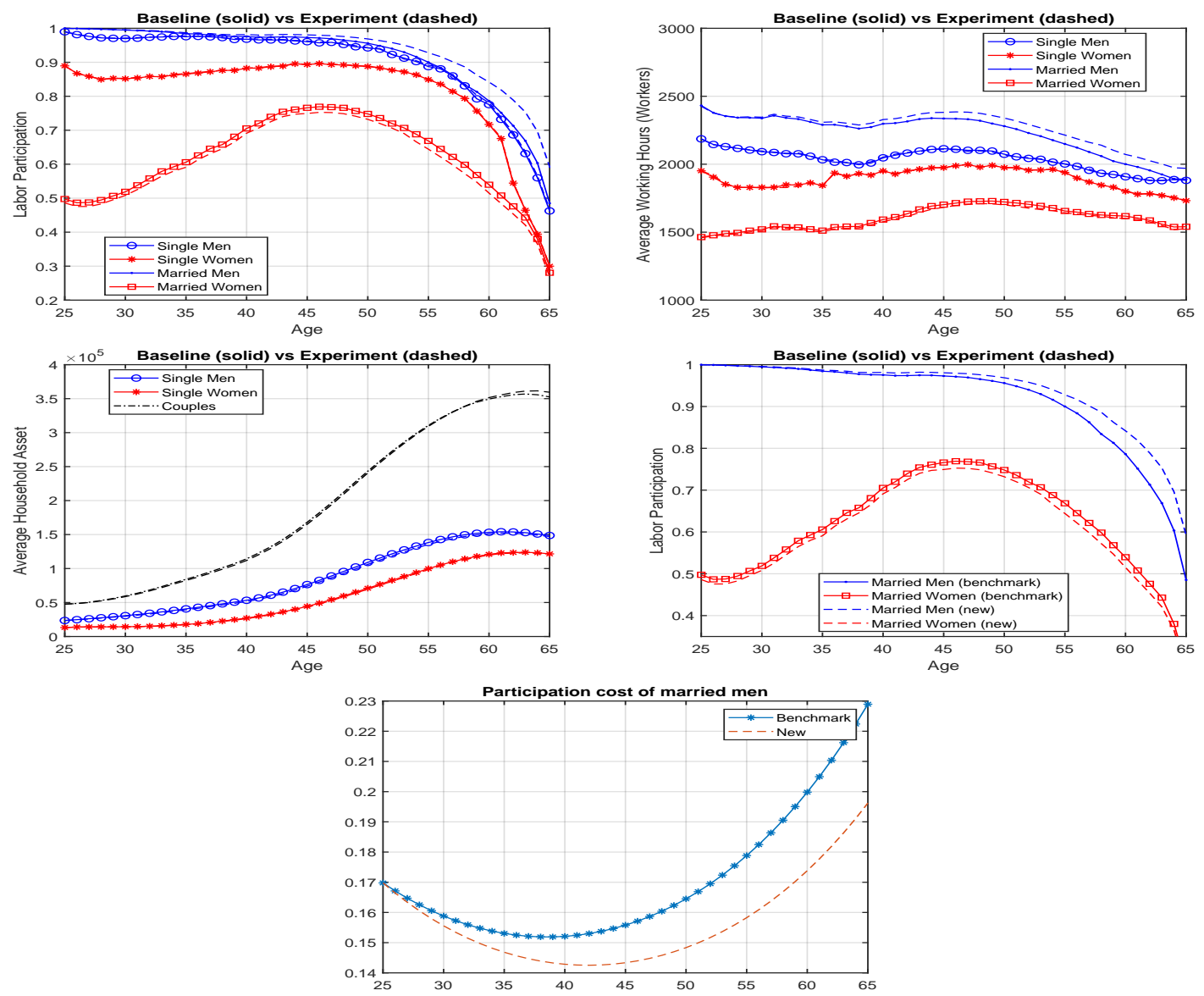

Figure 38: Profiles, 1945 cohort. Benchmark (solid), linear term in age in participation cost for married men $\phi_{1}^{1,2}$ increased $25 \%$ (dashed). 

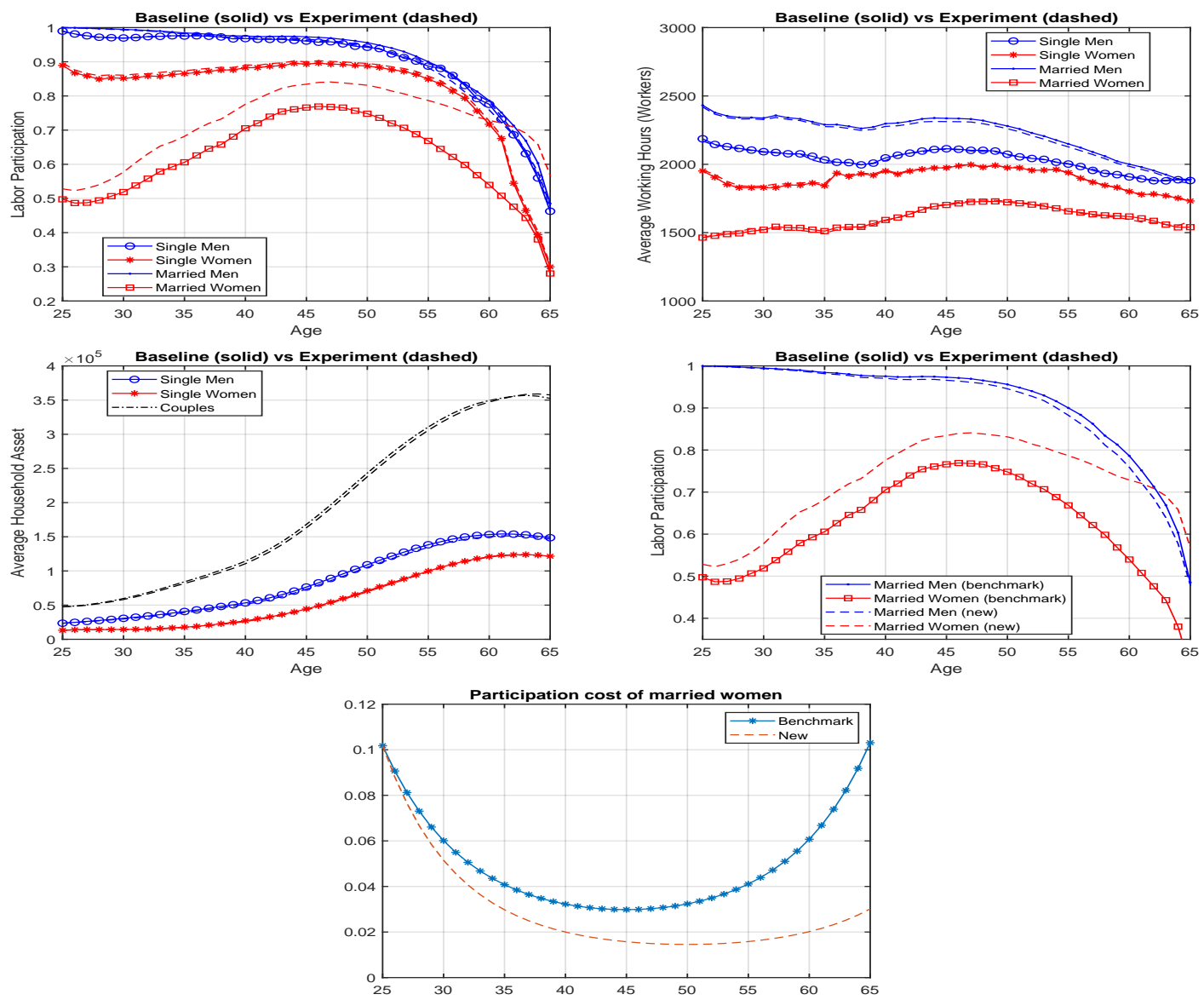

Figure 39: Profiles, 1945 cohort. Benchmark (solid), linear term in age in participation cost for married women $\phi_{1}^{2,2}$ increased $25 \%$ (dashed). 

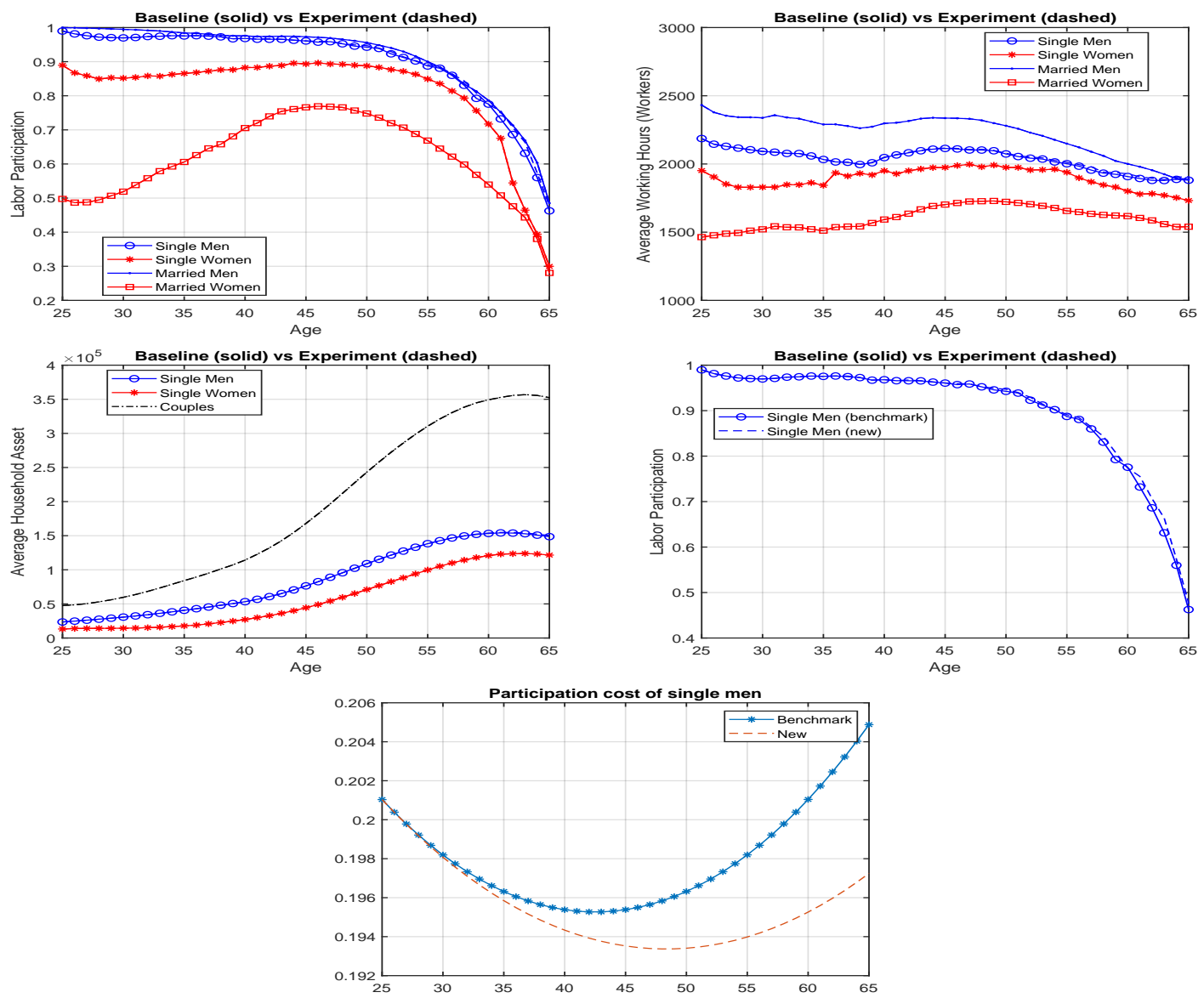

Figure 40: Profiles, 1945 cohort. Benchmark (solid), quadratic term in age in participation cost for single men $\phi_{2}^{1,1}$ decreased $25 \%$ (dashed). 

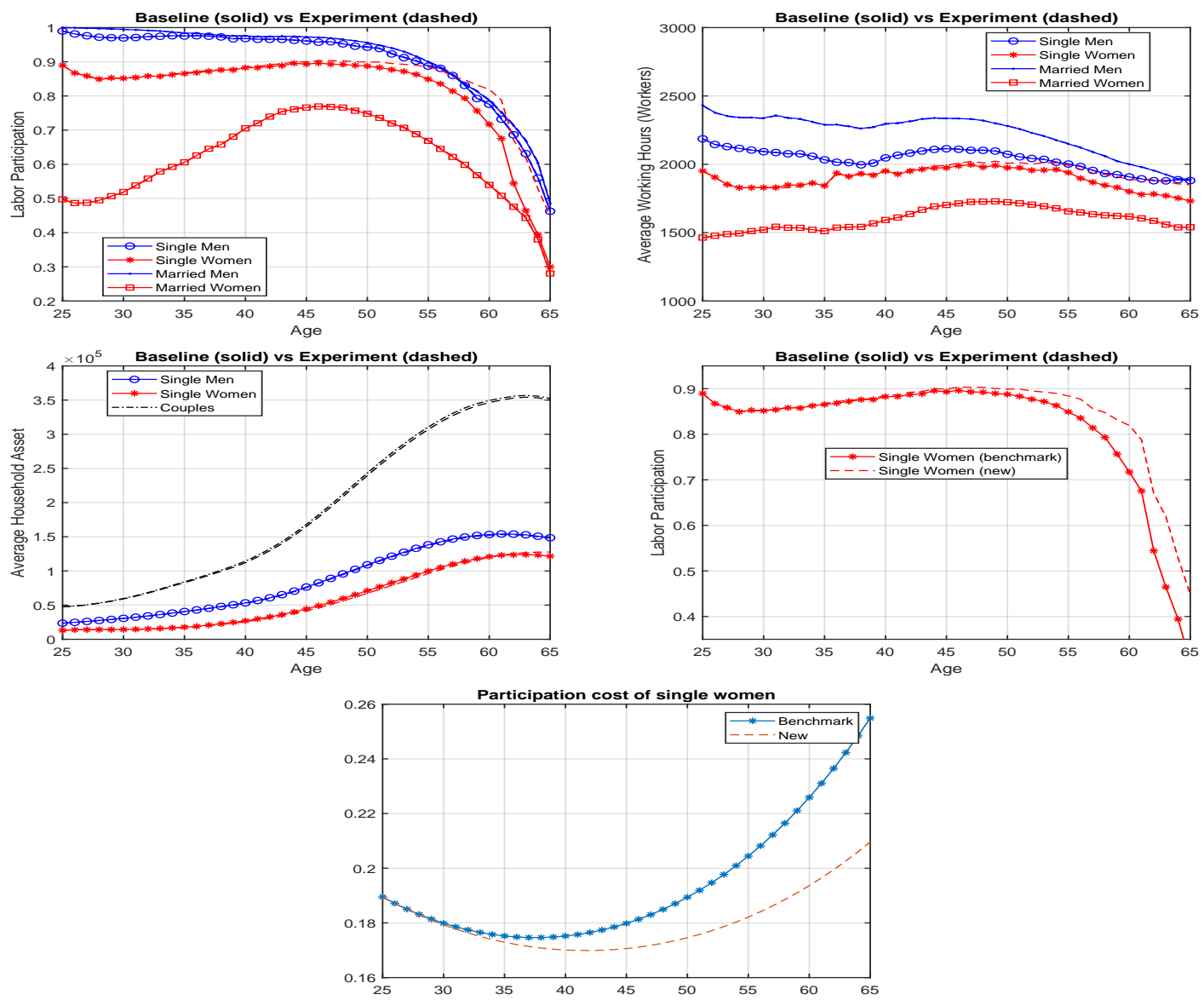

Figure 41: Profiles, 1945 cohort. Benchmark (solid), quadratic term in age in participation cost for single women $\phi_{2}^{2,1}$ decreased $25 \%$ (dashed). 

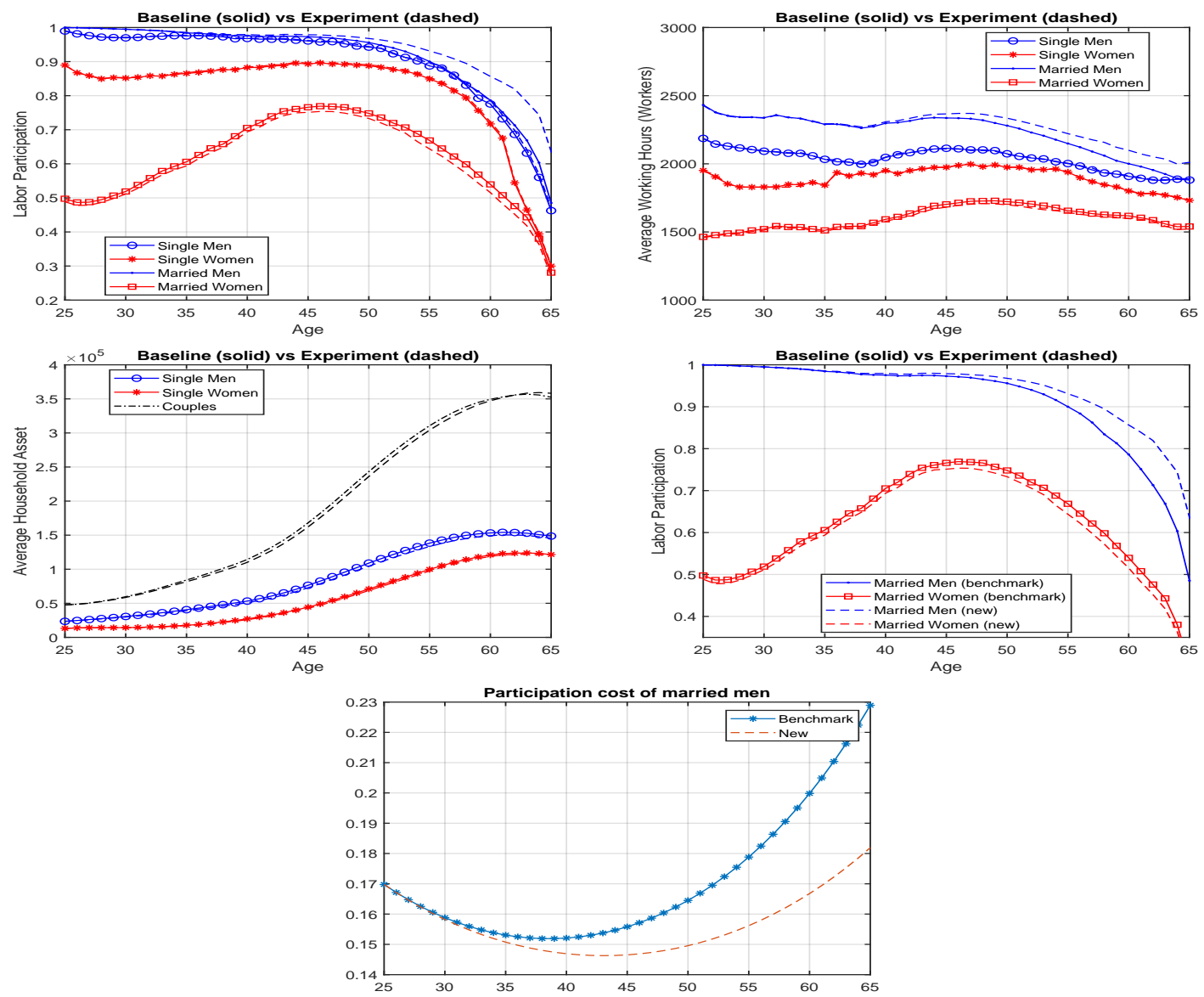

Figure 42: Profiles, 1945 cohort. Benchmark (solid), quadratic term in age in participation cost for married men $\phi_{2}^{1,2}$ decreased $25 \%$ (dashed). 

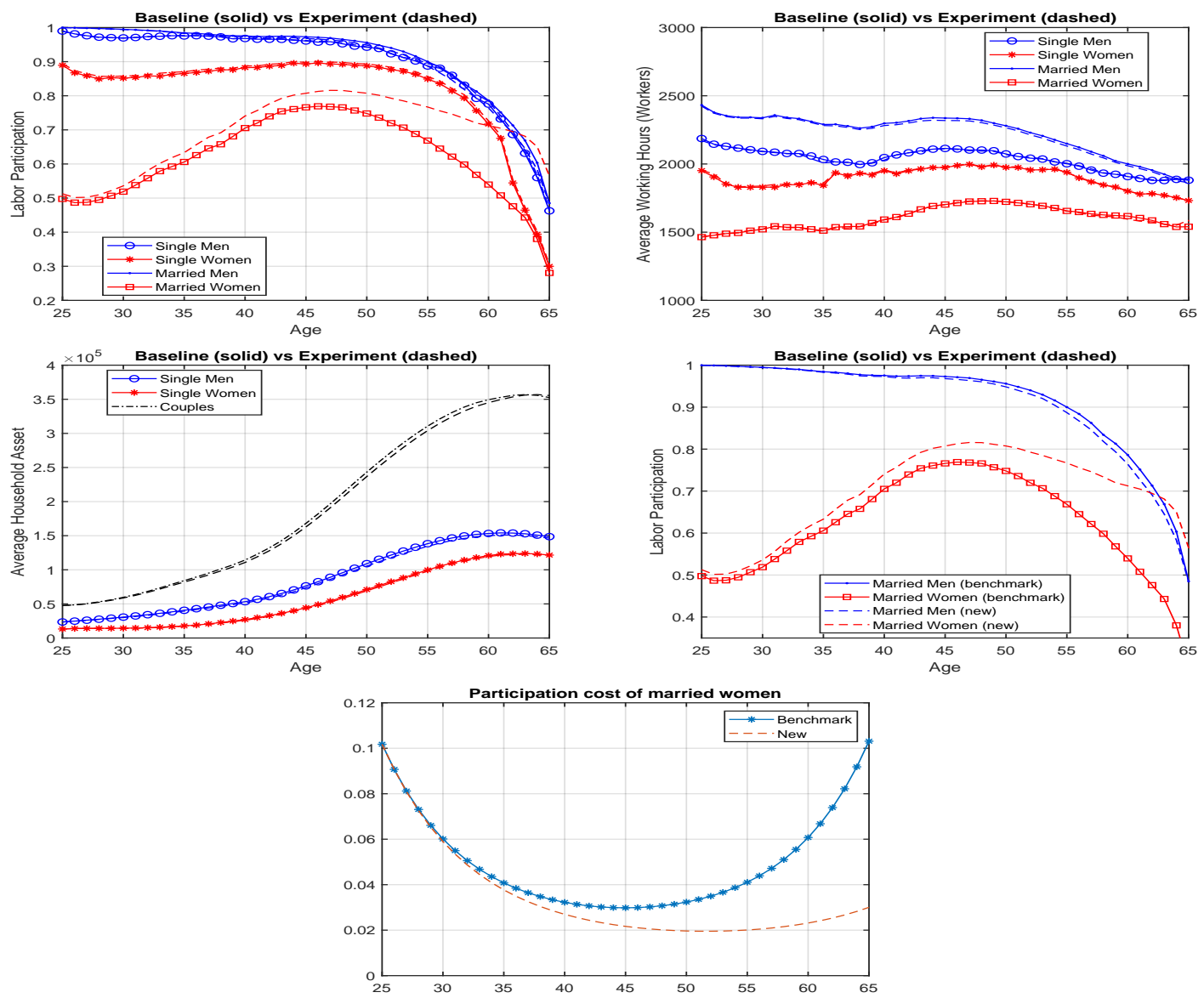

Figure 43: Profiles, 1945 cohort. Benchmark (solid), quadratic term in age in participation cost for married women $\phi_{2}^{2,2}$ decreased $25 \%$ (dashed). 


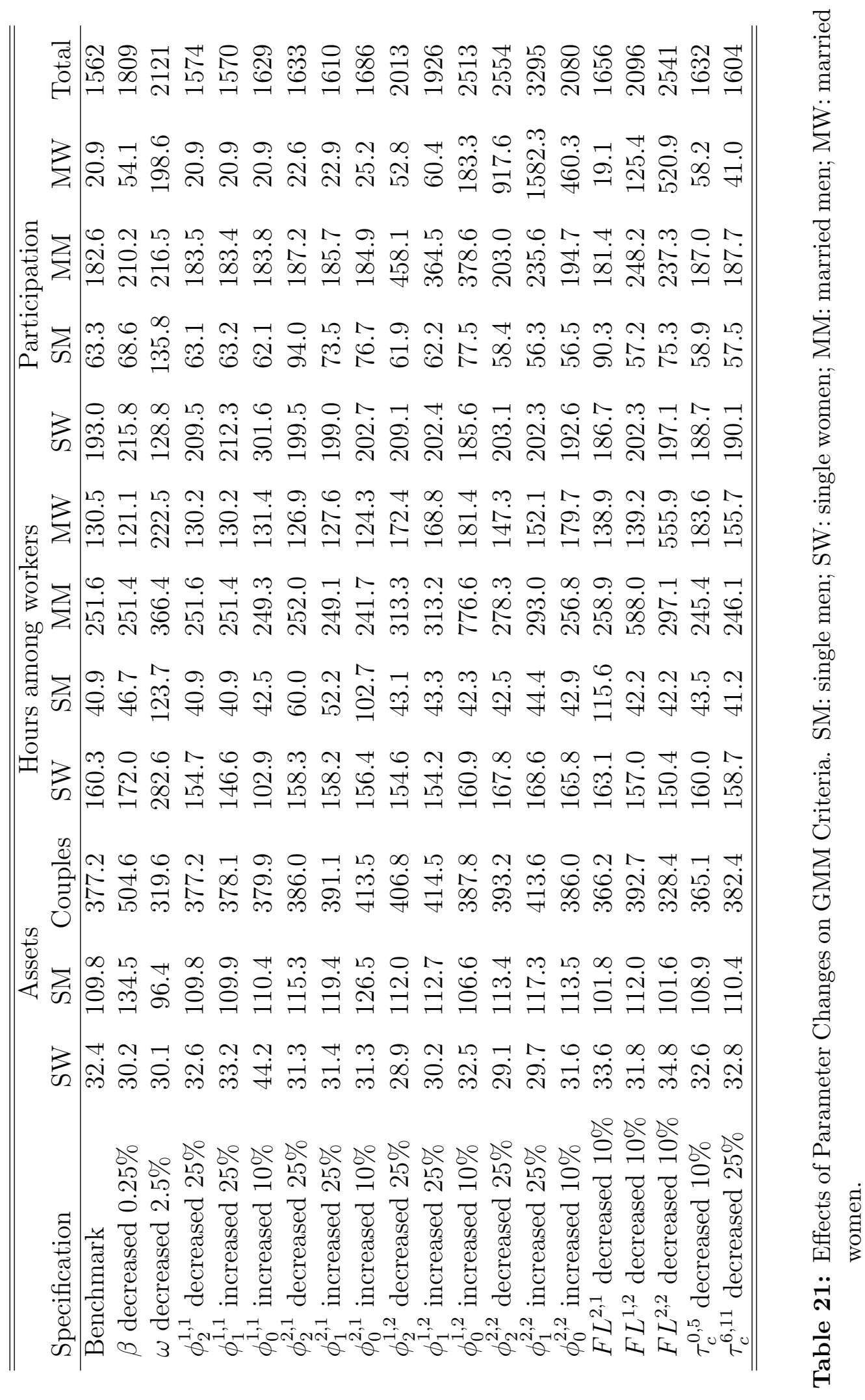




\section{Appendix J. Policy experiments results, additional results}
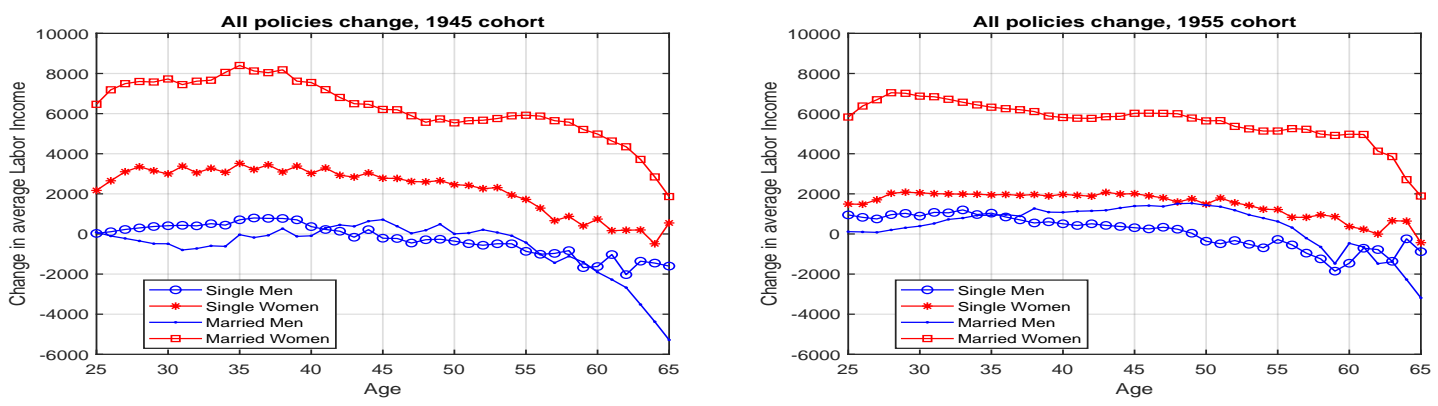

Figure 44: Income changes when all spousal Social Security benefits and joint income taxation are eliminated (under government budget balance). Left: 1945 cohort. Right: 1955 cohort. 


\section{Appendix K. Policy experiments results without balancing government budget for both cohorts}
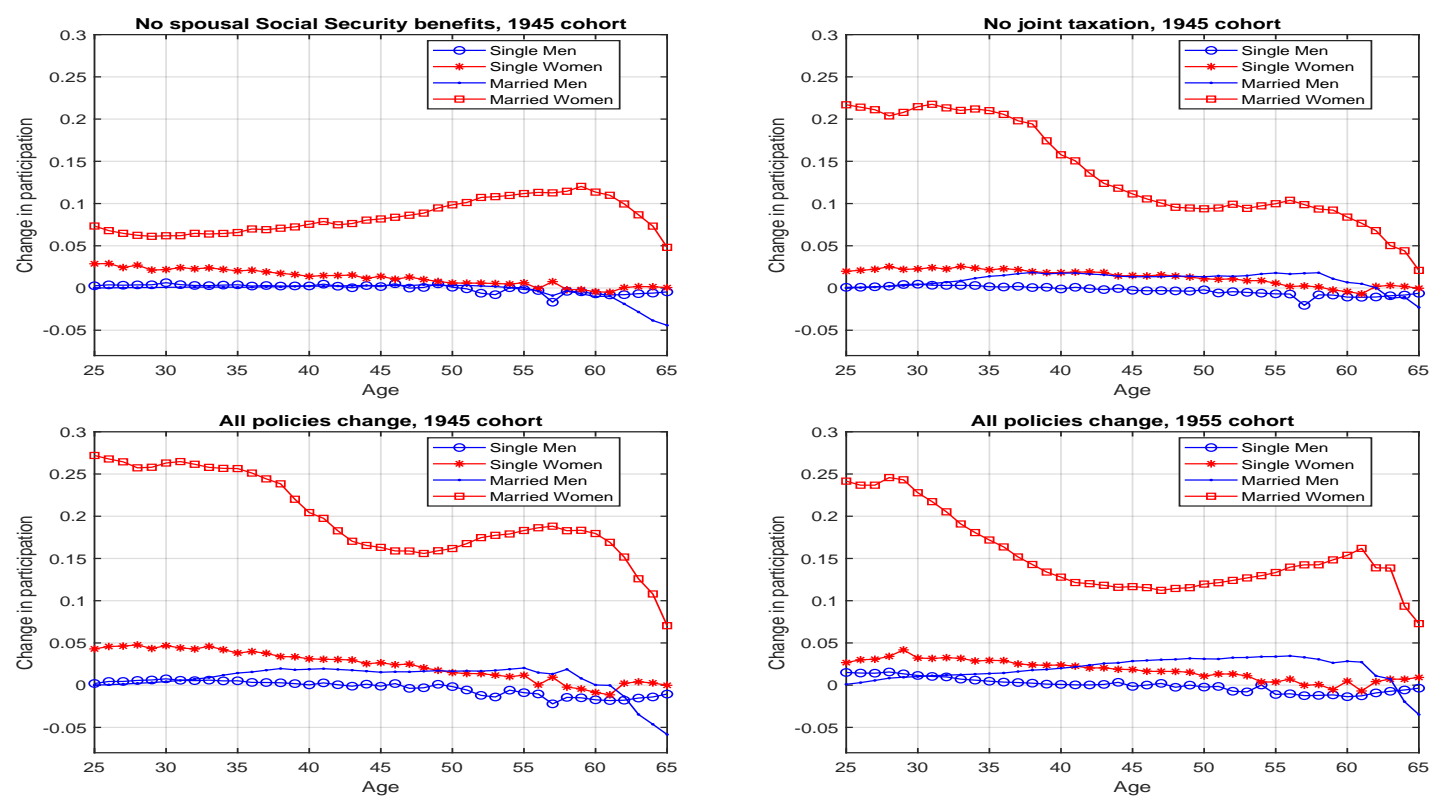

Figure 45: Changes in participation, unbalanced government budget. Elimination of, top left: all spousal Social Security benefits, top right: joint income taxation; bottom left: all marital-related policies, 1945 cohort; bottom right: all maritalrelated policies, 1955 cohort).

\begin{tabular}{l|ccc}
\hline \hline & Couples & Single men & Single women \\
\hline 1945, Removing spousal Social Security benefits & $9.2 \%$ & $1.7 \%$ & $4.0 \%$ \\
1945, Removing all marital-related policies & $13.9 \%$ & $3.4 \%$ & $8.2 \%$ \\
1955, Removing all marital-related policies & $12.5 \%$ & $3.0 \%$ & $6.7 \%$ \\
\hline \hline
\end{tabular}

Table 22: Change in wealth at age 66, in percentages, unbalanced government budget. 


\section{Appendix L. Comparing PSID and CPS data}

While the design of the PSID allows it to remain representative of the US population, we now compare key moments from the PSID with those from the Current Population Survey (CPS) to show that they are very consistent across the two data sets.
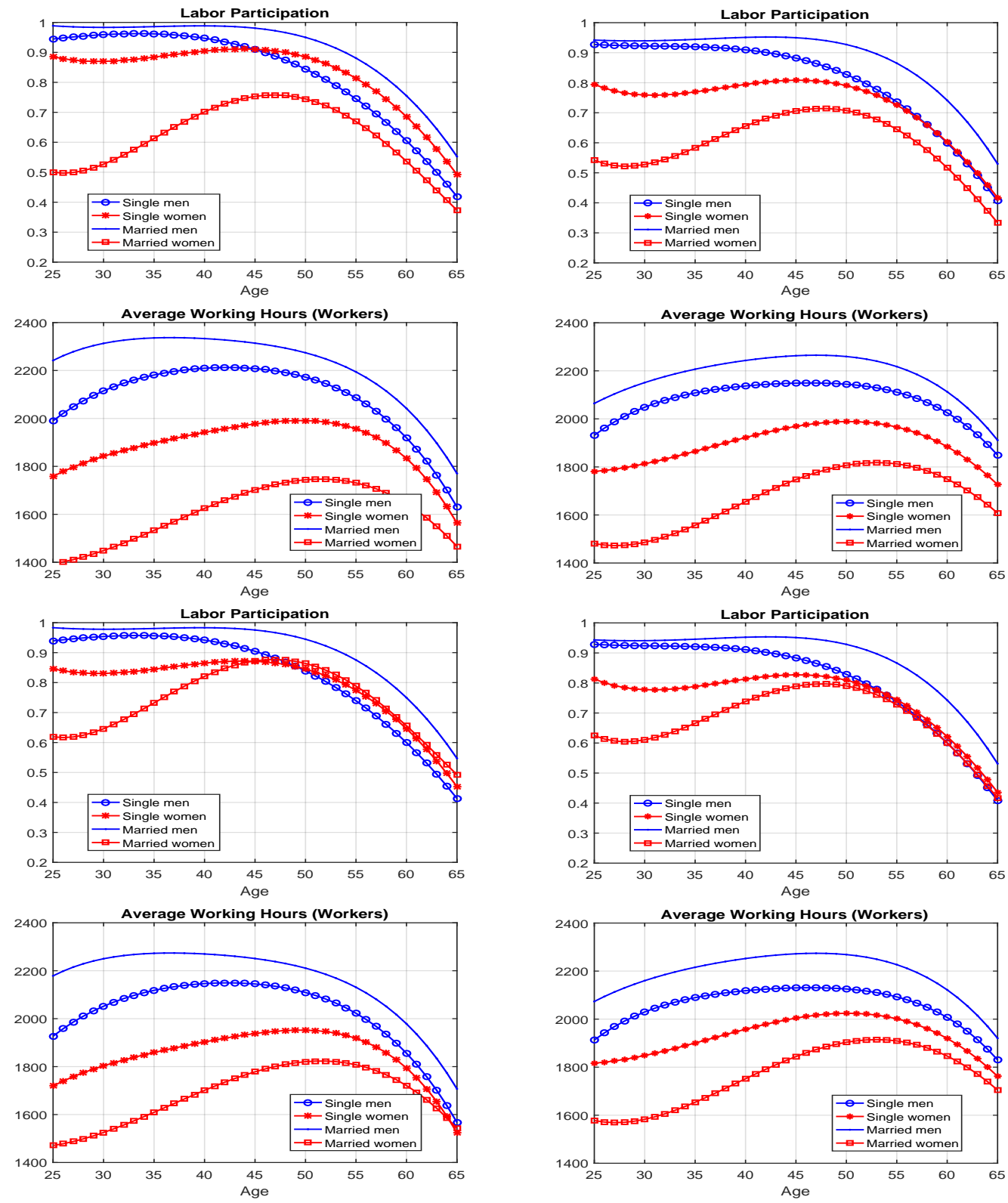

Figure 46: Profiles in the PSID (left) and CPS (right) for the 1945 (top two rows) and 1955 cohort (bottom two rows). 